\title{
Liquid crystals in photovoltaics: a new generation of organic photovoltaics
}

\author{
Manish Kumar and Sandeep Kumar
}

This article presents an overview of the developments in the field of organic photovoltaics (PVs) with liquid crystals (LCs). A brief introduction to the PV and LC fields is given first, followed by application of various LCs in organic PVs. Details of LCs used in bilayer solar cells, bulk heterojunction solar cells and dye-sensitized solar cells have been given. All the liquid crystalline materials used in PVs are structured and the efficiency of solar cells is tabulated. Finally, an outlook into the future of this newly emerging, fascinating and exciting field of self-organizing supramolecular LC PV research is provided.

Polymer Journal (2017) 49, 85-111; doi:10.1038/pj.2016.109; published online 9 November 2016

\section{INTRODUCTION}

For the sustainable growth of the global economy, availability of cheap energy is essential. Our energy demand is increasing continuously to improve our lifestyle. At present, fossil energy sources are the primary sources for most of the world's current energy requirements and only a little is provided by hydropower, nuclear energy and biomass. The exponential growth of carbon dioxide level in the atmosphere owing to the burning of fossil fuels is leading to the threat of a universal climate change. Moreover, there will be limited availability of conventional energy sources in the long term. Future energy demand cannot be met with conventional sources of energy. Nuclear energy sources are one of the promising energy sources, but owing to their associated hazardousness and cost effectiveness, these energy sources does not appear to be socially acceptable universally. Moreover, nuclear fuel is also limited to tackle gigantic demand of energy. Despite several efforts, the problem of energy provision around the world remains unsolved, and there is a great need of finding alternative clean energy sources. To solve the energy crisis of the globe, exploitation of solar energy is undoubtedly the best answer. It is the most abundant inexhaustible source of regenerative energy. It is known since the evolution of life on the Earth that Mother Nature generates chemical energy from solar energy via photosynthesis. The supply of energy by Sun on Earth in an hour is more than that we use in a year. Therefore, only a fraction of solar energy is required to overcome our all energy requirements, if it can be converted to electric energy efficiently. The device that is developed to convert solar energy into electrical energy is known as photovoltaic (PV) solar cell.

During the past 60 years, PV energy has been used as a promising candidate for energy devices because it is abundant, inexhaustible, cheap, straight to production ability and pollution-free that does not raise the green-house gases. The PV effect involves the generation of a photocurrent and photovoltage on absorption of light photons in a semiconductor. The three-step process, which is an important process for the conversion of light to electrical or chemical energy, includes the light-induced exciton (electron-hole pair) generation, separation and migration of electrons and holes in outer circuit. Inorganic semiconductors, such as $\mathrm{Si}, \mathrm{GaAs}$, CdSe and so on, have often been used owing to their high charge-carrier mobility and stability. High cost of these electronic-grade materials and processability are the main concerns in utilizing inorganic semiconductors. Therefore, recently organic semiconductors have attracted much attention for solar cell materials owing to their low cost processing, fabrication on both hard and flexible substrates, large-area application and the availability of unlimited variety of organic molecules with different opto-electronic properties.

Organic semiconducting materials is a field of intense scientific activity because of their potential application in electronic and opto-electronic devices, such as field effect transistors, light-emitting diodes, sensors and PV cells. ${ }^{1-6}$ During the past decade, organic solar cells have attracted considerable attention owing to their outstanding characteristics, such as potential low-cost fabrication, utilize high throughput, light weight, flexibility and easy processability with efficiency upto $10 \% .^{7-11}$ Organic PVs (OPVs) has been the subject of enormous scientific interest and therefore has been covered in many reviews, special issues and books. ${ }^{12-22}$ Significant attention has been given to overcome technological and materials problems in order to develop these OPV devices, which can perform better than inorganic PV devices. In recent years, several researches are conducted to improve the efficiency of organic solar cells and thereby realized applications, such as lightweight or flexible power sources. ${ }^{8}$ Organic solar cells have better potential than conventional solar cells owing to their easy fabrication with the common vacuum evaporation technique, spin-coating, inkjet printing, doctor-blading, drop-casting, screen printing and roll-to-roll printing. In addition to that, they can be readily processed on flexible substrates and devices could be translucent. 
The operation mechanism of light conversion in OPV cells is based on charge generation at the interface between two different organic semiconductors, followed by their separation and migration toward opposite electrodes. These cells are known as heterojunction solar cells. ${ }^{9}$ In these heterojunction solar cells, the transportation of the holes and electrons is conducted through organic p-type and n-type semiconductors and the spontaneous charge flow produces electricity. The concept of heterojunction was first introduced using bilayer structures $5^{5}$ where a layer stacking of donor and acceptor molecules with a planar interface (Figure 1) is realized. This provides a spatially uninterrupted pathway for the photogenerated charge carriers to the respective electrodes. ${ }^{23}$ However, creating an organic bilayer structure is not easy and economical, and therefore the concept of bulk heterojunction $(\mathrm{BHJ})$ is realized. Figure 1 represents the device structures of bilayer heterojunction (a), BHJ (b) and the fundamental steps occurring in donor-acceptor heterojunction solar cells with the highest occupied molecular orbital/lowest unoccupied molecular orbital (HOMO/LUMO) electronic band gap structure (c). In a bilayer heterojunction solar cell, both donor and acceptor materials are separately layered with cathode and anode while in $\mathrm{BHJ}$ a nanoscale blend of both donor (D) and acceptor (A) is used as active layer. The nanometer domain sizes of this blend allowing the excitons with short lifetimes to reach at an interface and dissociate owing to the large donor-acceptor interfacial area. An energy-level diagram and the conversion process are given in Figure 1c to illustrate the principle of operation of the conversion of energy. The ionization potential of the $\mathrm{D}$ is low and has high $E_{\mathrm{HOMO}}$, whereas the $\mathrm{A}$ has a high electron affinity (EA) and low $E_{\mathrm{LUMO}}$. When the light incidents on the surface, excitons (electron-hole pair) are formed in the material (1), these photogenerated excitons diffuse to the interface (2), electrons and holes are separated; electrons migrate to acceptor (3) and holes migrate toward anode (4). Charge separation is energetically favorable when

$$
E_{\mathrm{HOMO}}(\mathrm{D})-E_{\mathrm{LUMO}}(\mathrm{A})<E_{\mathrm{ex}}
$$

Many different types of organic materials have been used in OPVs, for example, small molecules, polymers, oligomers, dendrimers, organic dyes and liquid crystals (LCs). Owing to the paucity of space, it is not possible to cover the developments happened in all types of OPV cells; therefore, this article deals only with the use of LCs in OPVs.

\section{A BRIEF OVERVIEW OF LCS}

LCs, also referred to as mesophases, are materials that have the properties of both crystals and liquids. These materials show order and mobility at molecular, supramolecular and macroscopic levels. LCs are accepted as the fourth state of matter after the three classical states of matter: solid, liquid, and gas. LCs are ubiquitous in everyday life in the form of LC display devices, thermal sensors and so on. They are not only important in materials science but also in living systems and in biology. ${ }^{24}$ Several bio-molecules, such as DNA, lipids and proteins, form various liquid crystalline phases under appropriate conditions. ${ }^{24}$ The appearance of mesomorphism in DNA fragments (nano DNAs) has been related to the significant role of LCs in the evolution of life in the prebiotic world. ${ }^{25}$

LCs are classified in various ways, such as: depending on the molar mass of the constituent molecules, low molar mass (monomeric and oligomeric) and high molar mass (polymeric) LCs; depending on the process by which the liquid crystalline phase is obtained, whether by adding solvent (lyotropic) or by changing the temperature (thermotropic); depending on the nature of the constituent molecules (organic, inorganic, ionic, organometallic); depending on the geometrical shape of the molecules (rod-like, disc-like); and depending on the arrangement of the molecules in the liquid a

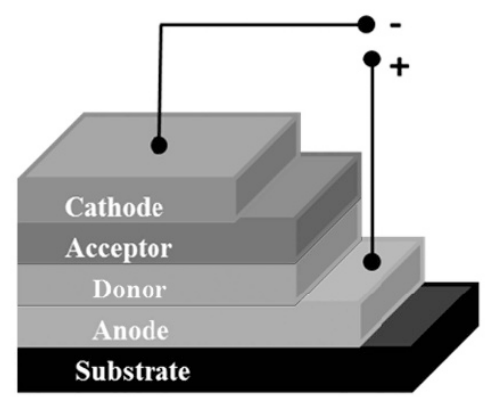

C

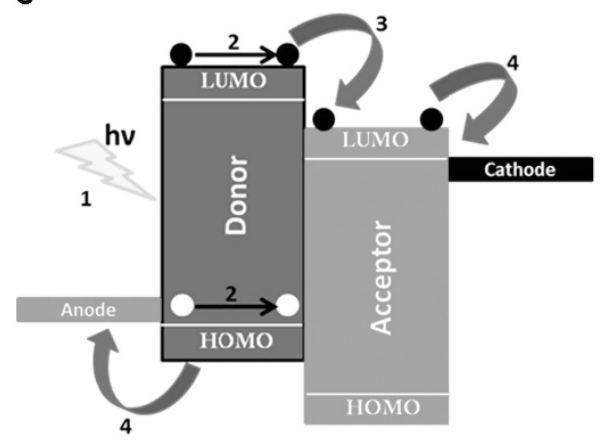

b

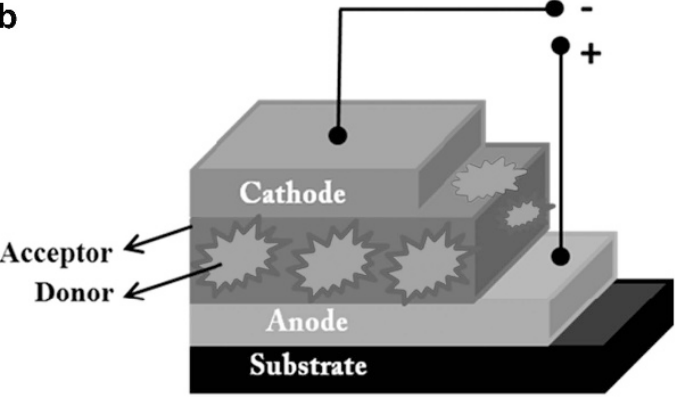

d

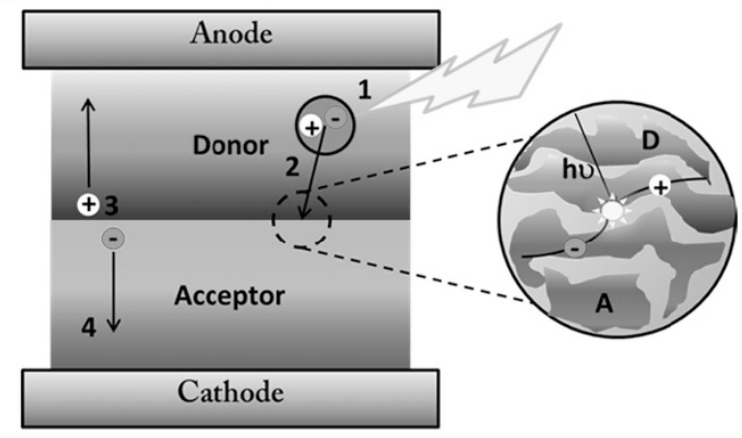

Figure 1 Device structure of (a) bilayer heterojunction, (b) bulk heterojunction, (c) device working principle with electronic HOMO/LUMO structure and (d) schematic illustration of charge separation at donor-acceptor interface ((1) exciton formation, (2) diffusion of exciton to interface, (3) dissociation and (4) charge transport in the active layer of organic photovoltaic solar cell). A full color version of this figure is available at the Polymer Journal online. 
crystalline phase (nematic, smectic, columnar, helical, B phases and so on). The most common class of LCs commonly known as calamitic LCs are derived from rod-like molecules. ${ }^{26}$ They have primarily been exploited for their applications in LC displays. ${ }^{27}$ Calamitic LCs were discovered more than a century ago in 1888 when Reinitzer ${ }^{28}$ noticed an unusual double melting behavior of cholesterol benzoate. For about 90 years, it was believed that only rod-like (calamitic) molecules can form LCs when Chandrasekhar et al. ${ }^{29}$ synthesized and realized the LC phases of disk-like molecules. These are now commonly referred to as discotic LCs (DLCs). Both calamitic and discotic mesogens exhibit nematic (having only long-range orientational order) or higher order smectic and columnar phases (Figure 2).

Another variety of LCs in which usually two calamitic molecules are joined via a central bent unit is classified as banana or bent-core LCs. ${ }^{30}$ Though they were known in literature as calamitic LCs since 1929, ${ }^{31}$ their ferroelectric properties owing to the formation of chiral mesophase are realized only in $1996 .^{32}$ Although bent-core LCs have not been much studied for PV properties, both calamitic and DLCs are explored to fabricate PV solar cells. As the story of LC PVs started with DLCs, we begin our discussion with these systems.

\section{DISCOTIC LCS}

The self-organization of disc-like or plate-like molecules leads to the formation of DLCs. A majority of DLCs are composed of polycyclic aromatic cores, such as triphenylene (TP), anthraquinone, phthalocyanine $(\mathrm{Pc})$ and so on, surrounded by plural number of flexible aliphatic chains. ${ }^{33,34}$ The strong $\pi-\pi$ interactions between aromatic cores favor columnar stacking of the molecules. The columnar mesophase is formed owing to the self-assembly of rigid disc-shaped aromatic cores, which consists usually 6-8 peripheral molten aliphatic chains with mobility. The separation between core- core (intracolumnar) is generally of the order of $0.35 \mathrm{~nm}$ while the separation between neighboring columns (intercolumnar) is in the range of $2-4 \mathrm{~nm}$. This assembly of molecules gives more interaction between neighboring molecules within the same column compared with the neighboring column. In this columnar arrangement of aromatic cores, each column acts as a molecular wire where the electrons or holes migrate efficiently along the columns in quasi one dimension (Figure 3). Owing to this unidirectional arrangement, the electrical conductivity along the columns have been observed to be many orders of magnitude greater than that in perpendicular direction. ${ }^{35}$ Because of this behavior, DLCs could be used in opto-electronic devices, such as PV solar cells, light-emitting diodes and gas sensors. Owing to the technological applications and fundamental importance of DLCs, they have received much attention of the scientists around the globe thtat has been reviewed in several articles. ${ }^{33,34,36-51}$

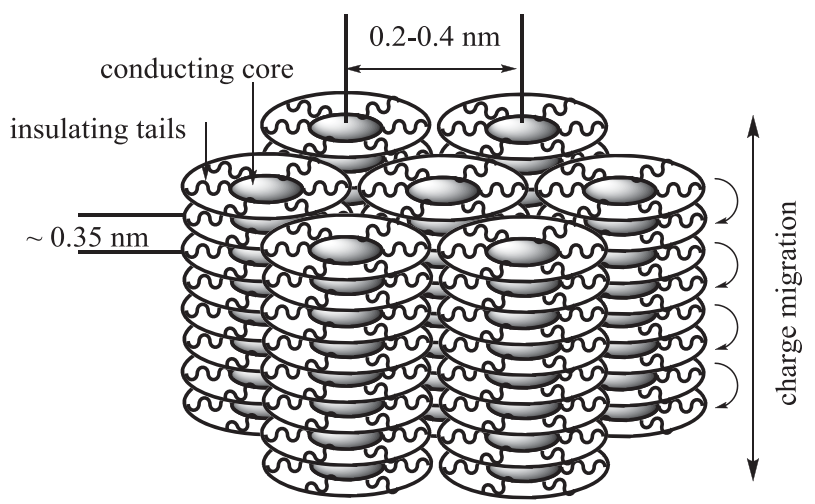

Figure 3 One-dimensional charge migration in DLCs.

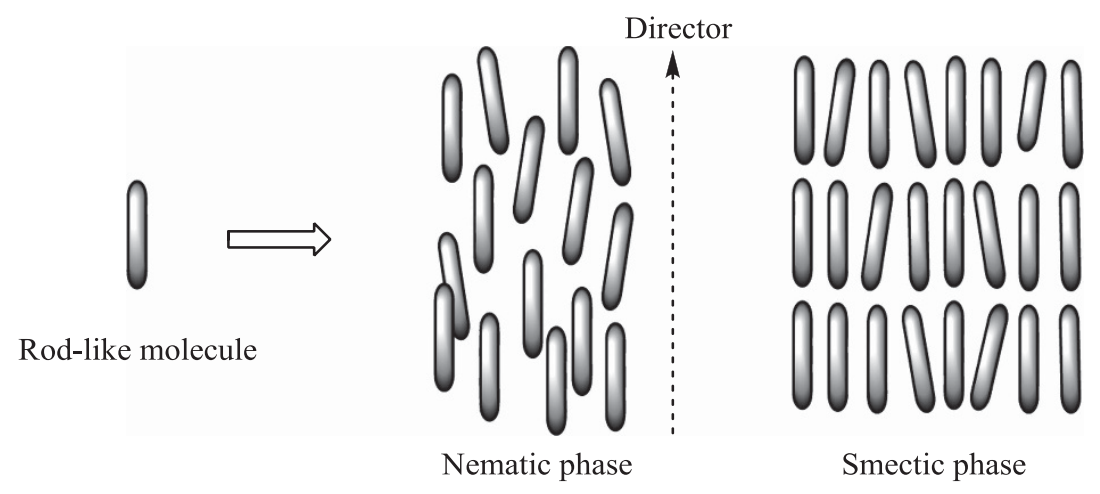

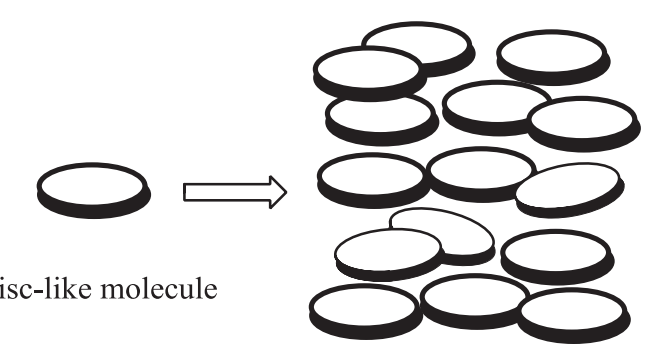

Nematic phase

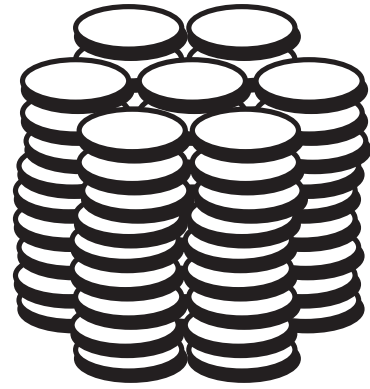

Columnar phase

Figure 2 Schematic representations of nematic-, smectic- and columnar-phase formation by calamitic and discotic mesogens. 
In comparison to other organic semiconducting materials such as single crystals and conducting polymers, DLCs possess many advantages. Both p-type and n-type DLCs can be easily designed and synthesized, their optical and electronic properties can be tuned via proper chemical modifications, they can be easily obtained in very high purity, they can be aligned parallel to the electrode surface (homeotropic alignment) for better one-dimensional charge migration (Figure 3), they display self-healing of structural defects owing to their fluid nature, they are soluble in common organic solvents and possess low melting point and therefore can be economically processed. ${ }^{52}$

Long exciton diffusion length and high charge-carrier mobility are the key factors to realize efficient OPV solar cells. Some DLCs exhibit very good exciton diffusion length $(\sim 70 \mathrm{~nm})$ and very high charge-carrier mobility $\left(\sim 1 \mathrm{~cm}^{2} \mathrm{~V}^{-1} \mathrm{~s}^{-1}\right) .{ }^{53}$ The simulated defect-free DLC assembly was reported to have the mobility in excess of $10 \mathrm{~cm}^{2} \mathrm{~V}^{-1} \mathrm{~s}^{-1}$. ${ }^{4}$ The charge-carrier mobility in organic materials may be correlated with the molecular structure and packing of constituting molecules. In DLCs, the charge-carrier mobility is expected to improve upon the close stacking of the columns, and the molecular order could be enhanced by enlarging the size of polycyclic aromatic core as a result of intense $\pi-\pi$ interactions. A speculative relationship between charge mobility and core size has been proposed, ${ }^{55}$ Several large polycyclic aromatic hydrocarbon cores, defined as 'nano-graphenes' have been explored by Müllen and co-workers to build various DLCs. ${ }^{39,45,56}$ The dispersion of large-size discotics in archetypal DLCs is reported to improve physical properties of the system significantly owing to complimentary polytopic interactions. ${ }^{57}$ In another innovative approach, we realized that the conductivity of DLCs can be enhanced by several orders of magnitude by dispersing a very small amount of metallic, semiconducting or carbon nanoparticles. ${ }^{58-67}$

Since the discovery of DLCs, there has been tremendous interest in utilizing these materials as one-dimensional semiconductors. Conducting and photoconducting properties of DLCs have been studied extensively. ${ }^{50,68}$ Owing to their excellent charge-transport property, DLCs have been applied to prepare bilayer and BHJ solar cells. ${ }^{6}$ They have also been used as additives in solar cells ${ }^{69-72}$ and also as electrolyte in dye-sensitized solar cell (DSSC). ${ }^{73}$ DLCs derived from porphyrin, $\mathrm{Pc}, \mathrm{TP}$, hexabenzocoronene and decacyclene have been used as hole-transporting layer while crystalline and liquid crystalline perylene derivatives and $\mathrm{C}_{60}$ derivatives have commonly been used as electron-transporting materials.

Gregg et al. ${ }^{74}$ and Petritsch et al. ${ }^{75}$ were the first ones to demonstrate the PV effect in porphyrin- and Pc-based DLCs. However, the seminal work of Schmidt-Mende et al. ${ }^{6}$ on well-defined discotic PV solar cell prepared from a hexa-perihexabenzocoronene (HBC)-based DLC, reported in 2001, generated tremendous interest in this field. Therefore, we open this section with HBC-based DLCs in PVs.

\section{HEXABENZOCORONENE DLCS IN PVS}

$\mathrm{HBC}$ is one of the largest and highly symmetrical all-benzenoid polycyclic aromatic hydrocarbons that has recently been realized to function as a core fragment for generating DLCs by Müllen and co-workers. $^{76}$ HBC-based DLCs show columnar phases with remarkably high mesophase breadth and charge-carrier mobilities. ${ }^{77,78}$ They act as donor materials (p-type, hole-transporting semiconductors) in electronic devices. SchmidtMende et al. ${ }^{6}$ prepared an OPV device using a HBC-based DLC, $\mathrm{HBC}-\mathrm{PhC12}$, 1a (Figure 4) in combination with an organic soluble electron-accepting perylenediimide (PDI) dye, 2a (Figure 5) to produce thin films with vertically segregated perylene and hexabenzocoronene with large interfacial surface area.

Power-conversion efficiency (PCE) upto $2 \%$ was achieved with a small incident irradiance $<1 \mathrm{~mW} \mathrm{~cm}^{-2}$. However, it degrades at higher intensities and reaches to $0.22 \%$ under 1 Sun illumination at AM 1.5G. ${ }^{79}$ Simple solution-processing steps are used to fabricate these OPV devices. Intermolecular and macroscopic ordering was reported to be responsible for the high performance of fabricated devices. For compound HBC-PhC12, the calculated HOMO level was $5.25 \mathrm{eV}$ and LUMO level was $2.64 \mathrm{eV}$, with a large band gap of $2.61 \mathrm{eV}$. Similarly, HOMO and LUMO energies for perylene were 5.32 and $3.29 \mathrm{eV}$, respectively. From $\mathrm{HBC}-\mathrm{PhC} 12$ to perylene, which has a high electron affinity as a result of the electron-withdrawing diimide bridges, there is $0.65 \mathrm{eV}$ LUMO step and $0.07 \mathrm{eV}$ HOMO step. The devices showed high external quantum efficiencies (EQEs; Figure 6), which is due to the large interfacial area within the bilayer structure, and possibly owing to the high exciton diffusion ranges in the separated $\mathrm{HBC}-\mathrm{PhC1} 12$ and perylene regions. The short circuit current $\left(J_{\mathrm{SC}}\right)$ and open circuit voltage $\left(V_{\mathrm{OC}}\right)$ were $-33.5 \mu \mathrm{A} \mathrm{cm}-2$ and $0.69 \mathrm{~V}$, respectively, and the fill factor (FF) was $40 \%$ (Figure 6). Later, they tried several other HBC-based DLCs (Figure 4) to prepare PV solar cells. ${ }^{80,81}$ However, none of these devices could cross the PCE of the above-mentioned first device. PCE of some of the HBC-based DLCs used in PV solar cells are presented in Table 1. In all tables, $\mathrm{Cr}=$ crystals; $\mathrm{LC}=$ liquid crystal; $\mathrm{Col}_{\mathrm{h}}=$ columnar hexagonal; $\mathrm{Col}_{\mathrm{p}}=$ columnar plastic; $\mathrm{N}=$ nematic and $\mathrm{SmA}=$ smectic $\mathrm{A}$.

Device prepared using chiral HBC derivative $\mathbf{1 b}$ (Figure 4) and perylene derivative 2a (Figure 5) exhibits $I_{\mathrm{SC}}, 3.3 \mu \mathrm{A} \mathrm{cm}^{-2}$, $V_{\mathrm{OC}} 0.46 \mathrm{~V}, \mathrm{FF} 32.5 \%$ and PCE of $0.1 \%$ at $490 \mathrm{~nm}$. Compared with the above-mentioned $\mathrm{HBC}-\mathrm{PhC1}$ /perylene device, it gives very poor results. This has been attributed to different film-forming properties and film morphologies of $\mathrm{HBC}$ derivative $\mathbf{1} \mathbf{b} .{ }^{80}$ In this case, vertical segregation of $\mathrm{HBC}$ and perylene layer was not observed in the spin-coated blends. A combination of $\mathbf{1 a}$ or achiral $\mathbf{1 b}$ with perylene acceptor $\mathbf{2 a}$ gives very poor PCE. ${ }^{81}$ Efforts have also been made to attach perylene dye covalently to $\mathrm{HBC}$ discotic as shown in structure 1n to realize phase-segregated donor-acceptor structure. However, this device exhibits very poor PCE. ${ }^{82}$ Replacing the perylene dye $2 \mathrm{a}$ by other perylene dyes such as $\mathbf{2 b - 2 d}$ (Figure 5) also did not improve the efficiency. ${ }^{81,82}$

Jung et al. ${ }^{83}$ added a photoconducting carbazole-based polymer in the $\mathrm{HBC} /$ perylene solar cell to improve its efficiency. It was observed that the PCE of the device is dependent on the morphology of film. An addition of the photoconducting polymer improves the device performance, albeit only for experiments performed in vacuum.

The PV properties of three HBC derivatives were investigated with respect to the influence of the alkyl side chains (Figure 4, structure 1d, 1f and $\mathbf{1 g}$ ) by Li et al. ${ }^{84}$ For the devices fabricated from $\mathbf{1 d}$ compound, the $V_{\mathrm{OC}}$ is $0.52 \mathrm{~V}$ and the PCE is $1.5 \%$ with EQE values of $12 \%$, which is much higher than the EQE of $6 \%$ and $4 \%$ in $\mathbf{1 f}$ and $\mathbf{1 g}$, respectively. This is due to the shielding effects of the alkyl chains, which reduces the HOMO level on increasing side chain length. HBC derivative 1c with normal dodecyl peripheral chains exhibits EQE of $29.5 \% .{ }^{85}$

The effect of chemical structure and self-assembly of HBC discotics were studied by Hesse and co-workers. ${ }^{79,86}$ Various phenyl-substituted HBCs (Figure 4, structure $\mathbf{1 h}, \mathbf{1} \mathbf{i}, \mathbf{1} \mathbf{j}, \mathbf{1} \mathbf{k}$ and $\mathbf{1}$ ) as electron donor blended with PDI, 2a were studied. They investigated the effect on the device performance by means of different parameters, such as different alkyl chain lengths $(6,8,12$ and 16) of carbon atoms, introduction of a triple bond linker between HBC core and residual phenyl group and a swallow-tailed dialkylphenyl chain. It was also observed that by 

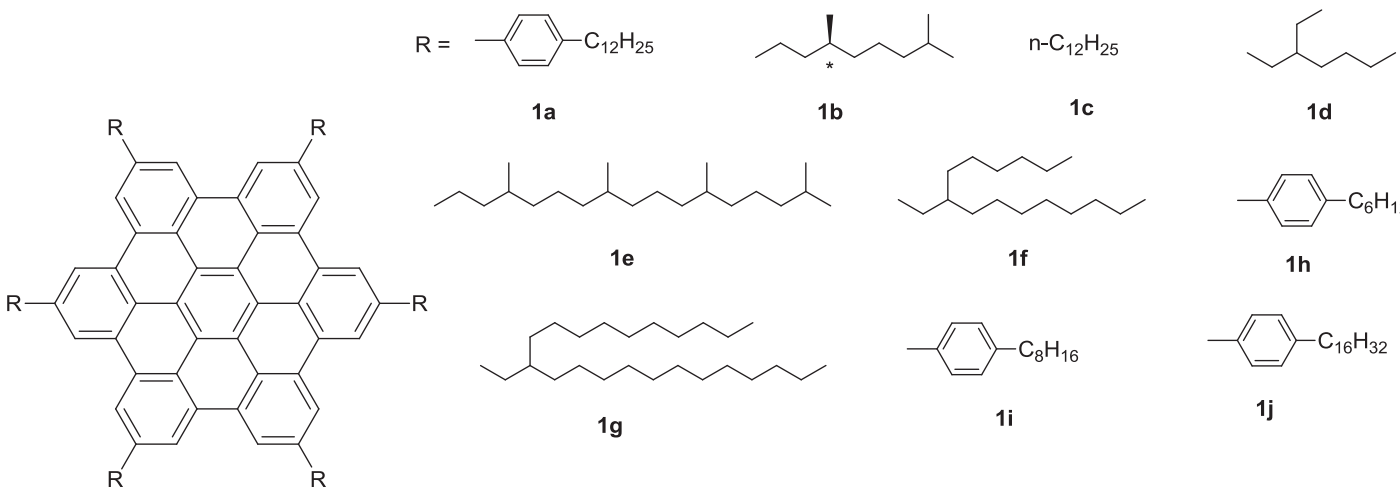

1a

$1 \mathrm{~b}$

$1 c$

1d
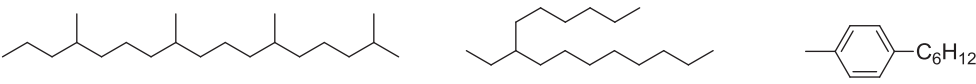

1f

$1 \mathrm{~h}$

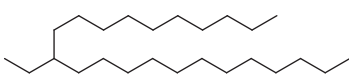

19

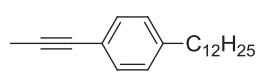

$1 \mathrm{k}$

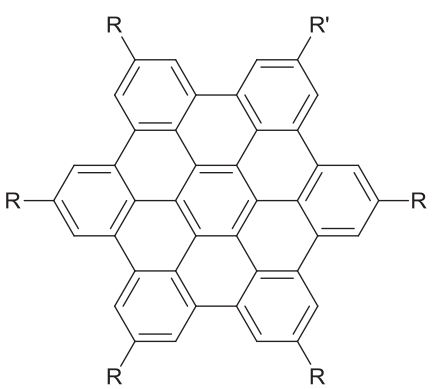<smiles>[R]CCCC(C)CCCC(C)C</smiles>

1n
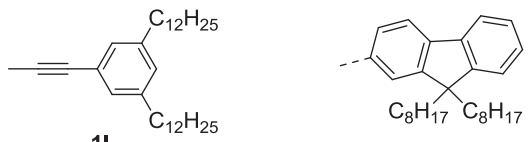

$1 \mathrm{~m}$

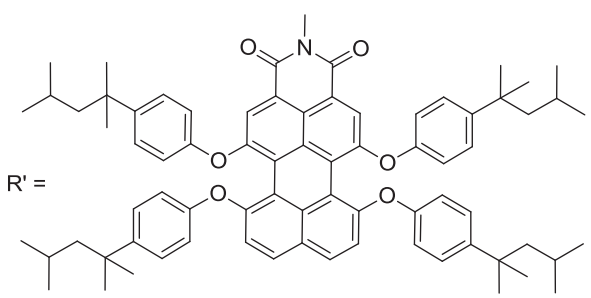

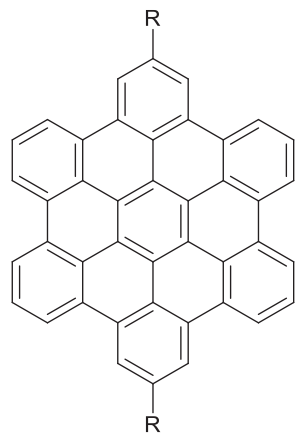

$\mathrm{R}=$

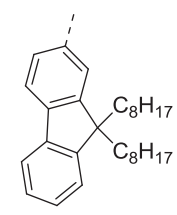

10

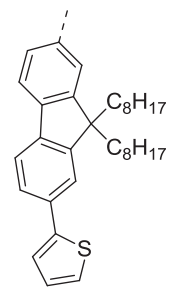

$1 \mathrm{p}$

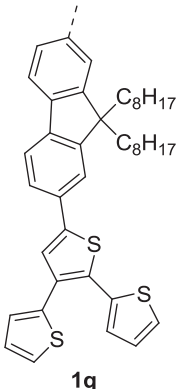

(1)

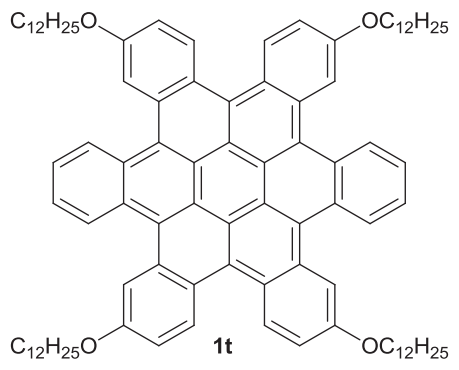

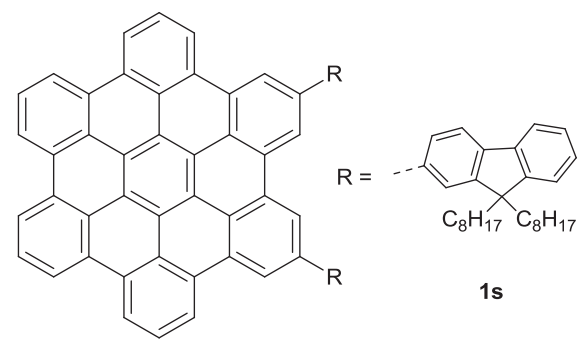

Figure 4 Chemical structure of HBC DLCs used in OPV.

increasing the side chain length of the HBC molecule the layered structure is disrupted, which results to disordered structure. PCE up to $0.24 \%$ was realized in these devices. ${ }^{79,86}$

Wong et al. ${ }^{87,88}$ prepared a number of fluorenyl-substituted HBC (FHBC) and their thiophene dendrimers (Figure 4, structure $\mathbf{1 m}, \mathbf{1 0}$, 1p, 1q, 1r and 1s). Formation of columnar structures is reported in these materials by X-ray diffraction studies. BHJ solar cells with the structure ITO/PEDOT:PSS/FHBC/PC ${ }_{61} \mathrm{BM}(1: 2 \mathrm{w} / \mathrm{w}) / \mathrm{TiOx} / \mathrm{Al}$ were fabricated and PCE up to $2.5 \%$ was observed in these devices (Table 1). ${ }^{87,88}$ In these devices, [6,6]-phenyl-C61-butric acid 


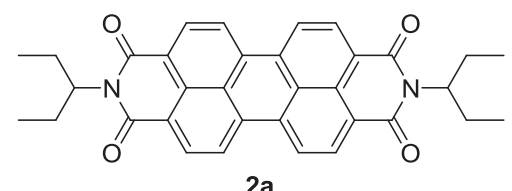

$2 a$

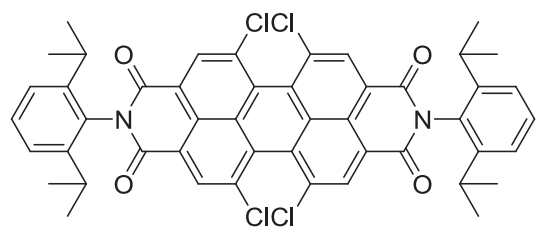

$2 b$

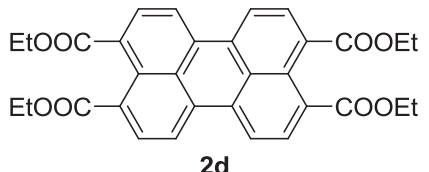

2d

Figure 5 Chemical structure of perylene-based electron acceptors used in OPV.

methyl ester $\left(\mathrm{PC}_{61} \mathrm{BM}\right)$ and [6,6]-phenyl-C71-butric acid methyl ester $\left(\mathrm{PC}_{71} \mathrm{BM}\right)$ have been used as electron acceptor. Addition of HBC-based amphiphilic interface modifier improves the PCE of the device made of compound 10 and $\mathrm{PC}_{61} \mathrm{BM}$ by $20 \%{ }^{89}$

Kang et al. ${ }^{90}$ demonstrated the self-assembled molecular structure of $\mathrm{p}-\mathrm{n}$ junction of $\mathrm{HBC}$ discotic 12-c-HBC, 1t (Figure 4) and $\mathrm{PC}_{70} \mathrm{BM}$. The PCE is increased up to $2.41 \%$ upon addition of $10 \%$ donor material with $10: 90 \mathrm{wt} \%$ of $21: \mathrm{PC}_{70} \mathrm{BM}$. The solution-processed fabricated device showed the $V_{\mathrm{OC}} 1 \mathrm{~V}$ and $J_{\mathrm{SC}} 6.37 \mathrm{~mA} \mathrm{~cm}^{-2} .{ }^{90}$ The enhancement to the PCE is due to the formation of ball-and-socket packing nest structure of $12-\mathrm{c}-\mathrm{HBC}$ molecules into $\mathrm{PC}_{70} \mathrm{BM}$, which results in the formation of well-defined molecular $\mathrm{p}-\mathrm{n}$ junctions.

\section{PORPHYRIN DLCS IN PVS}

Porphyrins are considered as 'pigments of life' owing to their biochemical involvement in various vital processes in the living systems. $^{91}$ Porphyrin derivatives, such as hemes, chlorophylls, cytochromes, peroxidases, myoglobins, catalases and so on, are some important biological representatives. They are the primary light-harvesting molecules in natural photosynthesis. ${ }^{92,93}$ Porphyrin derivatives absorb light up to the red region of the visible spectrum with high extinction coefficients. A number of porphyrin derivatives have been successfully used in DSSCs, bilayer and BHJ solar cells. ${ }^{94-97}$

The use of DLC porphyrin in OPV was first realized by Gregg et al. ${ }^{98}$ who prepared an unusual PV cell using a DLC porphyrin, zinc octakis(8-octyloxyethy1)porphyrin 3a (Figure 7), sandwiched in between two symmetrical indium tin oxide (ITO) electrodes in 1990. It was proposed that 'the illuminated electrode interface possesses much higher concentration of excitons than at the counter electrode owing to strong absorption of incident light by the porphyrin. The exciton dissociation at the porphyrin/ITO interface was inherently asymmetric, and this leads to a significant and persistent PV effect'. ${ }^{98}$

BHJ solar cells incorporating porphyrin discotic molecules $\mathbf{3 b}$ and 3c (Figure 7) with $\mathrm{PC}_{61} \mathrm{BM}$ electron acceptor were prepared by $\mathrm{Li}$ and co-workers that showed PCE upto $0.222 \% .{ }^{99,100}$ These porphyrin have high absorption range over solar spectrum and align homeotropically for efficient charge transport. Both bilayer heterojunction and $\mathrm{BHJ}$

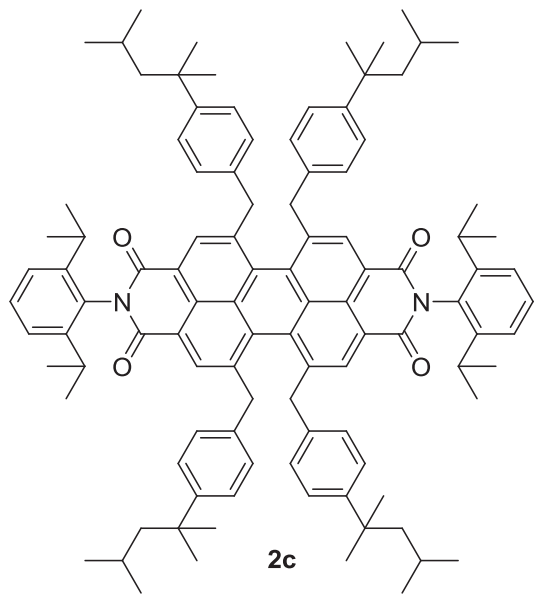

devices were fabricated with the cell structure of ITO/PEDOT: $\mathrm{PSS} / \mathrm{DLC} / \mathrm{PC}_{61} \mathrm{BM} / \mathrm{Ca}-\mathrm{Al}$. An active layer of $80-\mathrm{nm}$ porphyrin was spin-coated from its chlorobenzene solution and a 30-nm-thick $\mathrm{PC}_{60} \mathrm{BM}$ layer was thermally deposited under vacuum to construct bilayer solar cells. On the other hand, $\mathrm{BHJ}$ devices were prepared from a blend of porphyrin and $\mathrm{PC}_{60} \mathrm{BM}(1: 1 \mathrm{w} / \mathrm{w}, 230-250-\mathrm{nm}$ thick). It has been observed that thermal annealing of these devices induced alignment of discotic molecules in the photoactive layers, leading to a factor of 4-5 higher PCE. PV parameters of these devices are tabulated in Table 2 along with Pc discotics.

Although porphyrin DLCs exhibit many attractive features, such as broad absorption spectrum, low gap between HOMO and LUMO energy levels, facile homeotropic alignment, high charge-carrier mobility and resemblance with natural photosynthetic antenna, surprisingly, out of $>200$ DLCs derived from porphyrin nucleus only 2 DLCs have been so far used to fabricate real solar cell. Therefore, it would be quite interesting to further explore these interesting intriguing materials.

\section{PC DLCS IN PVS}

Pcs are closely related to porphyrins and are also known as tetrabenzo tetraazaporphyrins. Pcs are macrocyclic compounds with an alternative carbon atom-nitrogen atom ring structure, which acts as a tetradentate ligand. They have found applications in bio and electronic industries. ${ }^{101}$ Pcs can act both as p-type and n-type semiconductors depending on peripheral substitutions. ${ }^{102}$ Piechocki et al. ${ }^{103}$ discovered columnar mesophase properties of Pc LCs in 1982, and since then, about 400 Pc-based DLCs have appeared in the literature. ${ }^{34}$ Pc-based DLCs have been extensively studied for their conducting and photoconducting properties and charge-carrier mobility up to $0.71 \mathrm{~cm}^{2} \mathrm{~V}^{-1} \mathrm{~s}^{-1}$ has been realized. ${ }^{49}$ Several Pc-based DLCs have been used to fabricate solar cells. Chemical structures of these DLCs are presented in Figure 8 and their PV parameters are tabulated in Table 2.

Petristch et al. ${ }^{104}$ utilized discotic liquid crystalline Pc in organic solar cells in 1999. They investigated a double-layer PV device comprising a discotic Pc derivative 4a (Figure 8) as electron donor and a perylene derivative $2 \mathrm{e}$ (Figure 5 ) as electron-acceptor material. 

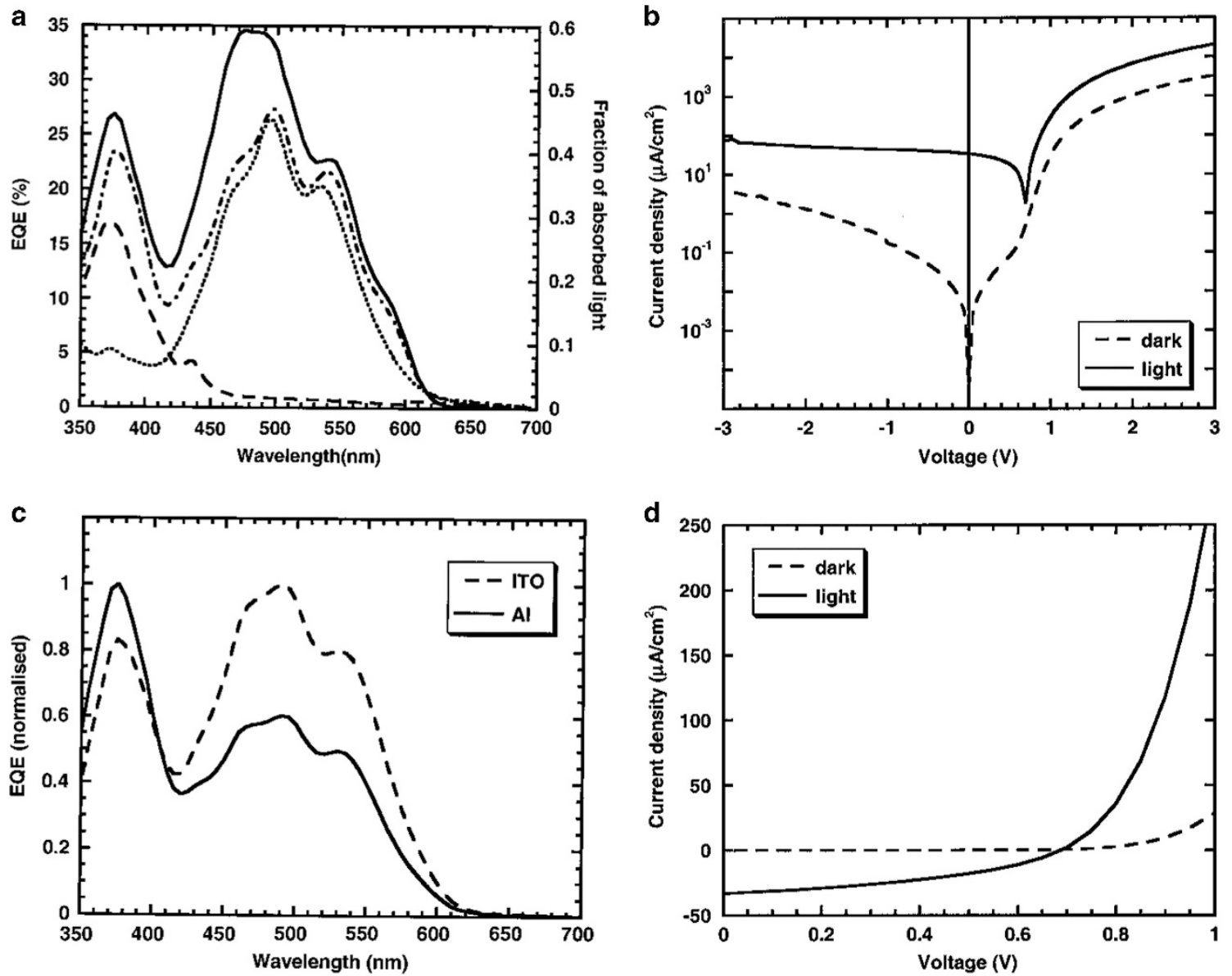

Figure 6 (a) EQE action spectra for a 40:60 HBC-PhC12:perylene diimide blend (solid line) and the fraction of absorbed light in an HBC-PhC12 film (dashed line), a perylene film (dotted line) and a 40:60 blend film (dash-dotted line). (b) Current-voltage characteristics for this device in the dark and under illumination at $490 \mathrm{~nm}$. The $J_{S C}$ and $V_{O C}$ under illumination are $-33.5 \mu \mathrm{Acm}^{-2}$ and $0.69 \mathrm{~V}$, respectively, and the $\mathrm{FF}$ is $40 \%$. The diode has a rectification ratio of $8.3 \times 10^{2}$ at $2 \mathrm{~V}$. (c, d) Normalized EQE action spectra taken under illumination through the ITO and Al electrodes, respectively, corrected for the absorption of the contacts and glass. Reproduced with permission from Schmidt-Mende et al. ${ }^{6}$ Copyright 2001 American Association for Advancement of Science.

Compound $4 \mathbf{a}$ was heated to its isotropic temperature $\left(292^{\circ} \mathrm{C}\right)$ and cooled slowly to room temperature. Then a thin layer of perylene as electron acceptor and $\mathrm{Al}$ as top contact electrode were deposited. The device exhibits EQE of 1\%. They also prepared a blended OPV device based on Pc $\mathbf{4 a}$ as donor and perylene derivative $\mathbf{2} \mathbf{a}$ as acceptor $^{105}$ that shows EQE upto $1 \%$ with $V_{\mathrm{OC}}$ of $0.1 \mathrm{mV}$ and $25 \% \mathrm{FF}$.

Levitsky et al. ${ }^{106}$ demonstrated a solar cell based on n-type nanoporous $\mathrm{Si}$ (PSi) filled with copper $\mathrm{Pc}(\mathrm{CuPc})$ and its discotic derivatives $\mathbf{4 b}$ (Figure 8 ). The fabricated device shows the PCE upto $2 \%$. Such organic filled nanoporous inorganic matrices may lead to the fabrication of hybrid PV systems with efficient photoinduced charge transfer and charge migration. Both $\mathrm{CuPc}$ and PSi contribute to the photocarrier generation, but the $\mathrm{CuPc}$ discotic derivative shows the property of increasing the hole mobility along the quasi-onedimensional columns. The device was fabricated as ITO/PSi-CuPc/Al architecture followed by the plasma etching of nanoporous $\mathrm{Si}$ to ensure the opening of the all pores. PSi was filled by dropping a solution $\left(10^{-2} \mathrm{M}\right)$ of $\mathrm{CuPc}$. The $I-V$ curves of Psi samples that were not treated by plasma etching to open all pores exhibited a 'kink' behavior leading to a decrease of the $V_{\mathrm{OC}}$ and $I_{\mathrm{SC}}$ values. The authors suggested that 'samples with a poorly developed pore structure or with partially opened pores cannot provide a sufficiently dense filling of $\mathrm{CuPc}$ molecules to form a conductive wire for hole transport to the anode. This is consistent with the theoretical model, which indicates that the $I-V$ curve degradation occurs as a result of a decrease of the hopping coefficient; poor filling leads to isolation of the $\mathrm{CuPc}$ aggregates making them insulated from each other'. ${ }^{106}$

Fujii and co-workers extensively studied various Pc DLCs in PVs. ${ }^{69,70,107-113}$ They prepared an OPV device based on Pc derivative 1,4,8,11,15,18,22,25-octahexylphthalocyanine (C6PcH2) 4d (Figure 8) as donor and the fullerene derivative $\mathrm{PC}_{61} \mathrm{BM}$ as acceptor in 2010. ${ }^{107}$ High EQE of $>70 \%$ in the Q-band absorption region of $\mathrm{C} 6 \mathrm{PcH} 2$ and a high energy-conversion efficiency of $3.1 \%$ were achieved with different compositions of both donor and acceptor materials. The values of $V_{\mathrm{OC}}$ is $0.81 \mathrm{~V}, I_{\mathrm{SC}}$ of $9.6 \mathrm{~mA} \mathrm{~cm}^{-2}$ and $\mathrm{FF}$ of $40 \%$ were observed for the solar cell with the $\mathrm{C} 6 \mathrm{PcH} 2: \mathrm{PC}_{61} \mathrm{BM}$ composite layer at a weight ratio of 2:1. To improve the FF of the above device, they studied the optimization of the active layer thickness and insertion of buffer layer. ${ }^{108}$ The optimized active layer thickness was determined to be $120 \mathrm{~nm}$. By inserting a hole-transporting $\mathrm{MoO}_{3}$ buffer layer between cathode and active layer, the PCE was enhanced to $3.2 \%$. Working on the same DLC $\mathbf{4 d}$, they studied the effect of additional additives on the surface morphology. ${ }^{109}$ By using processing additive 
Table 1 Photovoltaic parameters of some best-performing HBC DLC-based solar cells

\begin{tabular}{|c|c|c|c|c|c|c|c|c|c|}
\hline Donor & Acceptor & $\mathrm{V}_{O C}(V)$ & $\mathrm{J}_{S C}\left(m A \mathrm{~cm}^{-2}\right)$ & $F F(\%)$ & $E Q E(\%)$ & PCE (\%) & Illumination source $\left(\mathrm{mW} \mathrm{cm} \mathrm{cm}^{-2}\right) / \mathrm{nm}$ & Phase & Reference \\
\hline 1a & $2 a$ & 0.69 & 0.033 & 40 & 34 & 1.95 & $490 \mathrm{~nm}$ & $\mathrm{Col}_{\mathrm{h}}$ & 6 \\
\hline 1b chiral & $2 a$ & 0.46 & 0.033 & 32.5 & 34 & 0.1 & $490 \mathrm{~nm}$ & $\mathrm{Cr}$ & 80 \\
\hline $1 \mathrm{c}$ & $2 a$ & 0.70 & - & - & 29.5 & - & $460 \mathrm{~nm}$ & $\mathrm{Cr}$ & 85 \\
\hline $1 d$ & $2 a$ & 0.52 & - & - & 12 & 1.5 & $470 \mathrm{~nm}$ & $\mathrm{Cr}$ & 84 \\
\hline $1 \mathrm{e}$ & $2 a$ & 0.6 & - & 34.6 & 14 & - & $490 \mathrm{~nm}$ & LC & 72 \\
\hline $1 \mathrm{~h}$ & $2 a$ & 0.64 & 1.03 & 33.4 & - & 0.22 & $100 \mathrm{~mW} \mathrm{~cm}^{-2}$ & $\mathrm{Cr}$ & 79 \\
\hline $1 \mathrm{i}$ & $2 a$ & 0.665 & 1.065 & 34.3 & - & 0.24 & $100 \mathrm{~mW} \mathrm{~cm}-2$ & $\mathrm{Cr}$ & 79 \\
\hline $1 \mathrm{j}$ & $2 a$ & 0.59 & 0.34 & 39.2 & - & 0.08 & $100 \mathrm{~mW} \mathrm{~cm}^{-2}$ & LC & 79 \\
\hline $1 \mathrm{k}$ & $2 a$ & 0.69 & 0.81 & 39.3 & - & 0.22 & $100 \mathrm{~mW} \mathrm{~cm}^{-2}$ & LC & 79 \\
\hline 11 & $2 a$ & 0.54 & 0.3 & 44.5 & - & 0.07 & $100 \mathrm{~mW} \mathrm{~cm}-2$ & $\mathrm{Cr}$ & 79 \\
\hline $1 \mathrm{~m}$ & PCBM & 0.61 & 0.17 & 32 & 2 & 0.03 & $100 \mathrm{~mW} \mathrm{~cm}-2$ & LC & 87 \\
\hline $1 \mathrm{r}$ & PCBM & 1 & 6.37 & 38 & - & 2.5 & $100 \mathrm{~mW} \mathrm{~cm}^{-2}$ & $\mathrm{Col}_{\mathrm{h}}$ & 88 \\
\hline $1 \mathrm{~s}$ & PCBM & 0.87 & 2.03 & 60 & 27 & 1.06 & $100 \mathrm{~mW} \mathrm{~cm}^{-2}$ & LC & 87 \\
\hline $1 \mathrm{t}$ & PCBM & 1 & 6.37 & 38 & - & 2.41 & $100 \mathrm{~mW} \mathrm{~cm}^{-2}$ & $\mathrm{Cr}$ & 90 \\
\hline
\end{tabular}

Abbreviations: $\mathrm{Cr}$, crystalline; Col $\mathrm{h}$, columnar hexagonal; $\mathrm{Col}_{\mathrm{p}}$, columnar plastic; DLC, discotic liquid crystal; EQE, external quantum efficiency; $\mathrm{FF}$, fill factor; HBC, hexa-peri-hexabenzocoronene; $J_{\mathrm{SC}}$, short circuit current; LC, liquid crystalline; PCBM, [6,6]-phenyl-C61-butyric acid methyl ester; PCE, power-conversion efficiency; $V_{\mathrm{OC}}$, open circuit voltage.<smiles>[R]CO[GaH]</smiles>

$\mathrm{R}=\mathrm{CH}_{2} \mathrm{CH}_{2} \mathrm{OC}_{8} \mathrm{H}_{17}$<smiles>[R]c1ccc(C(=C(C)C)c2ccc([R])cc2)cc1</smiles>

3b: $\mathbf{R}$<smiles>CCOC(=O)c1cc(OCC)c(OCC)c(OCC)c1</smiles>

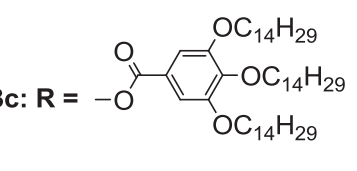

Figure 7 Chemical structure of porphyrin DLCs used in photovoltaics.

1,8-diiodooctane $(0.2 \% \mathrm{v} / \mathrm{v})$ in various organic solvents, such as toluene, trichloroethylene and chloroform, the performance of $\mathrm{BHJ}$ solar cells was markedly improved. The values of $V_{\mathrm{OC}}$ of $0.78 \mathrm{~V}, I_{\mathrm{SC}}$ of $9.1 \mathrm{~mA} \mathrm{~cm}^{-2}$, FF of $58 \%$ and the PCE $4.1 \%$ were recorded. Other additives such as 1,8-dichlorooctane and 1,8-dibromooctane also exhibit similar effect. However, increasing the amount of additives decreases the PCE. ${ }^{110}$ The marked improvement in the PCE has been attributed to distinctly different surface morphology (Figure 9) of the active layer where processing additive separated the donor-acceptor phases. ${ }^{110}$

The stability and the degradation mechanism of the solar cell have also been studied. ${ }^{111}$ Solar cells based on Pc show higher stability than the cells fabricated with the conventional donor material poly(3-hexylthiophene) (P3HT) in the same environment ( $45^{\circ} \mathrm{C}$ temperature and 1 Sun). It was observed that the irradiation of a solar simulator degrade the $\mathrm{C} 6 \mathrm{PcH} 2$ molecule by breaking chemical bonds of two pyrrole aza nitrogens as well as the four meso-bridging aza nitrogens with neighboring carbons and this affected the device lifetime. Deposition of various buffer layers between the active layer and counter electrode improve the stability. ${ }^{114,115}$
Solar cells with homologous series of 1,4,8,11,15,18,22,25-octahexylphthalocyanine (Figure 8, structure 4c, 4d, 4e, 4f and 4g) were prepared by Dao et al. ${ }^{112}$ to understand the effects of alkyl chain length on PV parameters. They observed that, 'by shortening the alkyl substituents length, the columnar structure of the Pc discotic altered from 2D rectangular lattices to pseudohexagonal structures and Davydov splitting at the Q-band of $\mathrm{CnPcH} 2$ absorbance spectra decreases, which results in the higher hole mobility and the deeper HOMO energy levels. As a result, the PCE of $\mathrm{CnPcH}$-based $\mathrm{BHJ}$ solar cell is improved from $0.3 \%$ to $3.7 \%$ by changing the alky substituent length'. ${ }^{112}$ In this series, the highest PCE was observed in the Pc $4 \mathbf{d}$ with hexyl alkyl chain.

Very recently, Dao et al. utilized various Pc-tetrabenzoporphyrin hybrid macrocycles $\mathbf{4 i - 4 m}$ to prepare solar cells. ${ }^{113}$ These compounds were prepared by replacing azo links of Pc $\mathbf{4 d}$ by methane groups. Thus non-peripherally substituted octahexyl tetrabenzoporphyrin (C6TBPH2, 4i), tetrabenzomonoazaporphyrin (C6TBMAPH2, 4j) tetrabenzodiazaporphyrins $\mathbf{4 k}$ and $\mathbf{4 l}\left(\mathrm{C}_{\mathrm{TBDAPH}}\right.$, a mixture of cis and trans compounds) and tetrabenzotriazaporphyrin $\left(\mathrm{C}^{2} \mathrm{TBTAPH}_{2}\right.$, $4 \mathbf{m})$ were prepared. These hybrid molecules were reported to exhibit 
Table 2 Photovoltaic parameters of some best-performing porphyrin and phthalocyanine DLC-based solar cells

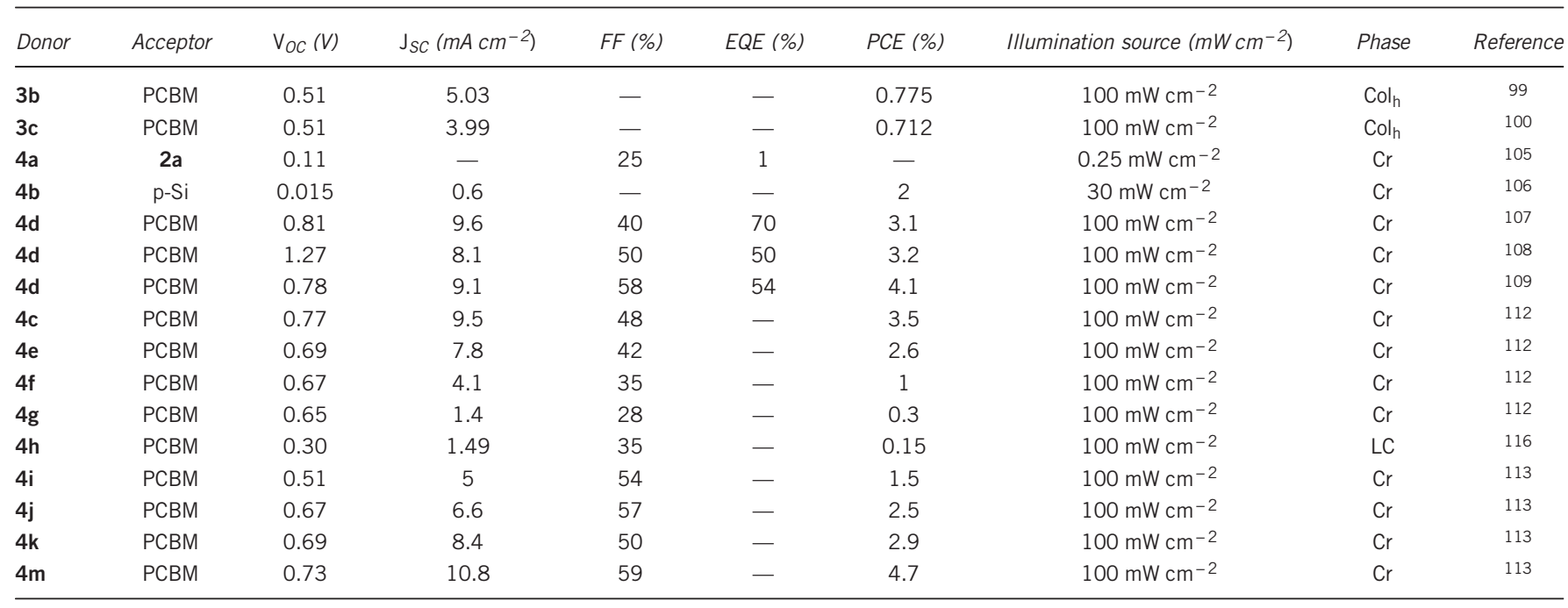

Abbreviations: $\mathrm{Cr}$, crystalline; $\mathrm{Col}_{\mathrm{h}}$, columnar hexagonal; DLC, discotic liquid crystal; EQE, external quantum efficiency; FF, fill factor; JsC, short circuit current; LC, liquid crystalline; PCBM, [6,6]phenyl-C61-butyric acid methyl ester; PCE, power-conversion efficiency; $V_{0 C}$, open circuit voltage.

rectangular columnar mesophases. Photovolatiac solar cells were prepared using various Pc-tetrabenzoporphyrin hybrid macrocycles mixed with $\mathrm{PC}_{70} \mathrm{BM}$ in $\mathrm{ITO} / \mathrm{MoOx} / \mathrm{BHJ} / \mathrm{Al}$ structures and solar cell performance was measured under AM $1.5 \mathrm{G}$ illumination at an intensity of $100 \mathrm{~mW} \mathrm{~cm}^{-2}$. PV parameters of these devices are presented in Table 2 . The best PCE of $4.7 \%$ with $V_{\mathrm{OC}}$ of $0.73 \mathrm{~V}, J_{\mathrm{SC}}$ of $10.8 \mathrm{~mA} \mathrm{~cm}^{-2}$ and $\mathrm{FF}$ of $59 \%$ was achieved for the devices prepared from C6TBTAPH2 mixed with $\mathrm{PC}_{70} \mathrm{BM}$.

Fujii and co-workers also used Pc DLCs $4 \mathbf{d}$ and $4 \mathrm{e}$ as additives in classical BHJ thin-film solar cells based on P3HT and [6,6]-phenyl-C61-butyric acid methyl ester (PCBM). ${ }^{69,70}$ The PV devices show EQEs of 74, 66 and $47 \%$ at a wavelength of $540 \mathrm{~nm}$ without $\mathrm{CnPcH} 2$, with $\mathrm{C} 6 \mathrm{PcH} 2$ and with $\mathrm{C} 7 \mathrm{PcH} 2$, respectively. The PCE of the solar cell without $\mathrm{CnPcH} 2$ was $2.3 \%$ with $I_{\mathrm{SC}}$ of $8.6 \mathrm{~mA} \mathrm{~cm}^{-2}, V_{\mathrm{OC}}$ of $0.57 \mathrm{~V}$ and $\mathrm{FF}$ of $48 \%$ that improves to $3.0 \%$ with $I_{\mathrm{SC}}$ of $12.1 \mathrm{~mA} \mathrm{~cm}^{-2}, V_{\mathrm{OC}}$ of $0.56 \mathrm{~V}$ and $\mathrm{FF}$ of $44 \%$ with $\mathrm{C} 6 \mathrm{PcH} 2$. However, the addition of $\mathrm{C} 7 \mathrm{PcH} 2$ does not show much improvement in PCE.

Jurow et al. ${ }^{116}$ synthesized a mixture of various thioalkyl-substituted Pc derivatives $\mathbf{4 h}$. Number of thioalkyl-substitution was estimated in between 3 and 10. Some of these mixtures were reported to be discotic liquid crystalline. Solar cells prepared from these materials exhibit PCE in between $0.06 \%$ and $0.15 \%$.

\section{TP DISCOTICS IN PVS}

TP-based DLCs are the most rigorously studied materials. More than 1000 TP DLCs have been prepared and studied for various physical properties. ${ }^{117-119}$ Because of their good photoconducting and charge-carrier mobility behavior, it was obvious to look for their use in PV solar cells. ${ }^{50}$ Chemical structures of TP DLCs used in PVs are presented in Figure 10. PV parameters of some best-performing devices are tabulated in Table 3. The first report appeared in 2005 when Oukachmih et al. ${ }^{120}$ prepared two-layered devices using TP ether 5a (Figure 10) as a hole-transporting material and perylene derivatives $\mathbf{2 d}$, $\mathbf{2} \mathbf{f}$ and $\mathbf{2 g}$ (Figure 5) as electron-transporting materials. These devices showed EQE of around 3\%. They studied the effect of UV-ozone and argon plasma treatment of ITO on the solar cell efficiency of these devices. On UV-ozone treatment, the work function of ITO increases while it decreases on argon plasma treatment. The $V_{\mathrm{OC}}$ depends both on the organic-organic interface as well as on the electrode-organic interface. The UV-ozone treatment of ITO decreases $V_{\mathrm{OC}}$, whereas it increases on the argon plasma treatment. ${ }^{121}$

In 2010, Jeong et al. ${ }^{71}$ used TP discotics as an additive to well-established P3HT:PC ${ }_{61} \mathrm{BM}$ BHJ OPV device to realize the effect on PCE. The devices configured with P3HT:PC ${ }_{61} \mathrm{BM}(1: 1.2 \mathrm{w}-\mathrm{w})$ layer doped with 2,3,6,7,10,11-hexaacetoxytriphenylene (3wt\%) exhibit an average PCE of $3.97 \%$ after thermal annealing. In comparison, the reference cells display only $3.03 \%$ PCE. Two derivatives of TP, namely, 2,3,6,7,10,11-hexaacetoxytriphenylene $\mathbf{5 b}$ and 2,3,6,7,10,11hexamethoxytriphenylene $5 \mathrm{c}$ were used to fabricate OPV devices. However, it may be noted that both these compounds do not show any thermotropic mesomorphism.

A year later, Zheng et al. ${ }^{122}$ reported the use of a well-known DLC, namely, 2,3,6,7,10,11-hexabutoxytriphenylene (HAT4) 5d (Figure 10) as an additive to improve the PCE of P3HT:PC ${ }_{61}$ BM-based solar cells. The TP discotics (HAT4) disperse in the active layer to form a more efficient pathway for charge carriers. The influence of charge-carrier mobility with annealing and insertion of HAT4 discotic were studied. The hole and electron mobilities of the pristine P3HT: $\mathrm{PC}_{61} \mathrm{BM}$ blended system devices were recorded as $7.86 \times 10^{-6}$ and $5.35 \times 10^{-5} \mathrm{~cm}^{2} \mathrm{~V}^{-1} \mathrm{~s}^{-1}$, respectively, after thermal annealing. On dispersion of HAT4, hole and electron mobilities increase to $4.50 \times 10^{-5}$ and $2.32 \times 10^{-4} \mathrm{~cm}^{2} \mathrm{~V}^{-1} \mathrm{~s}^{-1}$, respectively. They demonstrated that both $J_{\mathrm{SC}}$ and FF were increased without changing the $V_{\mathrm{OC}}$. PCEs up to $3.5 \%$ were realized in these devices. The improvement in $J_{\mathrm{SC}}$ and $\mathrm{FF}$ was attributed owing to efficient photoinduced charge transfer in BJH solar cells by inserting HAT4. The AFM (atomic-force microscopy) images of HAT4 film surface before and after annealing are shown in Figures 11a and b. The sectional morphology of the device after thermal annealing is shown in Figures $11 \mathrm{c}$ and $\mathrm{d}$.

We further explored the use of HAT4 as an additive in classical OPV cells. ${ }^{72}$ A conventional device was fabricated with cell structure of ITO/PEDOT:PSS/HAT4-PCBM:P3HT/Al and its PV parameters were compared with the device without HAT4. The PCE was improved $63 \%$ after addition of the DLC. A significant improvement in $J_{S C}$ from 


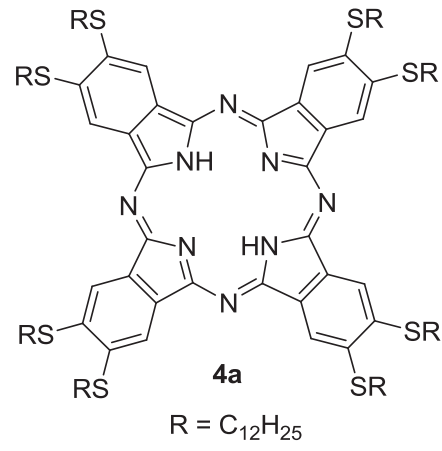<smiles></smiles>

4c: $\mathrm{R}=\mathrm{C}_{5} \mathrm{H}_{11}$

4d: $\mathrm{R}=\mathrm{C}_{6} \mathrm{H}_{13}$

4e: $\mathrm{R}=\mathrm{C}_{7} \mathrm{H}_{15}$

4f: $\mathrm{R}=\mathrm{C}_{8} \mathrm{H}_{17}$

4g: $\mathrm{R}=\mathrm{C}_{10} \mathrm{H}_{21}$

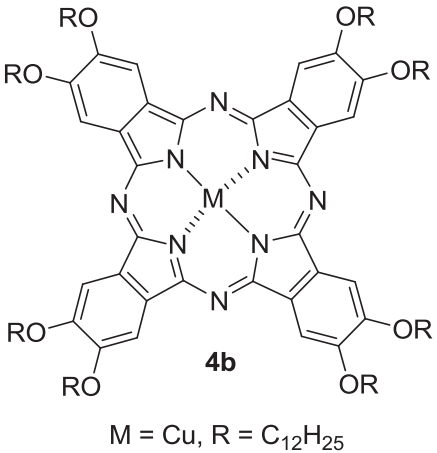

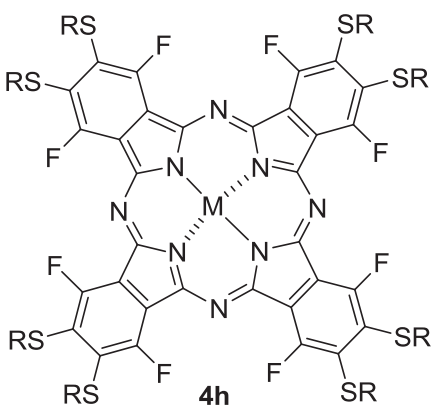

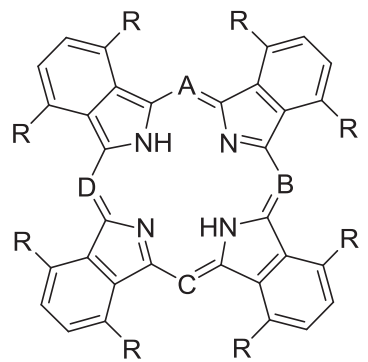

$\mathrm{R}=\mathrm{C}_{6} \mathrm{H}_{13}$

4i: $\mathrm{A}=\mathrm{B}=\mathrm{C}=\mathrm{D}=\mathrm{CH} ; \mathrm{C} 6 \mathrm{TBPH}_{2}$

4j: $\mathrm{A}=\mathrm{B}=\mathrm{C}=\mathrm{CH}, \mathrm{D}=\mathrm{N} ; \mathrm{C} \mathrm{TBMAPH}_{2}$

4k: $\mathrm{A}=\mathrm{B}=\mathrm{CH}, \mathrm{C}=\mathrm{D}=\mathrm{N}$; (cis)C6TBDAPH $\mathrm{T}_{2}$

4I: $\mathrm{A}=\mathrm{C}=\mathrm{CH}, \mathrm{B}=\mathrm{D}=\mathrm{N}$; (trans) $\mathrm{C} 6 \mathrm{TBDAPH}_{2}$

4m: $\mathrm{A}=\mathrm{CH}, \mathrm{B}=\mathrm{C}=\mathrm{D}=\mathrm{N} ; \mathrm{C} 6 \mathrm{TBTAPH}_{2}$

Figure 8 Chemical structure of phthalocyanine-based DLCs used in photovoltaics.
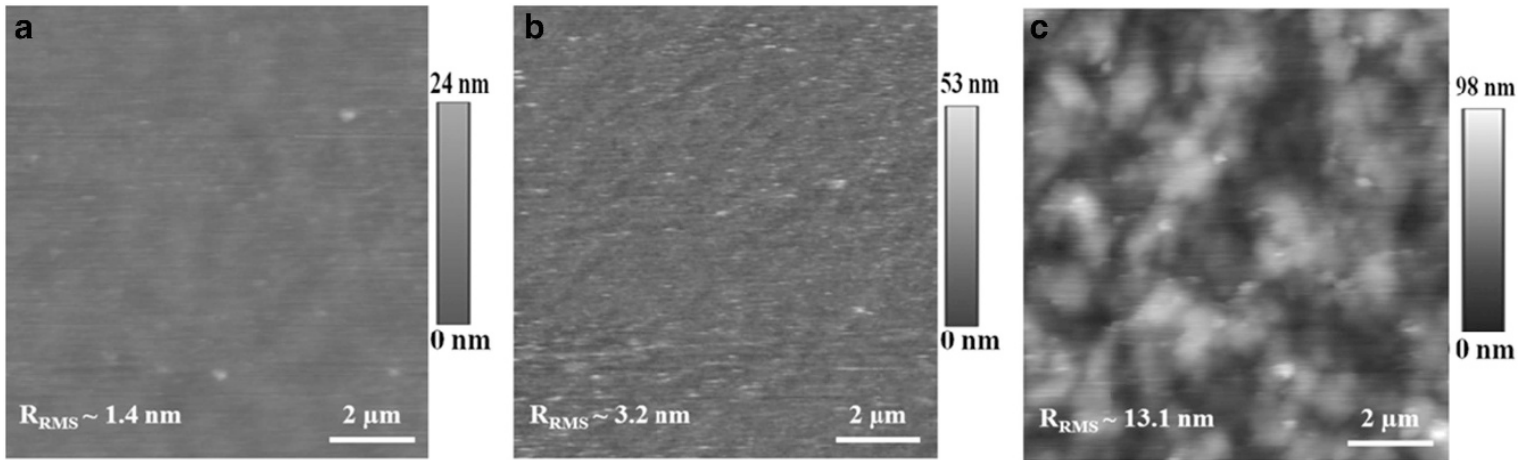

Figure 9 AFM images of surface of C6PcH2:PCBM composite thin films: (a) without DIO, (b) with $0.2 \% \mathrm{v} / \mathrm{v}$ of $\mathrm{DIO}$, and (c) with $0.8 \% \mathrm{v} / \mathrm{v}$ of $\mathrm{DIO}$. Reproduced with permission from Dao et al. ${ }^{110}$ Copyright 2013 Elsevier B.V. A full color version of this figure is available at the Polymer Journal online.

7.4 to $10.3 \mathrm{~mA} \mathrm{~cm}^{-2}$ was observed. This enhancement could be due to the increased charge-separation efficiency in active layer owing to HAT4. Thickness of DLC layer have important role in the device. When the thickness of the layer was 10-20 nm, the maximum value of $J_{\mathrm{SC}}$ and PCE was achieved. Further enhancement in the layer thickness decreases $J_{\mathrm{SC}}$ and PCE. On increasing thickness beyond a certain length, traps are created owing to the dislocation of columns. Annealing of the device is also crucial for getting high PCE. On annealing, traps get healed resulting in improved $J_{\mathrm{SC}}$ and efficiency of the devices with DLC increased to $12.9 \mathrm{~mA} \mathrm{~cm}^{-2}$ and $2.27 \%$, 
<smiles>[R]Oc1cc2c3cc([R2])c([R])cc3c3cc(O[R2])c([R])cc3c2cc1[R]</smiles>

5a: $\mathrm{R}=\mathrm{CH}_{2} \mathrm{CH}_{2} \mathrm{OCH}_{3}$ 5b: $\mathbf{R}=\mathrm{COCH}_{3}$ 5c: $\mathrm{R}=\mathrm{CH}_{3}$ 5d: $\mathrm{R}=\mathrm{C}_{4} \mathrm{H}_{9}$<smiles>[R2]Oc1cc2c3cc([R20])c(O)cc3c3cc(O[R])c([R])cc3c2cc1[R]</smiles>

5e: $\mathrm{R}=\mathrm{C}_{6} \mathrm{H}_{13}$

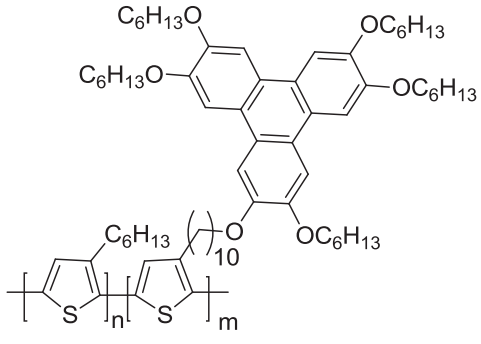

5f (P3HT-b-P3TPT)

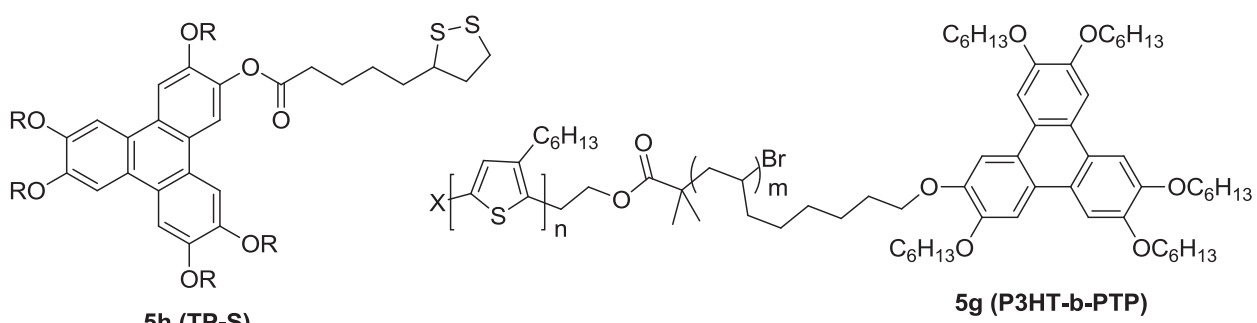

Figure 10 Chemical structure of triphenylene-based DLCs used in photovoltaics.

Table 3 Photovoltaic parameters of some best-performing TP DLC-based solar cells

\begin{tabular}{|c|c|c|c|c|c|c|c|c|}
\hline Donor & Acceptor & $\mathrm{V}_{O C}(V)$ & $\mathrm{J}_{S C}\left(m A \mathrm{~cm}^{-2}\right)$ & $F F(\%)$ & PCE (\%) & Illumination source $\left(\mathrm{mW} \mathrm{cm}^{-2}\right)$ & Phase & Reference \\
\hline $5 a$ & $2 d$ & 0.7 & 0.04 & 40 & - & 5.4 & $\mathrm{Cr}$ & 120 \\
\hline $5 b$ & PCBM & 0.67 & 9.15 & 64.9 & 3.97 & 100 & $\mathrm{Cr}$ & 71 \\
\hline $5 c$ & PCBM & 0.65 & 9.30 & 63.6 & 3.9 & 100 & $\mathrm{Cr}$ & 71 \\
\hline 5d/P3HT & PCBM & 0.62 & 10.6 & 56 & 3.5 & 100 & $\mathrm{Cr}$ & 122 \\
\hline 5d/P3HT & PCBM & 0.54 & 12.90 & 34 & 2.27 & 100 & $\mathrm{Cr}$ & 72 \\
\hline 5d/PCDTBT & PCBM & 0.85 & 10.40 & 58 & 5.14 & 100 & $\mathrm{Cr}$ & 124 \\
\hline $5 f$ & PCBM & 0.60 & 6.51 & 39 & 1.54 & 100 & $\mathrm{Cr}$ & 125 \\
\hline $5 g$ & PCBM & 0.60 & 10.36 & 64.9 & 4.03 & 100 & $\mathrm{Cr}$ & 126 \\
\hline 5h/ZnO@N719 & PCBM & 0.73 & 16.4 & 65 & 8 & 100 & $\mathrm{Cr}$ & 127 \\
\hline P3HT/TP-S@ZnO & - & 0.60 & 4.52 & 35 & 0.95 & 100 & $\mathrm{Cr}$ & 128 \\
\hline
\end{tabular}

Abbreviations: $\mathrm{Cr}$, crystalline; DLC, discotic liquid crystal; FF, fill factor; JSC, short circuit current; N719, ditetrabutylammonium cis-bis(isothiocyanato)bis(2,2'-bipyridyl-4,4'-dicarboxylato) ruthenium (II); PCBM, [6,6]-phenyl-C61-butyric acid methyl ester; PCDTBT, poly [N-9'”-heptadecanyl-2,7-carbazole-alt-5,5-(4',7'-di-2-thienyl-2', $1^{\prime}, 3^{\prime}$-benzothiadiazole)]; PCE, power-conversion efficiency; P3HT, poly(3-hexylthiophene); TP, triphenylene; TP-S, dithiol-functionalized TP; $V_{O C}$, open circuit voltage.

respectively. The device without DLC in it did not affect the PCE on annealing. Insertion of molybdenum oxide as a buffer layer between ITO and active layer also gives similar results. ${ }^{123}$

We also developed BHJ solar cells based on composites of copolymer poly [N-90-heptadecanyl-2,7-carbazole-alt-5,5(40,70-di-2-thienyl-20,10,30-benzothiadiazole)] (PCDTBT) and the fullerene derivative $\mathrm{PC}_{71} \mathrm{BM}$ with an inserted layer of HAT4. ${ }^{124}$ Two different materials, poly (3,4 ethylenedioxythiophene)-poly (styrenesulfonate) (PEDOT: PSS) and molybdenum trioxide $\left(\mathrm{MoO}_{3}\right)$ were used as buffer layers between ITO and DLC layers. All the devices with inserted DLC layer exhibited better performance compared with reference cells. PV solar cells containing 30-nm thick HAT4 layer display 5.14\% PCE under 1 Sun condition. This is a significant improvement in the PCE compared with earlier reports.

TP DLCs as a moiety to form self-assembly with diblock polythiophene on side chains were used by Chen et al. ${ }^{125}$ They synthesized diblock copolymers P3HT-block-poly[3-(10-(2,3,6,7,10-pentakis(hexyloxy)triphenylene)decyloxy)thiophene] (P3HT-b-P3TPT) 5f (Figure 10) having a TP liquid crystalline pendant. The copolymers form an extremely well-defined highly ordered nanowires owing to the presence of LCs that enhance the charge transport. Diblock copolymers of P3HT/P3TPT with molar ratios of 3:1, 6:1 and 9:1 termed H3P1, H6P1 and H9P1 were synthesized. The thin films were solution coated on ITO substrate and annealed. The morphology change to the thin film structures and self-assembly was studied by AFM. Different treatments were given to the thin films, such as as-cast, slow film growth (SA), thermal annealing (TA) and ortho-dichlorobenzene (o-DCB) vapor annealing followed by thermal annealing (SA+TA). The OPV device based on the SA+TA-treated $\mathrm{H} 9 \mathrm{P} 1 / \mathrm{PC}_{61} \mathrm{BM}$ blend exhibits the best performance with a PCE of $1.54 \%, J_{\mathrm{SC}}$ of $6.51 \mathrm{~mA} \mathrm{~cm}^{-2}, V_{\mathrm{OC}}$ of $0.601 \mathrm{~V}$ and $\mathrm{FF}$ of $39.4 \%$, whereas the device based on its analogous block copolymers H6P1 and H3P1 only shows PCE values of $0.99 \%$ and $0.24 \%$, respectively. The improved PCE results from the interaction between the TP moieties. The SA+TA treatment can easily drive interchain $\pi-\pi$ interactions to develop the fine formation of crystalline lamellar aggregation favoring an optimized morphology of the active 

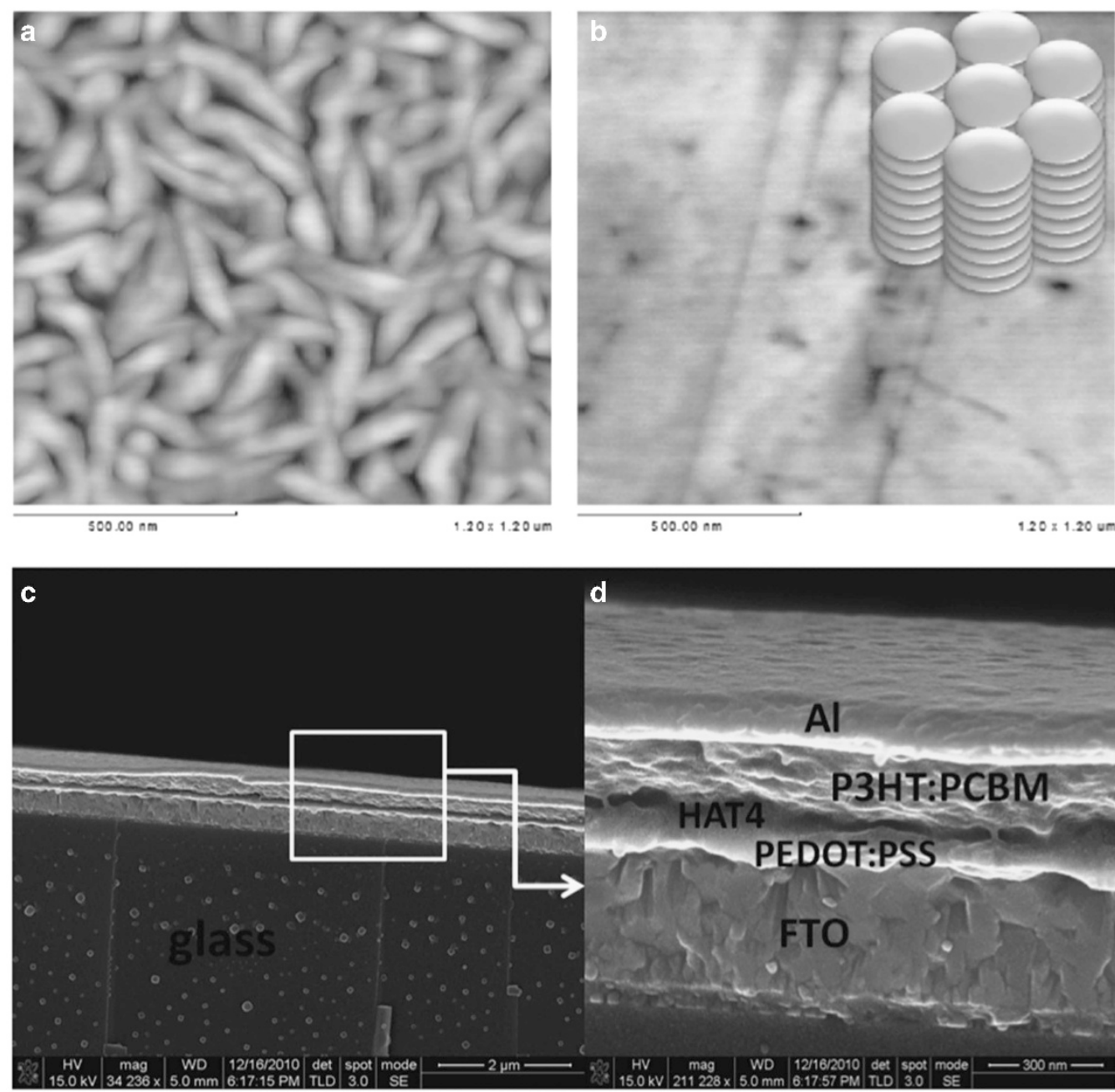

Figure 11 Tapping-mode AFM surface image of HAT4 film, (a) before annealing and (b) after annealing; the inset shows a simplified diagram of the $\pi-\pi$ stacking configuration in HAT4. (c, d) SEM images of the sectional morphology of the device with HAT4. Reproduced with permission from Zheng et al. ${ }^{122}$ Copyright 2011 Elsevier B.V. A full color version of this figure is available at the Polymer Journal online.

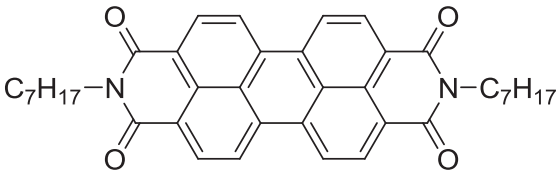

$6 \mathbf{a}$

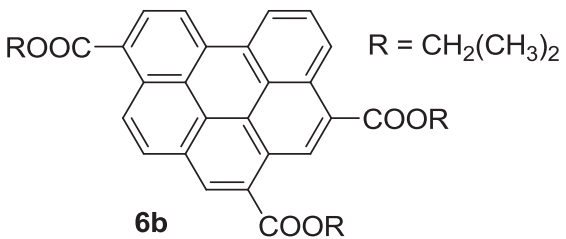

Figure 12 Chemical structure of perylene-based DLCs used in photovoltaics.

Table 4 Photovoltaic performance of perylene, decacylene and other DLCs

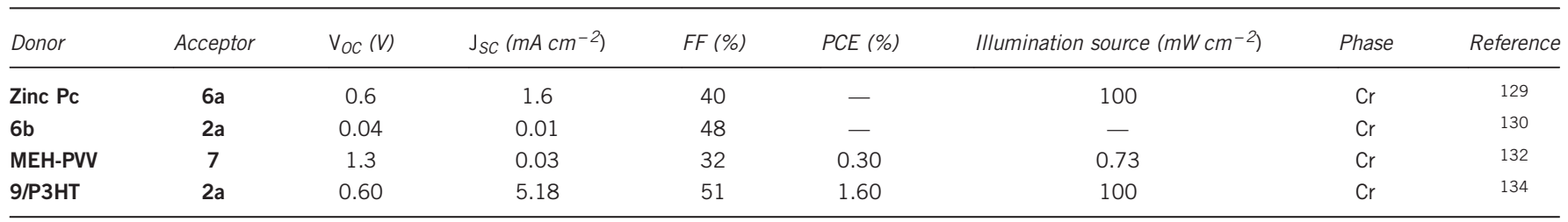

Abbreviations: $\mathrm{Cr}$, crystalline; DLC, discotic liquid crystal; FF, fill factor; JSc, short circuit current; MEH-PVV, [2-methoxy-5-(2'-ethylhexyloxy)-1,4-phenylenevinylene]; PCE, power-conversion efficiency; P3HT, poly(3-hexylthiophene); $V_{0 C}$, open circuit voltage. 
layer. Similarly, a DLC block poly(2,3,6,7,10-pentakis(hexyloxy)-11(oct-7-en-1-yloxy)triphenylene) (P3HT-b-PTP) 5g (Figure 10) was used to configure PV device structure of P3HT-b-PTP):PCBM)/LiF/ Al. ${ }^{126}$ The highest PCE of $4.03 \%$ is achieved when the concentration of P3HT-b-PTP is $5 \%$, with a $J_{\mathrm{SC}}$ of $10.36 \mathrm{~mA} \mathrm{~cm}^{-2}$ and an FF of $64.91 \%$.

They further prepared dye-sensitized nanoarrays (NAs) with DLC interlayer for high-efficiency inverted polymer solar cells. Inverted polymer solar cells were fabricated with well-aligned and highly uniform one-dimensional $\mathrm{ZnO}$ nanoparticles with organic ditetrabutylammonium cis-bis(isothiocyanato)bis(2,2'-bipyridyl-4,4' -dicarboxylato) ruthenium(II) (N719) dye and 3,6,7,10,11-pentakis(hexyloxy)2-hydroxytriphenylene 5e (Figure 10). ${ }^{127}$ The N719 shell and N719/ LC double-shells were introduced to modify the interface between the active organic layer and $\mathrm{ZnO}$ NAs. The self-organization of DLC facilitate the active layer components to rearrange, leading to a more orderly nanomorphology of active layer and consequently reduces the probability of electron/hole recombination at the interface donor/ acceptor materials. The best PCE of the device with only dye-coated NAs was $7.3 \%$, which increases to $8 \%$ when the NAs were coated with dye and DLC.

Chen et al. ${ }^{128}$ extended their work by synthesizing DLC ligands dithiol-functionalized TP (TP-S) $\mathbf{5 h}$ modified $\mathrm{ZnO}$ nanoparticles (TP-S@ZnO). Hybrid solar cells based on a blend of P3HT and TP-S@ZnO were prepared and characterized. They reported that 'DLC ligands improve the compatibility between P3HT polymer and $\mathrm{ZnO}$ nanoparticles, which is beneficial for enhanced charge separation and transfer efficiency. DLC molecular interface modification can provide a viable and interesting method to promote the compatibility and a large interfacial area between polymers and nanocrystals, which improve the performance of the device. The self-assembly of TP-S ligands tends to provide a better pathway for electrons and holes for transporting in the active layer'. ${ }^{128}$ Solar cells with a conventional device configuration 'ITOPEDOT:PSS/active layer/LiFAl' were prepared. The $\mathrm{BHJ}$ devices based on $\mathrm{P} 3 \mathrm{HT} / \mathrm{ZnO}$ film showed a PCE of $0.46 \%$, which improves to $0.51 \%$ on directly grafting the ligand TP-S onto ZnO NPs and annealing the sample at $130^{\circ} \mathrm{C}$. The device based on TP-S@ZnO/P3HT showed an improvement with a PCE of $0.70 \%$, which further improves to $0.95 \%$ on annealing the sample at $130^{\circ} \mathrm{C}$.

\section{PERYLENE DLCS IN PVS}

Perylene tetracarboxylic acid bisimides commonly known as perylenebisimides are among the best $n$-type organic semiconductors known to date. Many non-LC perylenebisimide derivatives have been used as electron acceptor in PV solar cells. Upon appropriate peripheral substitution, perylene derivatives exhibit columnar

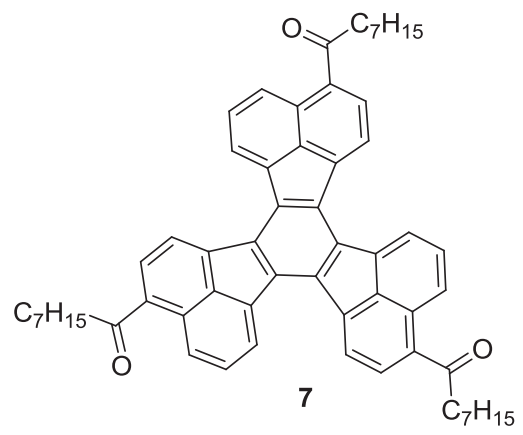

Figure 13 Chemical structure of 1,7,13-heptanoyldecacyclene. mesophases and the use of these liquid crystalline materials in PVs is presented here. Kim and $\operatorname{Bard}^{129}$ prepared an organic donor/ acceptor heterojunction PV devices based on a non-LC zinc Pc ( $\mathrm{ZnPc})$ as donor and a liquid crystalline perylene diimide, N,N-diheptyl3,4,9,10-perylenebiscarboximide (PTCDI) 6a (Figure 12) as acceptor with the cell configuration ITO/ZnPc/PTCDI/Ga:In. The device with D and A thickness of $100 \mathrm{~nm}$ generated FF of $22 \%$, with a $J_{\text {SC }}$ value of $0.40 \mathrm{~mA} \mathrm{~cm}^{-2}$ and $V_{\mathrm{OC}}$ of $0.60 \mathrm{~V}$. The FF was improved by $40 \%$ with a $J_{\mathrm{SC}}$ value of $1.58 \mathrm{~mA} \mathrm{~cm}^{-2}$ and $V_{\mathrm{OC}}$ of $0.60 \mathrm{~V}$ (Table 4 ) by lowering the donor and acceptor thickness to $25 \mathrm{~nm}$. The better performance of thin active layer device was attributed to the efficient separation of excitons and facile transport of free charges in thin layer.

In another study, Archambeau et al. ${ }^{130}$ used a benzoperylene LC $\mathbf{6 b}$ as an electron donor in conjunction with another perylene-based acceptor $\mathbf{2 f}$ (Figure 2). Compound $\mathbf{6 b}$ is actually a mixture of four regioisomers, which exhibit a columnar mesophase at ambient temperature and clears at $180^{\circ} \mathrm{C}$. The device exhibits an $\mathrm{FF}$ value of $48 \%$ with low $V_{\mathrm{OC}}$ of $0.4 \mathrm{~V}$.

\section{DECACYCLENE DLCS IN PVS}

1,7,13-Trialkanoyloxydecacyclene DLCs exhibit very interesting physicochemical properties and can be prepared easily by direct Friedel-Crafts acylation of parent hyderocarbon. ${ }^{131}$ Owing to the presence of keto groups, they act as electron-deficient molecules. Hirota et al. ${ }^{132}$ utilized discotic liquid crystalline 1,7,13-heptanoyldecacyclene $\left(\mathrm{C}_{7} \mathrm{DC}\right) 7$ (Figure 13 ) as an electronaccepting layer in a [2-methoxy-5-(2'-ethylhexyloxy)-1,4-phenylenevinylene] (MEH-PVV)-based solar cell. The PV device with ITOI PEDOT:PSSIMEH-PVVIC 7 DCILiF/Al structure was prepared by spincoating PEDOT:PSS and MEH-PVV/C 7 DC on ITO/glass substrate followed by vacuum deposition of $\mathrm{LiF} / \mathrm{Al}$. Crystal-like $\mathrm{C}_{7} \mathrm{DC}$ domains buried in MEH-PVV were observed in AFM images of active layer. Poor miscibility of $\mathrm{C}_{7} \mathrm{DC}$ and $\mathrm{MEH}-\mathrm{PVV}$ resulted in distinct phase separation between MEH-PVV and $\mathrm{C}_{7} \mathrm{DC}$. The PV cell showed $J_{\mathrm{SC}}$ of $3.6 \mu \mathrm{A} . \mathrm{cm}^{2}, V_{\mathrm{OC}}$ of $1.3 \mathrm{~V}$ and $\mathrm{FF}$ was $32 \%$ with PCE of $0.14 \%$, which increased to $0.30 \%$ upon annealing the device at $100{ }^{\circ} \mathrm{C}$.

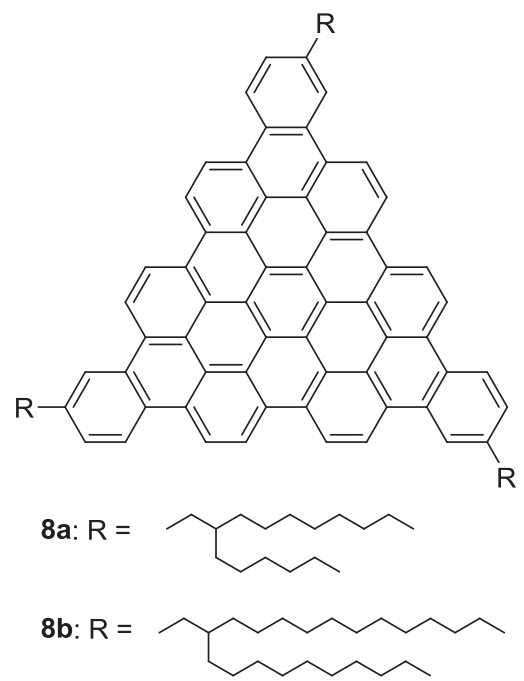

Figure 14 Chemical structure of benzo[o]ditriphenyleno[2,1,12,11-efghi: $11^{\prime}, 12^{\prime}, 1^{\prime}, 2^{\prime}$ - uvabc]ovalene DLCs. 


\section{BENZO[O]DITRIPHENYLENO[2,1,12,11-EFGHI:11',12', $1^{\prime}, 2^{\prime}$ -} UVABC]OVALENE DLCS IN PVS

Müllen and co-workers explored the 'bottom-up' approach to build DLCs derived from large polycyclic aromatic hydrocarbon cores, defined as 'nano-graphene' structures formed by $\pi-\pi$ stacking. With appropriate flexible alkyl chains, these larger aromatic cores lead to DLCs with enhanced columnar stability and supramolecular order with improved charge-carrier transport owing to the more extended p-orbital overlap. ${ }^{133}$ DLCs with three swallow-tailed alkyl substituted (benzo[o]bistriphenyleno[ 2,1,12,11-efghi:2',1',12', $11^{\prime}$-uvabc] ovalene, 8 (Figure 14), were prepared and utilized to fabricate solar cells. Crystalline PDI 2a (Figure 2) was used as an electron acceptor. Scanning electron microscopic investigations revealed homogeneous bicontinuous phase across the thickness with PDI crystals evenly dispersed in the liquid crystalline matrix. This morphology could be favorable for hole and electron migration in donor and acceptor domains. PV devices with ITO/DLC-PDI/Ag structure were fabricated by spin-coating from a chloroform solution of a mixture of donor and acceptor materials. The highest device efficiency was observed for blends with donor and acceptor ratio of 4:6. EQE up to $19 \%$ was achieved at $490 \mathrm{~nm}$ for these graphene discotics.

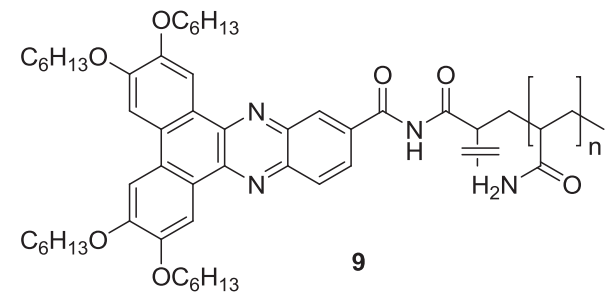

Figure 15 Chemical structure of polymer DLC-PAM.

\section{DIBENZO[A,C]PHENAZINE DLCS IN PVS}

Lee et al. ${ }^{134}$ attached a 2,3,6,7-tetra-6-hexyloxydibenzo[a,c] phenazine-11-carboxylic acid discotic monomer to polyacrylamide. The resultant polymer (DLC-PAM) 9 (Figure 15) exhibits a hexagonal columnar mesophase. It was used to prepare a conventional P3HT/PCBM cell with an active layer of DLC-PAM. The optimized thickness of the PAM-DLC layer was $90 \mathrm{~nm}$ to enhance the charge transport. The $J_{\mathrm{SC}}$ and $V_{\mathrm{OC}}$ values of $5.18 \mathrm{~mA} \mathrm{~cm}^{-2}$, and $0.60 \mathrm{~V}$, respectively, with $51 \% \mathrm{FF}$ and $1.60 \%$ PCE were achieved in this device.

\section{CALAMITIC LCS IN PVS}

Calamitic or rod-like LCs have primarily been explored in display devices and conducting impurities are considered as 'black sheep' in these materials. However, as the dark conductivity and photoconductivities of nematic, smectic and cholesteric materials were measured in 1969, ${ }^{135}$ calamitic LCs also became interesting materials for semiconducting applications. ${ }^{135}$ Kamei et al. ${ }^{136}$ studied the PV effect in the nematic LC (NLC) in 1972 and observed the maximum $V_{\mathrm{OC}}$ of $0.5 \mathrm{~V}$. Kelly and co-workers, in a series of papers, ${ }^{137-140}$ reported the preparation of real PV devices from various calamitic LCs. PV parameters of some best-performing calamitic LC-based solar cells are presented in Table 5. Nematic gel template is formed from a mixture of polymerizable mesogen $10 \mathbf{a}$ and non-polymerizable mesogen 10b (Figure 16), which contains phase-separated droplets of LC in crosslinked polymer. Compound 10a with terminal double bonds is a reactive mesogen that forms a nematic glass at room temperature on cooling. Compound $10 \mathrm{~b}$ exhibits a monotropic nematic phase stable down to room temperature. These materials have an ionization potential of $5.31 \mathrm{eV}$, so that they are suitable for use as an electron-donating species in the gel. Compound 11a is an electron-withdrawing perylene derivative having fluorene groups. In the thin film of compound 11a, rapid quenching introduces a glassy

Table 5 Photovoltaic parameters of some best-performing calamitic LC-based solar cells

\begin{tabular}{|c|c|c|c|c|c|c|c|c|}
\hline Donor & Acceptor & $\mathrm{V}_{O C}(\mathrm{~V})$ & $\mathrm{J}_{S C}\left(m A \mathrm{~cm}^{-2}\right)$ & $F F(\%)$ & PCE (\%) & Illumination source $\left(m W \mathrm{~cm}^{-2}\right)$ & Phase & Reference \\
\hline 10a:10b & $11 a$ & 1.37 & - & 25 & 0.6 & 45 & $\mathrm{~N}$ & 137 \\
\hline $10 \mathrm{c}$ & $11 a$ & 1.2 & - & 26 & 0.9 & 24 & $\mathrm{~N}$ & 138 \\
\hline $10 \mathrm{~d}$ & $11 a$ & 1.31 & - & - & 0.8 & 0.28 & $\mathrm{~N}$ & 139 \\
\hline $10 \mathrm{~d}$ & $11 a$ & 1.2 & 0.50 & 36 & 0.93 & 24 & $\mathrm{Cr}$ & 140 \\
\hline $10 \mathrm{e}$ & PCBM & 0.67 & 9.55 & 53 & 3.4 & 100 & $\mathrm{Cr}$ & 142 \\
\hline 12 & PCBM & 0.59 & 10.7 & 50 & 3.2 & 100 & $\mathrm{Cr}$ & 143 \\
\hline 13 & PCBM & 0.41 & 1.23 & 24 & 0.12 & 100 & $\mathrm{Cr}$ & 144 \\
\hline 14 & $\mathrm{ZnO}$ & 0.83 & 2.10 & 35 & 0.61 & 100 & $\mathrm{Cr}$ & 145 \\
\hline 15 & $\mathrm{ZnO}$ & 0.81 & 4.71 & 52 & 1.98 & 100 & $\mathrm{Cr}$ & 146 \\
\hline 17 & PCBM & 0.57 & 7.84 & 57 & 2.57 & 100 & $\mathrm{Cr}$ & 147 \\
\hline $18 / \mathrm{ZnO}$ & - & 0.64 & 3.77 & 51 & 1.23 & 100 & $\mathrm{Cr}$ & 148 \\
\hline $19 / \mathrm{ZnO}$ & - & 0.63 & 2.98 & 47.5 & 0.89 & 100 & $\mathrm{Cr}$ & 149 \\
\hline $12 / \mathrm{CdS}$ & - & 0.60 & 4.32 & 46.9 & 1.23 & - & $\mathrm{Cr}$ & 150 \\
\hline 20 & PCBM & 0.54 & 4.42 & 23.6 & 0.56 & 100 & $\mathrm{Cr}$ & 126 \\
\hline 21/22/PBDTTT-C-T & PCBM & 0.77 & 16.4 & 58.7 & 7.49 & - & $\mathrm{Cr}$ & 152 \\
\hline 23 & PCBM & 0.72 & 16.03 & 64.9 & 7.6 & 100 & $\mathrm{Cr}$ & 152 \\
\hline $25 a$ & PCBM & 0.93 & 8.27 & 55 & 4.3 & 100 & $\mathrm{Cr}$ & 153 \\
\hline 26 & PCBM & 0.90 & 13.90 & 77 & 9.3 & 100 & $\mathrm{Cr}$ & 154 \\
\hline $27 a$ & PCBM & 0.56 & 11.2 & 47 & 2.9 & 100 & $\mathrm{Cr}$ & 155 \\
\hline $27 b$ & PCBM & 0.2 & 3.68 & 37 & 0.27 & 100 & $\mathrm{Cr}$ & 156 \\
\hline $28 a$ & PCBM & 0.60 & 8.86 & 61.1 & 3.27 & 100 & $\mathrm{Cr}$ & 157 \\
\hline $28 b$ & PCBM & 0.60 & 9.64 & 63.9 & 3.72 & 100 & $\mathrm{Cr}$ & 157 \\
\hline $28 c$ & PCBM & 0.63 & 10.08 & 54.9 & 3.5 & 100 & $\mathrm{Cr}$ & 158 \\
\hline
\end{tabular}

Abbreviations: Cr, crystalline; FF, fill factor; JSC, short circuit current; LC, liquid crystal; PBDTTT-C-T, poly(4,8-bis(5-(2-ethylhexyl)thiophene-2-yl)-benzo[I,2-b:4,5-b']dithiophene-alt-alkylcarbonylthieno[3,4-b]thiophene); PCBM, [6,6]-phenyl-C61-butyric acid methyl ester; PCE, power-conversion efficiency; Voc, open circuit voltage. 


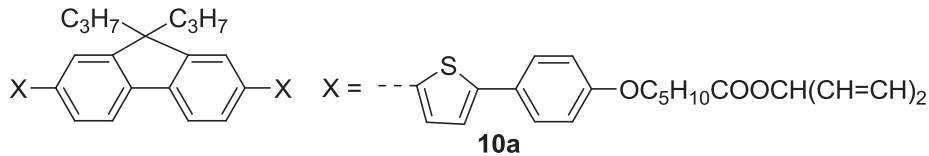<smiles>[X]c1ccc2c(c1)C([IH+])(CC)c1cc([X])ccc1-2</smiles><smiles></smiles><smiles>[X]C(=O)OCCOc1ccc(-c2ccc(-c3ccc4c(c3)C(C)(C)c3cc(-c5ccc(-c6ccc(-c7ccc(C=C)s7)s6)cc5)ccc3-4)s2)cc1</smiles>

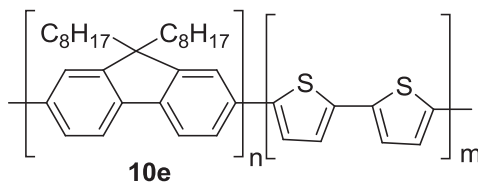<smiles>[X]N1C(=O)c2ccc3c4ccc5c6c(ccc(c7ccc(c2c37)C1=O)c64)C(=O)N([X])C5=O</smiles><smiles>COc1ccc(-c2ccc3c(c2)C([13CH2])([14CH2])c2cc(-c4ccc(F)cc4)ccc2-3)cc1</smiles>

11c

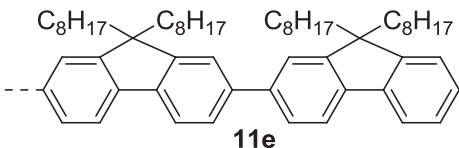

$\mathrm{X}=$<smiles>CCC1(CC)c2ccc(C)cc2C1(CC)CC</smiles>

$11 a$

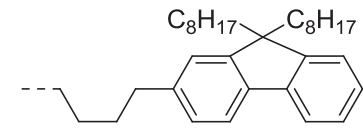

11b

Figure 16 Chemical structure of fluorene-thiophene donors and perylene-based acceptors.

state. It has a high EA of $3.94 \mathrm{eV}$ and therefore can be used as an electron-accepting material. From ionization potential and EA data, it is clear that charge separation at the interface is thermodynamically favorable in these donor-acceptor couples. A mixture of 10a and 10b in the ratio 1:2 forms a gel, which displays a nematic phase that remained stable at room temperature for a long period. A PV device with cell structure of ITO/PEDOT:PSS/LC gel/LiF/Al was fabricated that exhibits EQE of $5.3 \%$ and PCE of $0.6 \%$.

They extended their work by taking four different perylene-based electron acceptors having similar EAs but different thermotropic phases and two fluorene-thiophene LCs 10c and 10d (Figure 16). ${ }^{138}$ Best results are obtained when the nematic donor is mixed with an amorphous acceptor to give a super-cooled nematic glass at room temperature. AFM reveals phase separation on a nanometer scale with a broad distribution of domain sizes. PV device with a blend of donor 10c and acceptor 11a showed the best PCE of $0.9 \%{ }^{138,139}$
In another study, they prepared organic bilayer PV cell with an insoluble electron-donating layer formed by crosslinking a nematic reactive mesogen. ${ }^{140}$ In a nematic reactive mesogens, a planar alignment with the long molecular axis aligned on the substrate plane can be achieved upon crosslinking. ${ }^{141}$ The performance of the device is limited by the charge-carrier mobility of the acceptor material, which can be enhanced by the electron-donating layer formation by mesogens.

A number of PDI-based crystalline and liquid crystalline acceptors having fluorine or carbazole moieties were prepared (Figure 16). Bilayer solar cells prepared from crosslinkable donor 10d and acceptors 11a, 11c, 11e and 11f exhibit PCEs in between $0.42 \%$ and $0.93 \%$. It was observed that crosslinking of the monomer 10d by irradiation with UV light to obtain an insoluble layer does not degrade device performance

Kekuda et al. ${ }^{142}$ demonstrated the effect of donor-acceptor interface on the performance of $\mathrm{BHJ}$ device. They reported performance of a 
<smiles>CCCCCCc1cc(C)sc1-c1cc2sc(-c3sc(C)cc3CC)cc2s1</smiles>

12 (РBTTT)<smiles>CC(C)(C)/N=C/c1ccc(/N=C/c2ccc(N(c3ccccc3)c3ccc(C(C)(C)C)cc3)cc2)cc1</smiles><smiles>CCCCCCOc1ccc(-c2ccc(-c3ccc(OC(=O)CC4CCSS4)cc3)cc2)cc1</smiles>

18 (HTph-S)<smiles>[R]c1ccc(-c2ccc(-c3ccc(-c4ccc(-c5ccc([R])cc5)cc4)c4nsnc34)cc2)cc1</smiles>

19 (DPBT-S): $\mathrm{R}=\mathrm{OC}_{12} \mathrm{H}_{25}, \mathrm{R}^{\prime}=\mathrm{OC}_{6} \mathrm{H}_{12} \mathrm{SH}$<smiles>CC(C)(C)c1cc(CCCCCCOc2ccc(-c3ccc(C#N)cc3)cc2)c(C(C)(C)C)s1</smiles>

14 (P3HbpT)<smiles>CC(C)(C)c1ccc(-c2cc(CCCCCCOc3ccc(-c4ccc(C#N)cc4)cc3)c(C(F)(F)F)s2)c2nsnc12</smiles>

15 (P3HbpT-BTD)

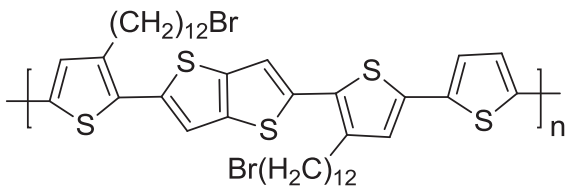

16 (PBbTTT-T)

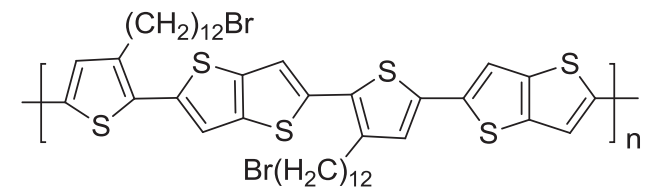

17 (PBbTTT-TT)

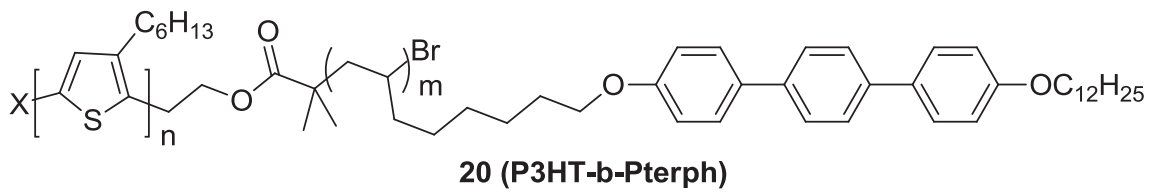<smiles>C[Z10](=O)(=O)O[S+](C)(C)CCOc1ccc(-c2ccc(C#N)cc2)cc1</smiles><smiles>CC(C)(C)c1cc2c(s1)C(C)(C)C2CCCCC[N+](C)(C)Br</smiles><smiles>[R]C1([R])c2cc(-c3ccc4c(c3)C([R])([R])c3cc(C(C)(C)C)ccc3-4)ccc2-c2ccc(C(C)(C)C)cc21</smiles><smiles>[R]=CCCCCOc1ccc(-c2ccc(C#N)cc2)cc1</smiles>

23 (PF6Ncbp) $\mathrm{R}^{\prime}=$

$24\left(\mathrm{PF}\right.$ Imicbp) $\mathrm{R}^{\prime}=$

Figure 17 Chemical structure of calamitic LCs used in photovoltaics. 
a
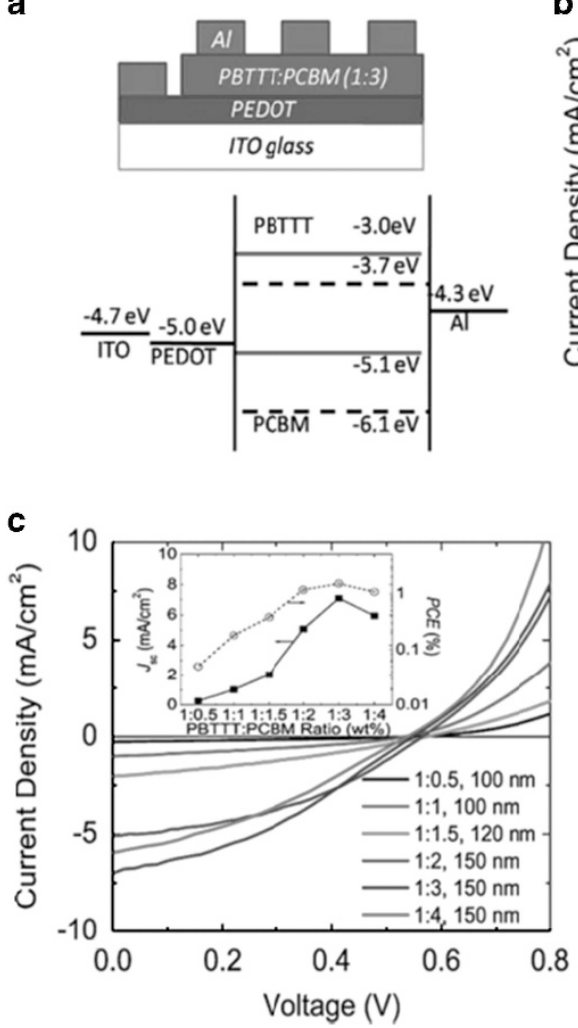

b

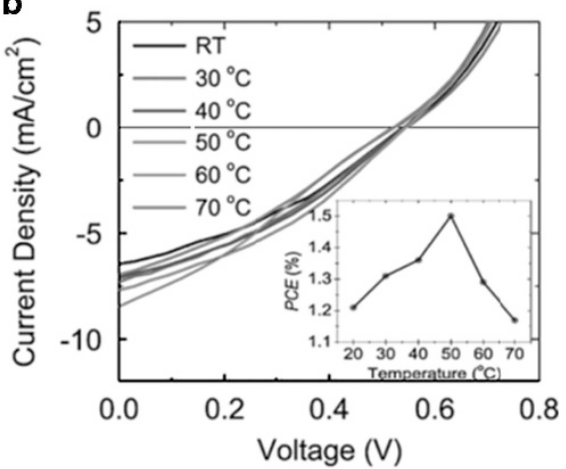

d

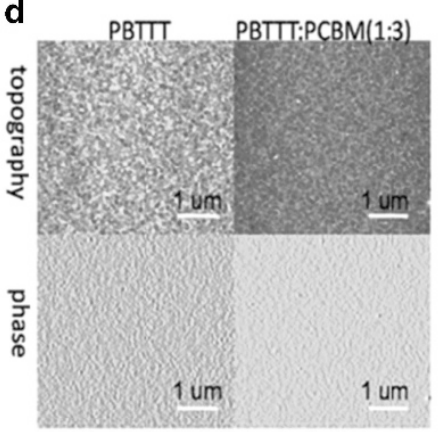

Figure 18 (a) A schematic representation of the device configuration (up) of a bulk heterojunction solar cell based on PBTTT:PCBM (1:3 wt \%) and the associated energy level diagram (bottom). (b) $J-V$ characteristics of the ITO/PEDOT/PBTTT:PCBM (1:3 wt \%)/Al solar cells at different substrate temperatures. The inset shows the PCE values as a function of the substrate temperature. (c) $J-V$ characteristics of the ITO/PEDOT/PBTTT:PCBM/AI solar cells with different weight ratios of PBTTT to PCBM at the substrate temperature of $50^{\circ} \mathrm{C}$. The inset shows the $J_{S C}$ and PCE values of the devices as a function of the PBTTT:PCBM weight ratio. (d) Topographical (up) and phase (bottom) AFM images of pure PBTTT films and PBTTT:PCBM (1:3 wt \%) films on the ITO/PEDOT substrate. Reproduced with permission from Sun et al. ${ }^{143}$. Copyright 2009, American Chemical Society. A full color version of this figure is available at the Polymer Journal online.

device based on a commercially available liquid crystalline polymer poly $\left(9,9^{\prime}\right.$-dioctylfluorene-cobithiophene) (F8T2) 10e (Figure 16). The conventional device configuration ITO/PEDOT:PSS/F8T2/C70/Al showed a PCE of $3.4 \%$ after annealing the polymer LC films at $200^{\circ} \mathrm{C}$.

Sun et al. ${ }^{143}$ used liquid crystalline poly(2,5-bis(3-alkylthiophen-2-yl) thieno[3,2-b]thiophene) (PBTTT) 12 (Figure 17) to fabricate a bilayer device (Figure 18) composed of the active layer of PBTTT: PCBM (1:2)/MDMO-PPV:PC ${ }_{70} \mathrm{BM}$ (1:4) and compared the results with single layer (PBTTT:PCBM or MDMO-PPV:PC ${ }_{70} \mathrm{BM}$ ) devices. The exact nature of the mesophase has not been revealed in this paper. The bilayer device exhibited a $V_{\mathrm{OC}}$ of $0.59 \mathrm{~V}, J_{\mathrm{SC}}$ values of $10.1-10.7 \mathrm{~mA} \mathrm{~cm}^{-2}$, FF of $50 \%$ and PCE values of $3.0-3.2 \%$, which were significantly (by a factor of 2) higher than single-layer devices.

Hindson et al. ${ }^{144}$ used liquid crystalline triphenylamine-based poly (azomethine)s as hole-transport materials in typical ITO/PEDOT:PSS/ TPA/PCBM/Al devices. 4,4'-Diaminotriphenylamine (TPA) was polymerized with either terephthalaldehyde (TPA-14Ta), 2,5-thiophenedicarboxaldehyde (TPA-25Th) or 1,3-isophthalaldehyde (TPA-13Iso) to yield various polymers. Structure of one of these polymers $\mathbf{1 3}$ is shown in Figure 17. The HOMO and LUMO energy levels of these polymers were in the range of $5.0-5.3$ and $2.4-3.3 \mathrm{eV}$. PV devices show the best PCE value of $0.12 \%$, with $V_{\mathrm{OC}}$ of $0.41 \mathrm{~V}, J_{\mathrm{SC}}$ of $1.23 \mathrm{~mA} \mathrm{~cm}^{-2}$ and FF of $24 \%$ after annealing the composite at $200{ }^{\circ} \mathrm{C}$.

Chen and co-workers used various calamitic LCs to prepare PV solar cells. ${ }^{126,145-152}$ An electron-donor material poly[3-(6-(4- cynaobiphenyloxy)-hexyl) thiophene](P3HbpT) 14 (Figure 17) having well-known LC cyanobiphenyl was prepared by attaching 4'-hydroxycyanobipheny to 3-(6-bromohexyl)thiophene followed by nuclear bromination of thiophene ring and its polymerization. It shows liquid crystalline property with order morphology and microstructure. ${ }^{145}$ $\mathrm{ZnO}$ nanoparticles were dispersed in it and a hybrid $\mathrm{BHJ}$ device was prepared with the active layer of $\mathrm{P} 3 \mathrm{HbpT} / \mathrm{ZnO}$. PCE of $0.61 \%$ was achieved.

The work was extended by the synthesis of a new donor-acceptortype liquid crystalline copolymer, poly[3-(6-(cyanobiphenyoxy)thiophene)-alt-4,7-(benzothiadiazole)] (P3HbpT-BTD) 15 (Figure 17). ${ }^{146}$ This liquid crystalline copolymer was reported to have good optical absorption abilities and spontaneous organizational properties on thermal annealing. The devices based on P3HbpT-BTD and $\mathrm{ZnO}$ nanoparticles show the PCE of $1.98 \%$ after annealing the composites at $180{ }^{\circ} \mathrm{C}$. The reason to the better performance could be ascribed owing to the self-assembly of mesogens, which induce the $\mathrm{ZnO}$ nanoparticles to form a well-dispersed and highly orientated region that resulted in better hole and electron transport.

In continuation to their work on thiophene-based LC donors, they prepared novel copolymer systems PBbTTT-T 16 and PBbTTT-TT 17 with high crystallinity and photocrosslinkable building blocks for $\mathrm{p}-\mathrm{p}$ intermolecular interactions by copolymerization of 2,5-bis (3- bromododecylthiophen-2-yl)thieno[3,2-b]thiophene (BbTTT) monomer with thiophene and thieno[3,2-b]thiophene. ${ }^{147}$ The solar cell 
device that consist of PBbTTT-TT:PC ${ }_{71} \mathrm{BM}$ in 1:3.5 ratio shows the PCE of $2.57 \%$. This could be ascribed owing to the high order and crystallinity of the LC material and also to the enhanced stability owing to the photocrosslinkable bromine-functionalized unit.

In another study, they demonstrated the OPV device based on $\mathrm{P} 3 \mathrm{HT} / \mathrm{ZnO}$ hybrid system by employment of liquid crystalline ligands 4-(5-(1,2-dithiolan-3-yl)pentanoate)-4'-(hexyloxy)-terphenyl 18 (HTph-S) at interface to induce the compatibility, charge separation and transfer efficiency enhancement and optimized micro-morphology. ${ }^{148}$ The device configuration was ITO/PEDOT: PSS/HTph-S@ZnO/P3HT. The effect of modification of active layer and annealing of layer was demonstrated. The unmodified $\mathrm{ZnO} / \mathrm{P} 3 \mathrm{HT}$ showed a $J_{\mathrm{SC}}$ of $2.01 \mathrm{mAcm}^{-2}, V_{\mathrm{OC}}$ of $0.57 \mathrm{~V}$ and an $\mathrm{FF}$ of $41 \%$ with low $0.47 \%$ PCE, but the device containing active layer of HTph-S@ZnO/P3HT gives the $J_{\mathrm{SC}}$ of $3.77 \mathrm{~mA} \mathrm{~cm}^{-2}, V_{\mathrm{OC}}$ of $0.64 \mathrm{~V}$ and an FF of 51\%, resulting in PCE of approximately $1.23 \%$. Similarly, $\mathrm{ZnO}$ nanoparticles passivated by a layer of 4,7-diphenyl-2,1,3-benzothiadiazole-based LC molecules 19 were prepared ${ }^{149}$ and used in $\mathrm{P} 3 \mathrm{HT} / \mathrm{ZnO}$ hybrid PV devices. The LC-ZnO layer acts as an electron-acceptor layer in hybrid solar cells and also enhances the order and crystallinity of P3HT chains. Moreover, the order of the P3HT/LC-ZnO blend morphology is significantly enhanced after thermal annealing at $160^{\circ} \mathrm{C}$, which improves PCE by 1.8 -fold compared with the device based on $\mathrm{P} 3 \mathrm{HT} / \mathrm{ZnO}$. PCE up to $0.89 \%$ was realized in these devices.

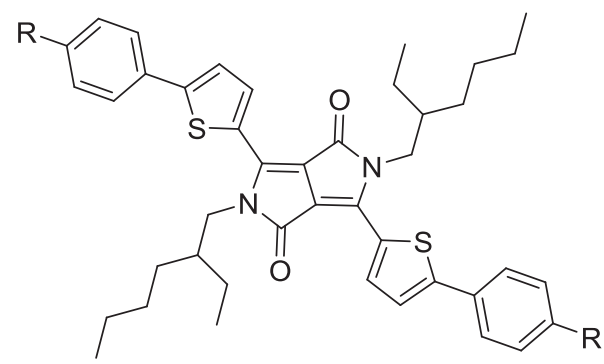

$$
\begin{aligned}
& \text { 25a (DPP-TP6): } R=C_{6} H_{13} \\
& \text { 25b (DPP-TP12): } R=C_{12} H_{25}
\end{aligned}
$$

Figure 19 Chemical structure of DPP-TP6 and DPP-TP12.

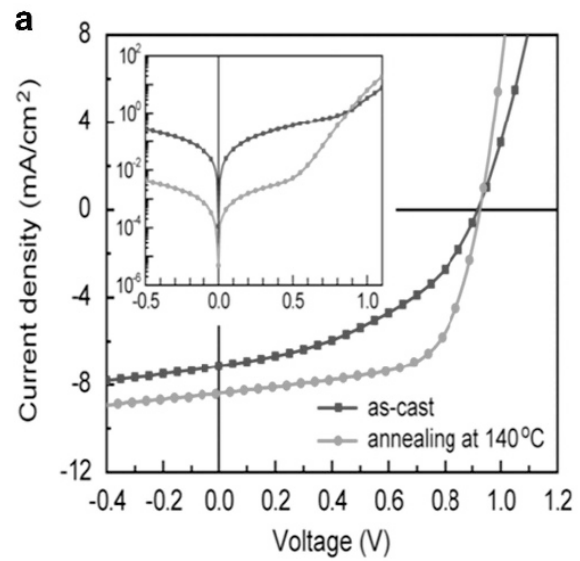

Liquid crystalline calamitic molecules DPBT-S 19 and PBTTT 12 were also used to prepare CdS nanocrystals for PV solar cells. ${ }^{150}$ A solution of LC and CdS precursor in chlorobenzene was spin-casted and annealed at different temperatures to decompose the CdS precursor to generate CdS nanoparticles embedded in LC matrix. The efficient charge transfer in the LC/CdS nanocomposites makes these materials suitable to be used as an active layer in PV solar cells. PV devices with inverted architecture (glass/ITO/ZnO/CdS interface layer/active layer/MoOx/Ag) were fabricated and the best PCE of $1.2 \%$ was realized.

They also synthesized P3HT-based liquid crystalline rod-coil block copolymers, that is, rod-like LC block poly(4-(dodecyloxy)-4" -(oct-7en-1-yloxy)-1,10:4' $1^{\prime \prime \prime}$-terphenyl), 20 (P3HT-b-Pterph). ${ }^{126}$ The configured device architecture ITO/PEDOT:PSS/P3HT-b-Pterp exhibit PCE of $0.34-0.44 \%$, which improve to $0.56 \%$ for P3HT-b-Pterph after annealing at $200{ }^{\circ} \mathrm{C}$. Corresponding PV devices with DLC block poly (2,3,6,7,10-pentakis(hexyloxy)-11-(oct-7-en-1-yloxy)triphenylene), (P3HT-b-PTP) show better performance than those based on P3HT: PCBM:P3HT-b-Pterph. It has been attributed that 'the DLC block in P3HT-b-PTP is more favorable in interpenetrating networks and also more compatible with the fullerene acceptors. This is because liquid crystalline state annealing promotes the orientation of mesogens to induce polythiophene backbone packing with higher ordering, which further enhances the charge-carrier mobility and improves the $J_{S C}{ }^{\prime}{ }^{126}$

Chen et al. ${ }^{151}$ also demonstrated that ionic LCs (ILCs) can be selfassembled with conjugated polymer as an interlayer to achieve high PCE via rapid LC-induced dipole orientation in polymer-based solar cell. The ILCs 3-((2'-(4"-cyanobiphenyl-4-yloxy)ethyl)dimethylammonio)propanesulfonate 21 (CbpNSO) with zwitterionic charges were blended with cationic conjugated polyelectrolyte (CPE) poly [3-(6-trimethylammoniumhexyl)-thiophene] 22 (PTNBr) to afford a novel CPE-ILC complex. It has been pointed out that 'the spontaneous orientation of LC favors more ordered structural arrangement in CPE-ILC complexes. LC-assisted electrostatic assembly can improve the orientation of dipole moments at cathode interface, which significantly reduces the work function of ITO. Compared with pure PTNBr CPE as electron transport layer (ETL), CPE - ILC complex increases the efficiency of P3HT:PCBM cell by $37 \%$. Solar cell prepared with donor poly(4,8-bis(5-(2ethylhexyl)thiophene-2-yl)-benzo[1,2-b:4,5-b'] dithiophene-alt-alkylcarbonyl-thieno[3,4-b]thiophene) (PBDTTT-C-T) and acceptor

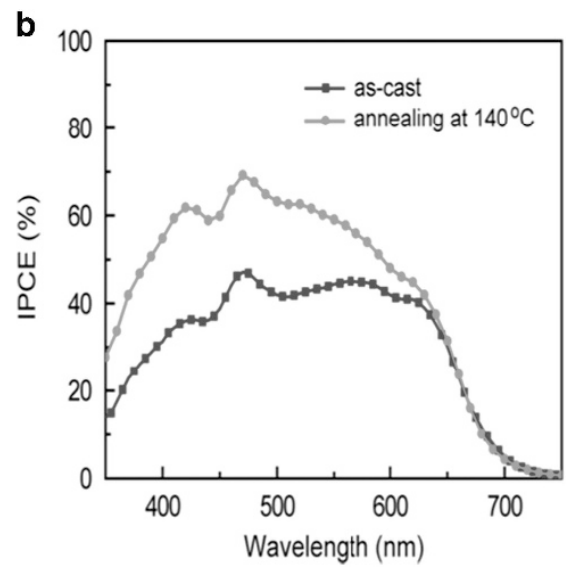

Figure 20 (a) $J-V$ characteristics under 1 sun illumination (inset: dark $J-V$ curves) and (b) IPCE spectra for BHJ solar cells based on DPP-TP6:PC 71 BM $\left(1: 1\right.$, w/w) blend as-cast and after thermal annealing at $140{ }^{\circ} \mathrm{C}$ for $10 \mathrm{~min}$. Reproduced with permission from Shin et al. ${ }^{153}$ Copyright 2013 , American Chemical Society. A full color version of this figure is available at the Polymer Journal online. 
PC70BM in the presence of PTNBr-CbpNSO exhibits PCE of 7.49\%'. ${ }^{151}$

Recently, they also synthesized LC-conjugated polyelectrolytes poly [9,9-bis[6-(4-cyanobiphenyloxy)-hexyl] - fluorene - alt-9,9-bis (6( $N, N$-diethylamino)-hexyl)-fluorene] 23 (PF6Ncbp) and poly[9,9-bis [6-(4-cyanobiphenyloxy)-hexyl] - fluorene - alt-9,9-bis(6-( $N$-methylimi dazole)-hexyl]-fluorene] 24 (PF6lmicbp) (Figure 17) by covalently linking cyanobiphenyl mesogen with conjugated polyelectrolytes. ${ }^{152}$ It has been pointed out that 'after deposition of a layer of LC-conjugated polyelectrolytes on $\mathrm{ZnO}$ interlayer, the spontaneous orientation of LC groups can induce a rearrangement of dipole moments at the interface, which leads to the better energy-level alignment'. The orientation of dipoles can be successfully improved without interference and can also induce the upper active layer to form better crystallization morphology, which facilitate the electron extraction and transportation. Significant PCE of $7.6 \%$ can be achieved by deposition of LC polyelectrolytes PF6Ncbp and PF6lmicbp on $\mathrm{ZnO}$ as ETL.

Shin et al. ${ }^{153}$ observed PV properties of diketopyrrolopyrrole (DPP)based mesomorphic small-molecules, 3,6-bis\{5-(4-alkylphenyl)thiophen-2-yl\}-2,5-di(2-ethylhexyl)-pyrrolo[3,4-c]-pyrrole-1,4-diones 25 (DPP-TP6 and DPP-TP12, Figure 19). DPP-TP6 with hexyl terminal chains exhibits LC properties while the higher homolog DPP-TP12 was found to be non-mesomorphic. BHJ PV solar cells were fabricated using DPP-TP6 and DPP-TP12 as an electron donor and $\mathrm{PC}_{71} \mathrm{BM}$ as an acceptor with a typical device structure; ITO/PEDOT:PSS/donor: $\mathrm{PC}_{71} \mathrm{BM}$ blend/LiF/Al. Solar cells with DPP-TP6:PC ${ }_{71} \mathrm{BM}$ films show a PCE as high as $4.3 \%$ with a $V_{\mathrm{OC}}$ of $0.93 \mathrm{~V}$ and an FF of $55 \%$, while only $1.2 \%$ PCE could be realized for DPP-TP12 (Figure 20). This clearly demonstrates that molecular organization induces the self-assembly, which is auspicious to fabricating high-performance solution-processable solar cells.

Recently, Sun et al. ${ }^{154}$ synthesized a new molecular donor NLC benzodithiophene terthiophene rhodanine 26 (Figure 21) and fabricated a device (Figure 22), which shows the promising PCE of $9.3 \%$ with FF of $77 \%$, which is rare in OPV devices. They attributed that the donor phase in OPV is well ordered, which favors the exciton diffusion length for efficient charge separation. Interestingly, thick solar cells with active layer of thicknesses up to $400 \mathrm{~nm}$ also exhibits high FF of $\sim 70 \%$ and high PCE of $\sim 8 \%$.

\section{CALAMITIC LCS AS ADDITIVES IN PVS}

Similar to DLCs, the effect of doping calamitic LCs on the PV performance of classical solar cells have been studied. ${ }^{155-158}$ Canli et al. ${ }^{155}$ investigated the effect of a chiral smectic LC namely
(S)-5-octyloxy-2-[\{4-(2-methylbuthoxy)-phenylimino\}-methyl]-phenol 27a (Figure 23) in a P3HT/PCBM BHJ organic solar cell. The charge-carrier mobility of the composites increased on addition of the LC material. The addition of LC in P3HT:PCBM solar cells increases $J_{S C}$ from 4.1 to $11.2 \mathrm{~mA} \mathrm{~cm}^{-2}$ and result in substantial improvement of PCE from $1.1 \%$ to $2.9 \%$. The LC forms a nanomorphology between donor and acceptor phases owing to the higher degree of order of films, which leads to the improved photocurrent, larger IPCE values and higher PCE. They extended their work on another smectic LC, namely, 5-(10-undecenyloxy)-2-[[[4-hexylphenyl]imino]methyl] phenol 27b (Figure 23). ${ }^{156}$ The addition of LC improves the crystallinity of the P3HT layer, the $J_{\mathrm{SC}}$ from 0.53 to $3.68 \mathrm{~mA} \mathrm{~cm}^{-2}$ and PCE from $0.008 \%$ to $0.27 \%$.

Jeoung et al. ${ }^{157}$ incorporated classical NLCs 4-cyano-4'-pentylbiphenyl 28a (5CB) and 4-cyano-4'-octylbiphenyl 28b (8CB) in a typical P3HT:PC ${ }_{61} \mathrm{BM}$ solar cells. They reported that 'the incorporation of NLC additives led to a higher absorbance in blend thin film, a higher crystallinity of $\mathrm{P} 3 \mathrm{HT}$, closer $\mathrm{P} 3 \mathrm{HT}$ chains, larger $\mathrm{PC}_{61} \mathrm{BM}$ domains and enhanced hole/electron mobilities even without postthermal annealing'. The non-annealed cell with $4 \mathrm{wt} \% 8 \mathrm{CB}$ additives showed an increase in all parameters, resulting in PCE of $3.72 \%$ compared with $2.14 \%$ of the reference device without NLC additives. The $J_{S C}$ is strongly dependent on the absorption intensity derived from the crystallinity of $\mathrm{P} 3 \mathrm{HT}$ and the charge-transport properties of networks in PV blend films, hence the blending of the LC in blend enhance the absorption peak improving the spectral overlap with solar emission at $603 \mathrm{~nm}$ for the P3HT and this further leads to closer $\pi-\pi$ stacking of the P3HT and lower to the band energy.

Shi et al. ${ }^{158}$ used 4-octyloxy-4'-cyanobiphenyl 28c (8OCB), another classical NLC to evaluate the performance of P3HT:PCBM solar cell. Pristine P3HT:PCBM device and the devices with the LC weight ratios of 3, 6 and $10 \mathrm{wt} \%$ exhibited a $J_{\mathrm{SC}}$ of $8.11,9.10,10.08$ and $6.36 \mathrm{~mA} \mathrm{~cm}^{-2}$, respectively. The device performance depends on doping percentage of NLC, too much additives led to a lower $J_{\mathrm{SC}}$ because of the decreased crystallinity and the phase separation in large scale, which were unfavorable for charge transport. The performance was better after mixing $6 \% 8 \mathrm{OCB}$ and annealed at $70{ }^{\circ} \mathrm{C}$, which gives the $J_{\mathrm{SC}}$ of $10.08 \mathrm{~mA} \mathrm{~cm}^{-2}$ and high $\mathrm{FF}$ of $54.9 \%$. The annealing temperature of $70{ }^{\circ} \mathrm{C}$ in liquid crystalline transitions facilitated the formation of an optimized phase separation in P3HT:PCBM:8OCB system (Figure 24). PCE up to $3.5 \%$ was realized.

\section{LCS IN DSSCS}

DSSCs are highly promising candidates for the next-generation PVs owing to their low fabrication cost and good PCE. After the pioneering

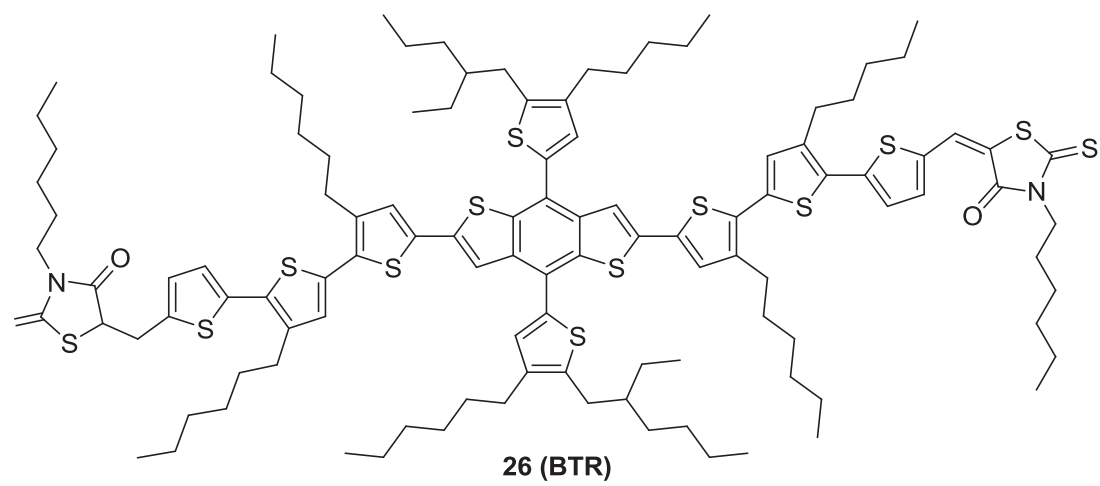

Figure 21 Chemical structure of BTR. 
a

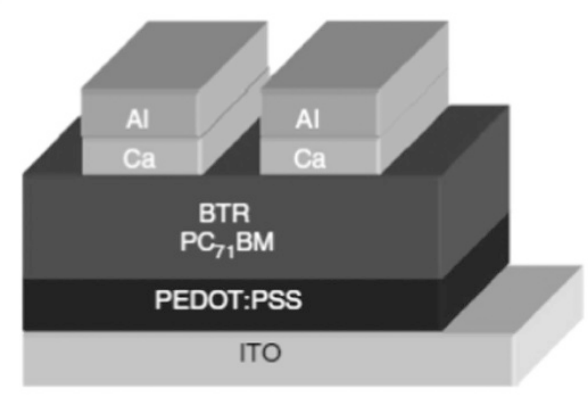

C

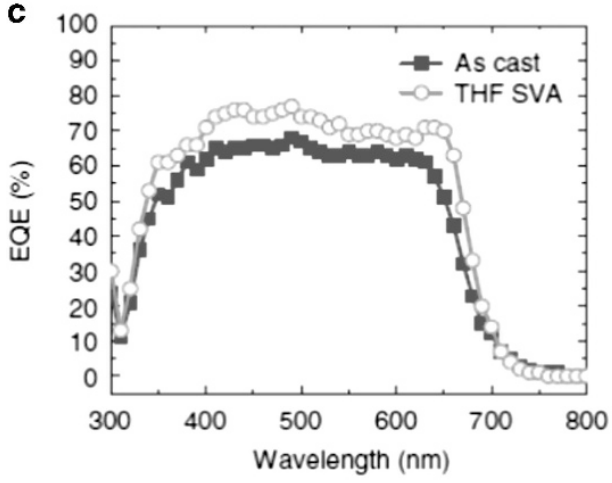

b

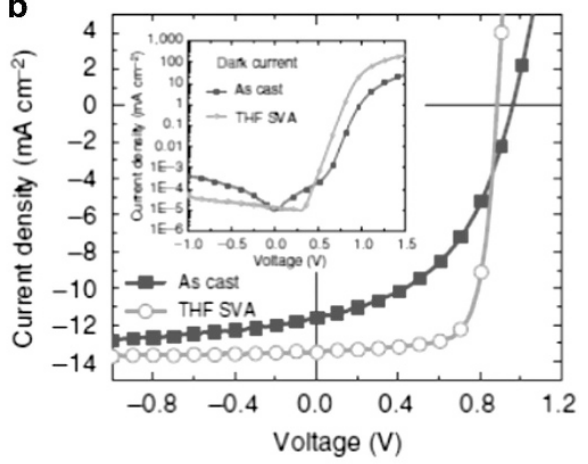

d

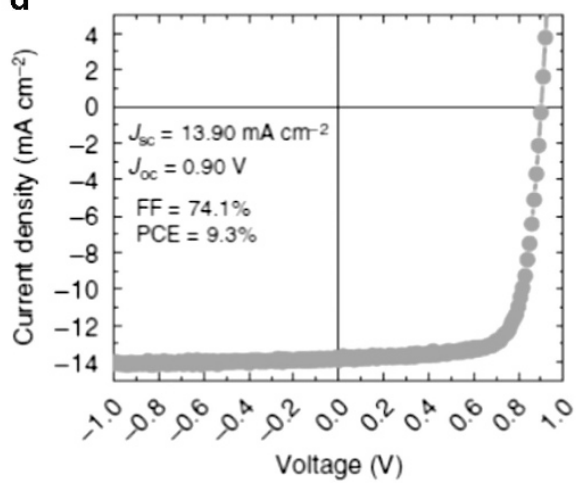

Figure 22 Device architecture and photovoltaic performances. (a) Schematic diagram of a normal cell architecture used in this study. (b) $J-V$ characteristics of $\mathrm{BTR}: \mathrm{PC} \mathrm{7}_{71} \mathrm{BM} \mathrm{BHJ}$ solar cells with or without THF solvent vapor annealing tested in air under $98 \mathrm{~mW} \mathrm{~cm}^{-2} \mathrm{AM} 1.5 \mathrm{G}$ illumination. Inset: dark current plotted in a semi-log scale of the two solar cells. (c) EQE spectra of optimized BTR-based solar cells with or without THF SVA treatment. (d) J-V curve of the most efficient BTR:PC ${ }_{71} \mathrm{BM}$ BHJ solar cell after $15 \mathrm{~s}$ of THF SVA measured by an independent research institute in nitrogen atmosphere under an illumination of $100 \mathrm{~mW} \mathrm{~cm}^{-2}$. Reproduced with permission from Sun et al. ${ }^{154}$ Copyright 2015, Nature Publishing Group. A full color version of this figure is available at the Polymer Journal online.

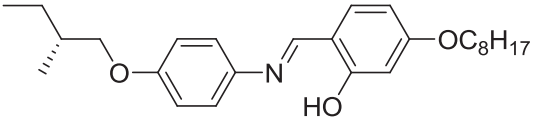

27a

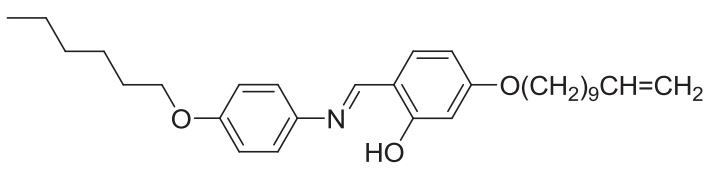

27b

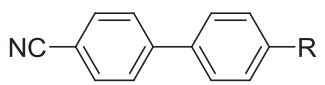

28a: $\mathrm{R}=\mathrm{C}_{5} \mathrm{H}_{11}(5 \mathrm{CB})$

28b: $\mathrm{R}=\mathrm{C}_{8} \mathrm{H}_{17}(8 \mathrm{CB})$

28c: $\mathrm{R}=\mathrm{OC}_{8} \mathrm{H}_{17}(8 \mathrm{OCB})$

Figure 23 Chemical structure of calamitic LCs used as additives in photovoltaics.

work of O'Regan and Grätzel, ${ }^{159}$ huge interest has been developed in these PV devices and PCE values up to $13 \%$ has been achieved. ${ }^{160}$ A schematic structure of a DSSC is shown in Figure 25. DSSC differs from both BHT and bilayer solar cell by its basic construction and operational process. A DSSC basically consists of a sandwich structure of nanocrystalline $\mathrm{TiO}_{2}$ /dye-electrolyte between transparent anode and counter cathode. As shown in Figure 25, the light photons are absorbed by the dye adsorbed over $\mathrm{TiO}_{2}$ nanocrystals that provides larger surface area for absorption. In this process, the dye molecules absorb the photons and excited electrons flow into $\mathrm{TiO}_{2}$ and become oxidized. Electrons travel to anode, external load and finally to the cathode, where it transferred to electrolyte usually containing $\mathrm{I}^{-} / \mathrm{I}_{3}$. The electrolyte works as brokers between cathode and $\mathrm{TiO}_{2}$. The oxidized dye receives electrons from $\mathrm{I}^{-}$ion redox, and the iodide is oxidized into $\mathrm{I}_{3}^{-}$. The process continues and the circuit is completed.

As ionic conductivity is quite important in DSSC, early efforts have been made to use ILCs in these devices. ${ }^{161,162}$ Yamanaka et al. ${ }^{161}$ synthesized a new ILC, 1-dodecyl-3-methylimidazolium iodide $29\left(\mathrm{C}_{12} \mathrm{MImI}\right.$, Figure 26), and used in DSSC cells as a hole transport layer to enhance the $J_{\mathrm{SC}}$ and PCE. The bilayer structure of interdigitated alkyl chains of the imidazolium cations in ILC with the smectic A phase localized the $\mathrm{I}^{-}$and $\mathrm{I}_{3}{ }^{-}$between the smectic A layers. The exchange reaction can be promoted by the presence of localized high concentration of $\mathrm{I}^{-}$and $\mathrm{I}_{3}{ }^{-}$ions. The higher conductivity of the LC-conjugated electrolyte leads to high value of $J_{S C}$ compared with non-liquid crystalline ionic liquid electrolyte. ${ }^{161}$ The higher 

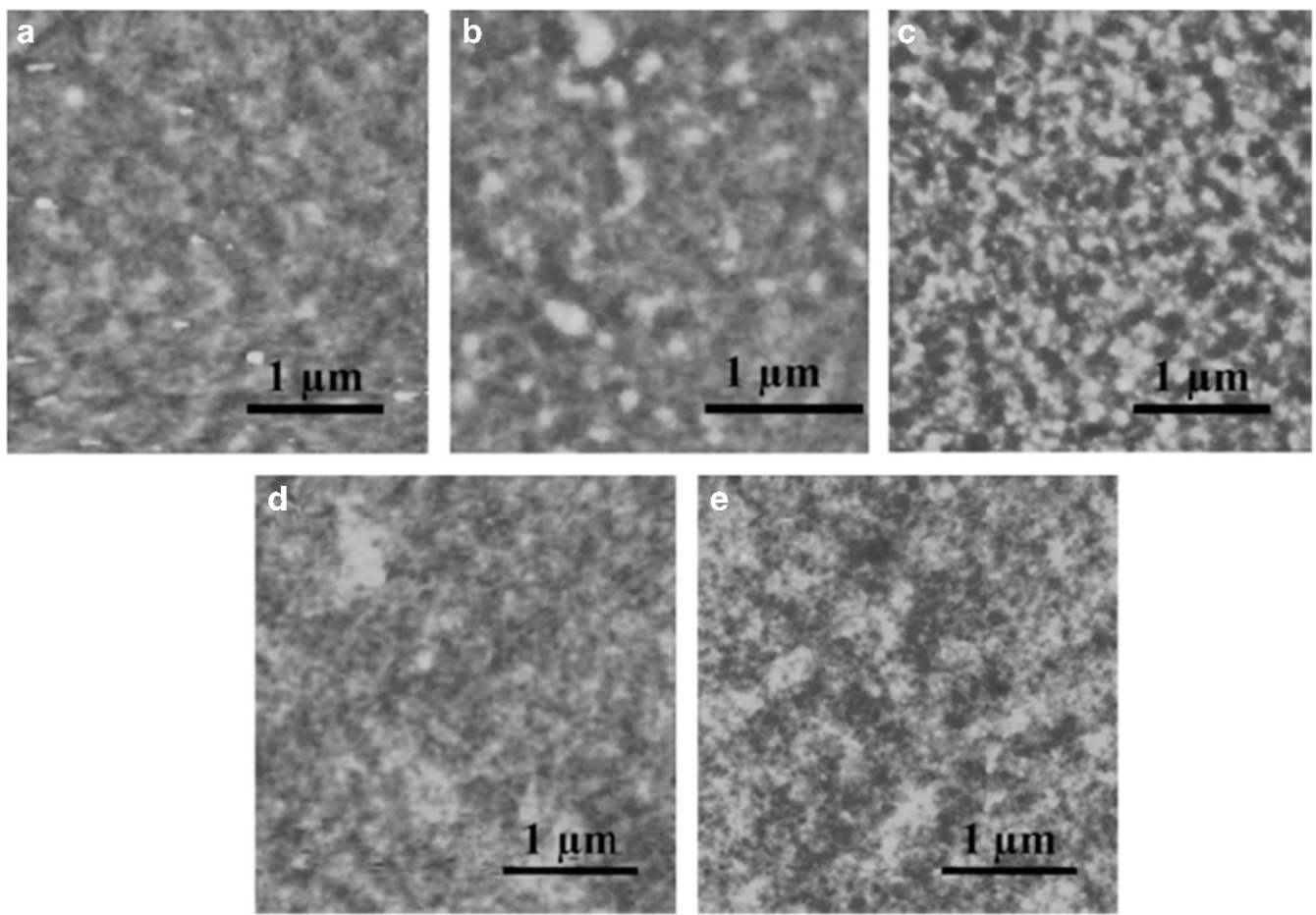

Figure 24 AFM images of P3HT:PCBM:80CB films with $80 \mathrm{CB}$ weight ratio of $3 \mathrm{wt} \%$ (a), $6 \mathrm{wt} \%$ (b) and $10 \mathrm{wt} \%$ (c) after annealing at $70{ }^{\circ} \mathrm{C}$ for $20 \mathrm{~min}$, and the films with $80 \mathrm{CB}$ weight ratio of $6 \mathrm{wt} \%$ without (d) or with annealing (e) at $130^{\circ} \mathrm{C}$ for $10 \mathrm{~min}$, respectively. Reproduced with permission from Shi et al. ${ }^{158}$ Copyright 2014, Springer-Verlag Berlin Heidelberg. A full color version of this figure is available at the Polymer Journal online.

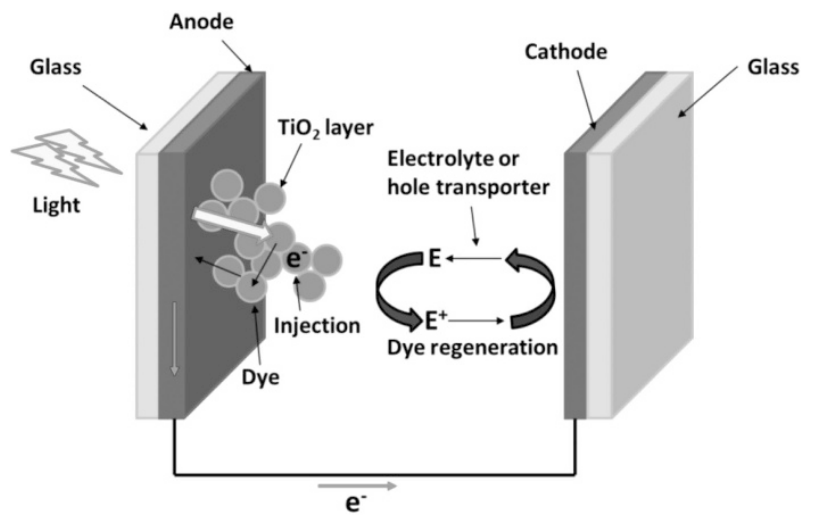

Figure 25 Schematic representation of a typical DSSC. A full color version of this figure is available at the Polymer Journal online.

conductivity of ILC is attributed to the enhancement of the exchange reaction between iodide species, which was supported by the large exchange reaction-based diffusion coefficients. ${ }^{162}$ They utilized these ILCs to prepare a quasi-solid-state DSSC by incarcerating a low molecular weight gelator. Furthermore, improvement to the PCE could be achieved on addition of $5.0 \mathrm{~g} \mathrm{l}^{-1}$ gelator to ILC, which also increase $J_{S C}$ owing to the enhancement of the conductivity of the liquid crystalline gel electrolyte. ${ }^{162}$ The device exhibits $J_{\mathrm{SC}}$ value of $7.7 \mathrm{~mA} \mathrm{~cm}^{-2}$. Full characterization of these devices has not been revealed.

Similar to LC additives in BHJ solar cells, efforts have also been made to evaluate the performance of DSSC by adding LCs. The embedded LC induced a diffusing pathway, which may increase the ordering strength in the electrolyte and enhance the transportation of redox species in the quasi-solid-state DSSCs. Kim et al. ${ }^{163}$ mixed the classical LC mixture E7 in a polymer electrolyte and demonstrated the effect of the function of the concentration rate of the LC on the PCE and the FF of the DSSC. The polymer electrolyte consists of ethylene carbonate, propylene carbonate, acetonitrile, tetrabutylammonium iodide, iodine, 1-propyl-3-methylimidazolium iodide and polyacrylonitrile (PAN). The quasi-solid-state DSSCs with optimized concentration of LC as $10 \mathrm{wt} \%$ exhibit the best PCE of $4.52 \%$ (Table 6).

They further studied the effects of LC E7 or ML-0249 addition in PAN-based electrolyte composed of $\mathrm{I}^{-} / \mathrm{I}_{3}{ }^{-}$redox species. ${ }^{164}$ The high order and molecular arrangement of the LC incarcerated in polymeric electrolyte molecules creates the transport pathway of redox species. This high mobility and transportation of carriers improved the photocurrent density and also the PV performance. The devices based on ML-0249:PAN (1:1) was fabricated and showed a $V_{\mathrm{OC}}$ of $0.703 \mathrm{~V}$, $J_{\text {SC }}$ of $13.57 \mathrm{~mA} \mathrm{~cm}^{-2}$, FF of $66.8 \%$ and PCE of $6.29 \%$ and E7:PAN (3:1) device showed a $V_{\mathrm{OC}}$ of $0.719 \mathrm{~V}, J_{\mathrm{SC}}$ of $13.27 \mathrm{~mA} \mathrm{~cm}^{-2}$, FF of $65.1 \%$ and PCE of $6.21 \%$ at 1 Sun. It has been revealed that 'the higher ionic conductivity of the LC embedded in polymeric electrolytes leads to enhancement in both $J_{\mathrm{SC}}$ and FF of the quasi-solid-state DSSCs, which significantly improved the PV performance'. ${ }^{164}$

Karim et al. ${ }^{165}$ prepared solar cells with device configuration of $\mathrm{SnO}_{2}: \mathrm{F} \mathrm{TiO}_{2} \mid \mathrm{N} 719$ |polymer LC electrolytelpt where the polymer electrolyte was composed of iodine, tetrabutylammoniumiodide, 1-propyl-3-methylimidazolium iodide, ethylene carbonate/propylene carbonate (EC/PC, 3/1 as weight ratio), PAN or click polymers as a polymer matrix, LC (ML-0249) as a plasticizer and acetonitrile. Click polymers (Figure 26) were prepared from 2,7-diazido-9, 9-dioctylfluorene and 2,7-diethynyl-9,9-dioctylfluorene, respectively, using CuI-catalyzed (P1) and non-CuI-catalyzed (P2) click polymerization. The liquid electrolyte was trapped in the polymer matrix to 
<smiles>CCCCCCCCCCCCCCCCCC</smiles>

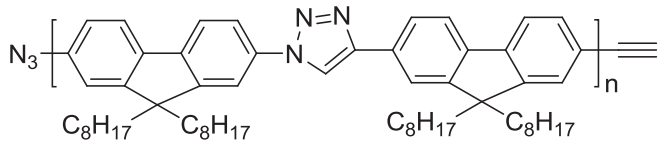

30 (Click Polymer)<smiles>[R4]c1cc2c3cc([R4])c([R2])cc3c3cc([R2])c([R])cc3c2cc1[R4]</smiles>

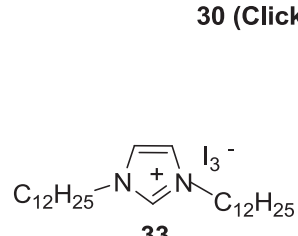<smiles></smiles>

34<smiles></smiles>

Figure 26 Chemical structure of LCs used in DSSCs.

Table 6 Photovoltaic performance of quasi-solid state DSSCs with liquid crystals

\begin{tabular}{|c|c|c|c|c|c|c|c|c|}
\hline$L C$ & Dye & $\mathrm{V}_{O C}(\mathrm{~V})$ & $\mathrm{J}_{S C}\left(m A \mathrm{~cm}^{-2}\right)$ & $F F(\%)$ & PCE (\%) & Illumination source $\left(\mathrm{mW} \mathrm{cm}^{-2}\right)$ & Phase & Reference \\
\hline E7 & N719 & - & - & 63 & 4.52 & - & $\mathrm{Cr}$ & 163 \\
\hline ML-0249 & N719 & 0.703 & 13.57 & 66 & 6.29 & 100 & $\mathrm{Cr}$ & 164 \\
\hline 30/ML-0249 & N719 & 0.65 & 10.73 & 68.5 & 4.78 & 100 & $\mathrm{Cr}$ & 165 \\
\hline 7CB/PVDF & C106 & 0.685 & 17.20 & 68 & 8.01 & 100 & $\mathrm{Cr}$ & 166 \\
\hline E7 & N719 & 0.72 & 14.62 & 64.8 & 6.82 & 100 & $\mathrm{Cr}$ & 167 \\
\hline HHTT & N719 & 0.95 & 0.534 & 88.2 & 0.45 & 100 & $\mathrm{Cr}$ & 73 \\
\hline 33 & N719 & 0.46 & 8.3 & - & 1.5 & 100 & $\mathrm{Cr}$ & 168 \\
\hline 34 & D205 & 0.67 & 14.6 & 60 & 5.8 & 100 & $\mathrm{SmA@30}{ }^{\circ} \mathrm{C}$ & 169 \\
\hline 35 & D205 & 0.67 & 5.9 & 40 & 1.6 & 100 & $\mathrm{Cr@30} \mathrm{C}$ & 169 \\
\hline 35 & D205 & 0.55 & 10.1 & 43 & 2.4 & 100 & SmA@90 C & 169 \\
\hline 36 & D205 & 0.54 & 1.0 & 31 & 0.2 & 100 & $\mathrm{SmA@30}{ }^{\circ} \mathrm{C}$ & 169 \\
\hline 36 & D205 & 0.55 & 10.9 & 35 & 2.1 & 100 & SmA@90 ${ }^{\circ} \mathrm{C}$ & 169 \\
\hline
\end{tabular}

Abbreviations: Cr, crystalline; DSSC, dye-sensitized solar cell; FF, fill factor; HHTT, hexahexylthiotriphenylene; JSC, short circuit current; LC, liquid crystal; PCE, power-conversion efficiency; PVDF, poly(vinylidenefluoride-co-hexafluoropropylene); $V_{O C}$, open circuit voltage.

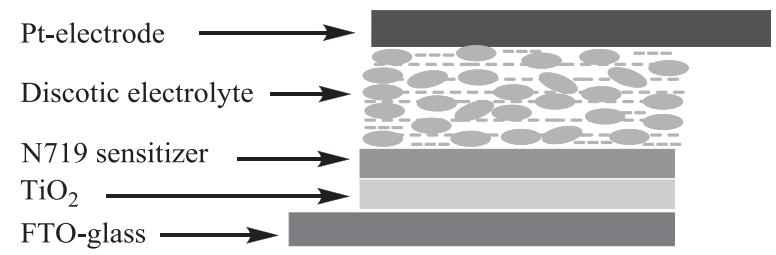

Figure 27 The geometry of DSSC with discotic electrolytes. A full color version of this figure is available at the Polymer Journal online.

generate polymer electrolyte. The DSSCs without ML-0249 (LC) showed a PCE of $3.53 \%$ for PAN-based electrolyte. The highest PCE of $4.70 \%$ and $4.78 \%$ were resulted for the DSSCs devices for P1: ML-0249 (1:3) and PAN:ML-0249 (1:3), respectively. The PAN:
ML-0249 (1:3) system showed the highest PV performance with a PCE of $4.78 \%$. It has been described that 'by using LC, the viscosity of the electrolyte became low, which provided high diffusion properties of the $\mathrm{I}_{3}^{-}$ion. As a result, the performance of the DSSC was improved'. ${ }^{165}$

Wang et al. ${ }^{166}$ used the classical NLC, 4-cyano-4'-n-heptyloxybiphenyl (7CB), into the poly(vinylidenefluoride-co-hexafluoropropylene) (PVDF)-based polymeric gel electrolyte for quasi-solid-state DSSC. The device architect FTOITiO ${ }_{2}|\mathrm{C} 106| \mathrm{LC}-\mathrm{PVDF} \mid \mathrm{Pt}$ were fabricated, DSSC with the PVDF electrolyte shows a $J_{\mathrm{SC}}$ of $14.89 \mathrm{~mA} \mathrm{~cm}^{-2}$, $V_{\mathrm{OC}}$ of $685 \mathrm{mV}$, FF of $74 \%$ and an PCE of $7.54 \%$ upon adding of the LC was into the PVDF-based polymeric gel electrolyte, no change in the $V_{\mathrm{OC}}$, a decrease in FF and a remarkable increase (from 14.89 to $17.20 \mathrm{~mA} \mathrm{~cm}^{-2}$ ) in the $J_{S C}$ were obtained with higher PCE of $8.01 \%$. This change is attributed to 'the light trapping scheme formed by the 


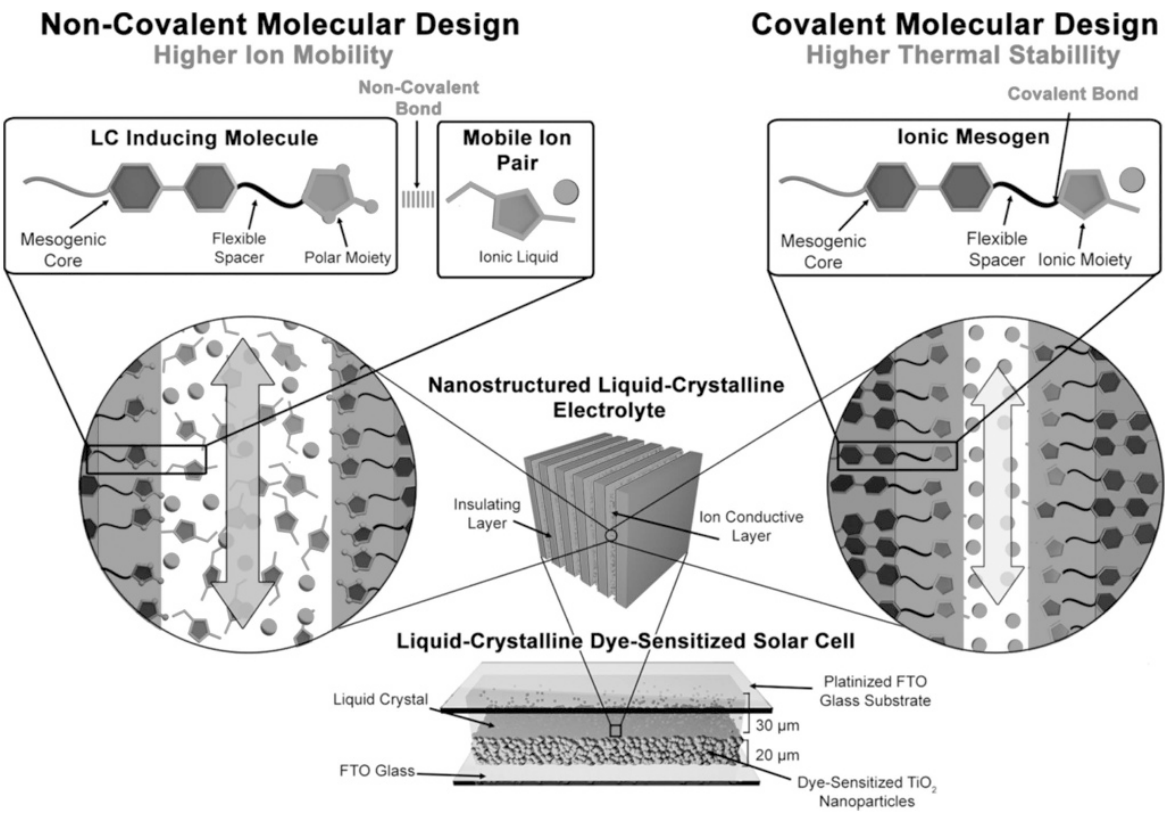

Figure 28 The schematic illustration of the assembly of LC electrolytes into layered smectic A phases and an LC-based dye-sensitized solar cell. Blue areas represent insulating parts, and red areas show ion conductive parts. FTO, fluoride-doped tin oxide. Reproduced with permission from Högberg et al. ${ }^{169}$ Copyright 2016, American Chemical Society. A full color version of this figure is available at the Polymer Journal online.

addition of LC, the optical path of incident light is enhanced and consequently the light harvesting efficiency, which benefit the generation of photoelectron. Therefore, the electron diffusion coefficients and diffusion length of the DSSC were enlarged as well as photocurrent density, which offsets the lower FF and results in higher PCE'. 166

Ahn et al. ${ }^{167}$ developed DSSCs composed of LC-embedded electrospun polymer gel electrolyte. Two types of solar cells having electrospun poly(vinylidene fluoride-co-hexafluoropropylene) (e-PVdF-co-HFP) polymer gel electrolyte were fabricated; first with doping of E7 LC and, in another device, without doping with the LC E7 and with a liquid electrolyte. DCCS containing the E7-embedded e-PVdF-co-HFP polymer gel electrolyte show a much higher PCE of $6.82 \%$ than that of an e-PVdF-co-HFP nanofiber $(6.35 \%)$ with $V_{\mathrm{OC}}$ of $0.72 \mathrm{~V}, J_{\mathrm{SC}}$ of $14.62 \mathrm{~mA} \mathrm{~cm}^{-2}$ and $\mathrm{FF}$ of $64.8 \%$ values.

In DSSC, the use of iodine solution is highly problematic owing to its corrosive nature. Recently, we demonstrated the use of discotic mesogenic molecules, hexahexylthiotriphenylene 31 (HHTT) and hexahexyloxytriphenylene 32 (HAT6) as iodine-free redox electrolyte in DSSCs (Figure 27). ${ }^{73}$ The cell shows $V_{\mathrm{OC}}$ of $0.95 \mathrm{~V}, J_{\mathrm{SC}}$ of $0.534 \mathrm{~mA} \mathrm{~cm}^{-2}$, FF of $88.24 \%$ and overall PCE of $0.45 \%$ in a typical fluorine-doped tin oxide/ $\mathrm{TiO}_{2} / \mathrm{N} 719 / \mathrm{HHTT} / \mathrm{Pt}$ DSSC configuration. The discotic material acts as charge carrier and mediator in these solar cells.

Guldi et al. ${ }^{168}$ demonstrated the effect of LC phases in solid-state DSSCs. They synthesized novel imidazolium-based ILCs, which shows 3 -D self-assembled motifs in LC phase. The devices with compound 33 showed $J_{\mathrm{SC}}$ of $8.3 \mathrm{~mA} \mathrm{~cm}{ }^{-2}, V_{\mathrm{OC}}$ of $0.46 \mathrm{~V}$ and PCE upto $1.5 \%$ at $40{ }^{\circ} \mathrm{C}$ temperature under 1 Sun illumination. In solid crystalline phase, efficiency increases linearly owing to the decrease in viscosity, which leads to the better electrode/dye/LC contact. A good balance between dye and hole transport is accumulated by the presence of liquid crystalline phase, which gives rise to the stability of the device.
Very recently, Kato et al. ${ }^{169}$ developed nanostructures of liquid crystalline electrolytes 34-36 (Figure 26) to prepare DSSCs. They demonstrated two types of electrolyte assemblies, first as non-covalent assemblies of two-component mixtures consisting of $\mathrm{I}_{2}$-doped imidazolium ionic liquids and carbonate-terminated mesogenic compounds and second as single-component mesogenic compounds covalently bonded with an imidazolium moiety doped with $\mathrm{I}_{2}$ (Figure 28). The fabricated device with components 34 shows PCEs of $5.8 \pm 0.2 \%$, with $V_{\mathrm{OC}}$ of $0.65 \mathrm{~V}, J_{\mathrm{SC}}$ of $14.6 \mathrm{~mA} \mathrm{~cm}^{-2}$ and $\mathrm{FF}$ of $60 \%$ in the liquid crystalline smectic phase at $30^{\circ} \mathrm{C}$. The PCE decreases to $0.9 \pm 0.1 \%$ in the isotropic phase at $120^{\circ} \mathrm{C}$. DSSC prepared from 35 exhibits PCE of $2.4 \%$ in the smectic phase at $90{ }^{\circ} \mathrm{C}$. The efficiency decreases both in the crystalline phase at $30^{\circ} \mathrm{C}$ to $1.6 \%$ as well as in the isotropic phase at $120^{\circ} \mathrm{C}$ to $1.4 \%$. However, in the covalent-type electrolyte 36 , the PCE increases with temperature in the smectic phase. It shows PCE of $0.2 \%$ at $30^{\circ} \mathrm{C}$ in the $\mathrm{SmA}$ phase, which increases to $2.4 \%$ at $120^{\circ} \mathrm{C}$ in the same LC phase. These liquid crystalline DSSCs have been reported to exhibit excellent stability over $1000 \mathrm{~h}$.

\section{SUMMARY AND OUTLOOK}

Past few years have witnessed tremendous development in the field of OPVs owing to the predicted limited availability of fossil fuels and the impact of burning of these hydrocarbons on environment. The potential inexpensive fabrication, lightweight, flexible, semitransparency and so on of solar cells made of organic materials make them one of the most promising candidates for environmentally acceptable and commercially viable energy devices. A number of organic monomeric, oligomeric and polymeric materials have been prepared to make bilayer and BHJ solar cells. Recently, LCs have been introduced in OPVs to impart order in active layers. LC state represents a fascinating state of matter that combines both order and mobility at molecular level to macroscopic levels. The use of LCs in OPVs is currently a subject of great importance. In this paper, we have given an overview of the development of liquid crystalline 
materials in OPV devices. Both calamitic and DLCs have been used in bilayer, BHJ and DSSCs.

Discotic derivatives of $\mathrm{HBC}$, porphyrins, Pcs, TP, perylene and decacylene have been used both as donor and acceptor as well processing additives for bilayer and BHJ solar cells. PCE exceeding $4 \%$ has been achieved in discotic PV devices. In some cases, columnar phase forming DLCs have been deployed as facilitating additives in the active layer of conventional polymer solar cells to dramatically enhance their efficiencies. Among these derivatives, HBC and TP derivatives showed significant improvement to PCE. The highest efficiency was achieved using a TP derivative $\mathbf{5 h}$, which showed PCE of $8 \%$, with enriched $J_{\mathrm{SC}}$ of $16.4 \mathrm{~mA} \mathrm{~cm}^{-2}, V_{\mathrm{OC}}$ of $0.73 \mathrm{~V}$ and $65 \%$ FF. PCE of $5.14 \%$ was achieved for PV solar cells containing HAT4 layer of 30-nm thickness as an inserted layer. Porphyrin derivatives showed PCE upto $4.1 \%$ while Pcs derivative-based devices performed upto $4.7 \%$ PCE.

Among the calamitic LCs, LC-conjugated polyelectrolytes poly [9,9-bis[6-(4-cyanobiphenyloxy)-hexyl] - fluorene - alt-9,9-bis (6- $(\mathrm{N}$, $\mathrm{N}$-diethylamino)-hexyl)-fluorene] 23 (PF6Ncbp) and poly[9,9-bis [6-(4-cyanobiphenyloxy)-hexyl] - fluorene - alt-9,9-bis(6-(N-methylimidazole)-hexyl]-fluorene] 24 (PF6lmicbp) used in device fabrication showed PCE upto 7.6\%. A molecular-donor NLC benzodithiophene terthiophene rhodanine $\mathbf{2 6}$ have been employed to fabricated a device that shows the promising PCE of $9.3 \%$ with FF of $77 \%$, which is rare in OPV devices. This is the highest reported PCE among calamitic-based OPV devices.

Various LCs have been employed in dye sensitizers as well as in solid-state dye sensitized solar cells. The NLC 4-cyano-4'-n-heptyloxybiphenyl (7CB) into thePVDF-based polymeric gel electrolyte for quasi-solid-state DSSC showed a remarkable increase (from 14.89 to $17.20 \mathrm{~mA} \mathrm{~cm}^{-2}$ ) in the $J_{\mathrm{SC}}$ with higher PCE of $8.01 \%$. PCE of $5.8 \%$ has been achieved in the liquid crystalline SmA phase of LC polyelectrolytes.

The field of liquid crystalline PVs is relatively young, but it has made significant advances during the past decade. With the help of LCs, the efficiency of OPV devices has reached to about $10 \%$, which is considered essential for the commercial viability of solar cells. However, at present, these experiments are only at the 'proof of concept' stage and more rigorous efforts are required to move forward. Despite the promising properties of LCs, they have not yet been explored well and more efforts have to be made to realize their full potential. Porphyrins are natural light-harvesting antennas and hundreds of porphyrin-based LCs have been realized, but, surprisingly, only a few are used in OPVs. Hardly $0.01 \%$ of total known LCs have so far been explored in OPV field. No doubt LCs will have more prevalent roles in OPVs in the near future. However, there are several difficulties associated with LCs in OPV systems, such as proper alignment, stability, proper matching of energy levels and so on, which have to be solved to materialize their application. LCs may find significant role in next-generation advanced functional and/or engineered materials for OPV application that can only be realized as the field progresses.

\section{CONFLICT OF INTEREST}

The authors declare no conflict of interest.

1 Garnier, F., Hajlaoui, R., Yassar, A. \& Srivastava, P. All-polymer field-effect transistor realized by printing techniques. Science 265, 1864-1866 (1994).
2 Dimitrakopoulos, C. D., Purushothaman, S., Kymissis, J., Callegari, A. \& Shaw, J. M. Low-voltage organic transistors on plastic comprising high-dielectric constant gate insulators. Science 283, 822-824 (1999).

3 Tang, C. W. \& VanSlyke, S. A. Organic electroluminescent diodes. Appl. Phys. Lett. 51, 913-915 (1987).

4 Shirota, Y. \& Kageyama, H. Charge carrier transporting molecular materials and their applications in devices. Chem. Rev. 107, 953-1010 (2007).

5 Tang, C. W. Two-layer organic photovoltaic cell. Appl. Phys. Lett. 48, 183-185 (1986).

6 Schmidt-Mende, L., Fechtenkötter, A., Müllen, K., Moons, E., Friend, R. H. \& MacKenzie, J. D. Self-organized discotic liquid crystals for high-efficiency organic photovoltaics. Science 293, 1119-1122 (2001).

7 Green, M. A., Emery, K., Hishikawa, Y., Warta, W. \& Dunlop, E. D. Solar cell efficiency tables (Version 45). Prog. Photovoltaics 23, 1-9 (2015).

8 Hains, A. W., Liang, Z., Woodhouse, M. A. \& Gregg, B. A. Molecular semiconductors in organic photovoltaic cells. Chem. Rev. 110, 6689 (2010).

9 Varotto, A., Nam, C. Y., Radivojevic, I., Tomé, J.P., Cavaleiro, J. A., Black, C. T. \& Drain, C. M. Phthalocyanine blends improve bulk heterojunction solar cells. J. Am. Chem. Soc. 132 (2010)

10 Ma, W., Yang, C., Gong, X., Lee, K. \& Heeger, A. J. Thermally stable, efficient polymer solar cells with nanoscale control of the interpenetrating network morphology. Adv. Funct. Mater. 15, 1617-1622 (2005).

11 Kim, J. Y., Lee, K., Coates, N. E., Moses, D., Nguyen, T. Q., Dante, M. \& Heeger, A. J. Efficient tandem polymer solar cells fabricated by all-solution processing. Science 317, 222 (2007).

12 Bisoyi, H. K. \& Li, Q. in Nanomaterials for Sustainable Energy (ed. Li, Q.) 215-252 (Springer International Publishing, 2016).

13 Coakley, K. M. \& McGehee, M. D. Conjugated polymer photovoltaic cells. Chem. Mater. 16, 4533-4542 (2004).

14 Brabec, C. J., Hauch, J. A., Schilinsky, P. \& Waldauf, C. Production aspects of organic photovoltaics and their impact on the commercialization of devices. MRS Bull. 30, 50-52 (2005).

15 Günes, S., Neugebauer, H. \& Sariciftci, N. S. Conjugated polymer-based organic solar cells. Chem. Rev. 107, 1324-1338 (2007).

16 Lloyd, M. T., Anthony, J. E. \& Malliaras, G. G. Photovoltaics from soluble small molecules. Mater. Today 10, 34-41 (2007).

17 Thompson, B. C. \& Frechet, J. M. Polymer-fullerene composite solar cells. Angew. Chem. Int. Ed. 47, 58-77 (2008).

18 Krebs, F. C. Fabrication and processing of polymer solar cells: a review of printing and coating techniques. Sol. Energy Mater. Sol. Cells 93, 393-412 (2009).

19 Brabec C. J., Dyakonov V., Parisi J. \& Sariciftci N. S. (eds). Organic Photovoltaics: Concepts and Realization (Springer, New York, USA, 2003).

20 Sun S. S. \& Sariciftci N. S. (eds). Organic Photovoltaics: Mechanisms, Materials, and Devices (CRC Press, Taylor \& Francis Group, Florida, USA, 2005).

21 Krebs F. C. (ed). Polymer Photovoltaics: A Practical Approach (SPIE Press, Bellingham, USA, 2008).

22 Brabec C., Scherf U. \& Dyakonov V. (eds). Organic Photovoltaics: Materials, Device Physics and Manufacturing Technologies (Wiley-VCH, Weinheim, Germany, 2011).

23 Service, R. F. Solar energy. Outlook brightens for plastic solar cells. Science New York, NY, USA 332, 293 (2011).

24 Hamley, I. W. Liquid crystal phase formation by biopolymers. Soft Matter 6 , 1863-1871 (2010)

25 Nakata, M., Zanchetta, G., Chapman, B. D., Jones, C. D., Cross, J. O., Pindak, R., Bellini, T. \& Clark, N. A. End-to-end stacking and liquid crystal condensation of 6- to 20-base pair DNA duplexes. Science 318, 1276-1279 (2007).

26 Demus D., Goodby J. W., Gray G. W., Spiess H. W. \& Vill V. (eds). Handbook of Liquid Crystals, Low Molecular Weight Liquid Crystals I: Calamitic Liquid Crystals (John Wiley \& Sons, Weinheim, Germany, 2011)

27 Kirsch, P. \& Bremer, M. Nematic liquid crystals for active matrix displays: molecular design and synthesis. Angew. Chem. Int. Ed. 39, 4216-4235 (2000).

28 Reinitzer, F. Beiträge zur kenntniss des cholesterins. Monatsh. Chem. 9, 421-441 (1888).

29 Chandrasekhar, S., Sadashiva, B. K. \& Suresh, K. A. Liquid crystals of disc-like molecules. Pramana 9, 471-480 (1977).

30 Kumar, S. \& Gowda, A. N. The chemistry of bent-core molecules forming nematic liquid crystals. Liq. Cryst. Rev. 3, 99-145 (2015).

31 Vorlander, D., Fuchs, K. \& Katscher, E. E. Über die einwirkung von chlorsulfonsäure auf aldehyde. Ber. Dtsch. Chem. Ges. 62, 2381-2386 (1929).

32 Niori, T., Sekine, T., Watanabe, J., Furukawa, T. \& Takezoe, H. Distinct ferroelectric smectic liquid crystals consisting of banana shaped achiral molecules. J. Mater. Chem. 6, 1231-1233 (1996).

33 Goodby J., Collings P. J., Kato T., Tschierske C., Gleeson H.F. \& Raynes P. (eds). Handbook of Liquid Crystals Vol. 4, part III, 467 (Wiley-VCH, Weinheim, Germany, 2014).

34 Kumar, S. Chemistry of Discotic Liquid Crystals: From Monomers to Polymers, (CRC press, Boca Raton, FL, USA, 2011).

35 Balagurusamy, V. S. K., Prasad, S. K., Chandrasekhar, S., Kumar, S., Manickam, M. \& Yelamaggad, C. V. Quasi-one dimensional electrical conductivity and thermoelectric power studies on a discotic liquid crystal. Pramana 53, 3-11 (1999).

36 Kumar, S. Functional discotic liquid crystals. Israel J. Chem. 52, 820-829 (2012)

37 Bisoyi, H. K. \& Kumar, S. Carbon-based liquid crystals: art and science. Liq. Cryst. 38, 1427-1449 (2011). 
38 Bushby, R. J. \& Kawata, K. Liquid crystals that affected the world: discotic liquid crystals. Liq. Cryst. 38, 1415-1426 (2011).

39 Pisula, W., Feng, X. \& Müllen, K. Charge-carrier transporting graphene-type molecules. Chem. Mater. 23, 554 (2010).

40 Bisoyi, H. K. \& Kumar, S. Discotic nematic liquid crystals: science and technology Chem. Soc. Rev. 39, 264 (2010).

41 Kumar, S. Playing with discs. Liq. Cryst. 36, 607 (2009).

42 Goodby, J. W., Saez, I. M., Cowling, S. J., Görtz, V., Draper, M., Hall, A. W., Sia, S. Cosquer, G., Lee, S. E. \& Raynes, E. P. Transmission and amplification of information and properties in nanostructured liquid crystals. Angew. Chem. Int. Ed. 47 2754 (2008)

43 Tschierske, C. Liquid crystal engineering-new complex mesophase structures and their relations to polymer morphologies, nanoscale patterning and crystal engineering. Chem. Soc. Rev. 36, 1930 (2007)

44 Sergeyev, S., Pisula, W. \& Geerts, Y. H. Discotic liquid crystals: a new generation of organic semiconductors. Chem. Soc. Rev. 36, 1902 (2007).

45 Wu, J., Pisula, W. \& Müllen, K. Graphenes as potential material for electronics. Chem. Rev. 107, 718 (2007).

46 Laschat, S., Baro, A., Steinke, N., Giesselmann, F., Haegele, C., Scalia, G., Judele, R., Kapatsina, E., Sauer, S., Schreivogel, A. \& Tosoni, M. Discotic liquid crystals from tailor-made synthesis to plastic electronics. Angew. Chem. Int. Ed. 46, 4832 (2007)

47 Kato, T., Mizoshita, N. \& Kishimoto, K. Functional liquid-crystalline assemblies: self organized soft materials. Angew. Chem. Int. Ed. 45, 38 (2006).

48 Kumar, S. Self-organization of disc-like molecules: chemical aspects. Chem. Soc. Rev. 35, 83 (2006)

49 Ohta, K., Hatsusaka, K., Sugibayashi, M., Ariyoshi, M., Ban, K., Maeda, F., Naito, R. Nishizawa, K., Van de Craats, A. M. \& Warman, J. M. Discotic liquid crystalline semiconductors. Mol. Cryst. Liq. Cryst. 397, 25 (2003)

50 Bushby, R. J. \& Lozman, O. R. Photoconducting liquid crystals. Curr. Opin. Solid State Mater. Sci 6, 569 (2002).

51 Percec, V., Glodde, M., Bera, T. K., Miura, Y., Shiyanovskaya, I., Singer, K. D., Balagurusamy, V. S. K., Heiney, P. A., Schnell, I., Rapp, A. \& Spiess, H. W. Selforganization of supramolecular helical dendrimers into complex electronic materials. Nature 419, 384 (2002).

52 Wöhrle, T., Wurzbach, I., Kirres, J., Kostidou, A., Kapernaum, N., Litterscheidt, J., Haenle, J. C., Staffeld, P., Baro, A., Giesselmann, F. \& Laschat, S. Discotic liquid crystals. Chem. Rev. 116, 1139-1241 (2016).

53 Adam, D., Schuhmacher, P., Simmerer, J., Häussling, L., Siemensmeyer, K., Etzbachi, K. H., Ringsdorf, H. \& Haarer, D. Fast photoconduction in the highly ordered columnar phase of a discotic liquid crystal. Nature 371, 141 (1994).

54 Feng, X., Marcon, V., Pisula, W., Hansen, M. R., Kirkpatrick, J., Grozema, F. Andrienko, D., Kremer, K. \& Müllen, K. Towards high charge-carrier mobilities by rational design of the shape and periphery of discotics. Nat. Mater. 8, 421 (2009).

55 Van de Craats, A. M. \& Warman, J. M. The core-size effect on the mobility of charge in discotic liquid crystalline materials. Adv. Mater. 13, 130 (2001).

56 Yang, S., Bachman, R. E., Feng, X. \& Müllen, K. Use of organic precursors and graphenes in the controlled synthesis of carbon-containing nanomaterials for energy storage and conversion. Acc. Chem. Res. 46, 116 (2012).

57 Arikainen, E. O., Boden, N., Bushby, R. J., Lozman, O. R., Vinter, J. G. \& Wood, A. Complimentary polytopic interactions. Angew. Chem. Int. Ed. 39, 2333 (2000).

58 Kumar, S. \& Lakshminarayanan, V. Inclusion of gold nanoparticles into a discotic liquid crystalline matrix. Chem. Commun. 14, 1600-1601 (2004).

59 Kumar, S., Pal, S. K., Kumar, P. S. \& Lakshminarayanan, V. Novel conducting nanocomposites: synthesis of triphenylene-covered gold nanoparticles and their insertion into a columnar matrix. Soft Matter 3, 896 (2007).

60 Bisoyi, H. K. \& Kumar, S. Carbon nanotubes in triphenylene and rufigallol-based room temperature monomeric and polymeric discotic liquid crystals. J. Mater. Chem. 18 3032-3039 (2008).

61 Gowda, A. N., Kumar, M., Thomas, A. R., Philip, R. \& Kumar, S. Self-assembly of silver and gold nanoparticles in a metal-free phthalocyanine liquid crystalline matrix: structural, thermal, electrical and nonlinear optical characterization. Chem. Select 1 1361-1370 (2016)

62 Avinash, B. S., Lakshminarayanan, V., Kumar, S. \& Vij, J. K. Gold nanorods embedded discotic nanoribbons. Chem. Commun. 49, 978 (2013)

63 Kumar, S. \& Sagar, L. K. CdSe quantum dots in a columnar matrix. Chem. Commun. 47, 12182 (2011)

64 Kumar, M. \& Kumar, S. Luminescent CdTe quantum dots incarcerated in a columna matrix of discotic liquid crystals for optoelectronic applications. RSC Adv. 5, 1262 (2015)

65 Kumar, M. \& Kumar, S. Stacking of ultra-thin reduced graphene oxide nanoparticles in supramolecular structures for optoelectronic applications. RSC Adv. 5, 14871 (2015).

66 Shivanandareddy, A. B., Krishnamurthy, S., Lakshminarayanan, V. \& Kumar, S. Mutually ordered self-assembly of discotic liquid crystal-graphene nanocomposites. Chem. Commun. 50, 710 (2014).

67 Shivanandareddy, A. B., Kumar, M., Lakshminarayanan, V. \& Kumar, S. Self-assembly of thiolated graphene oxide onto a gold surface and in the supramolecular order of discotic liquid crystals. RSC Adv. 5, 47692 (2015).

68 Bushby, R. J. \& Lozman, O. R. Discotic liquid crystals 25 years on. Curr. Opin. Colloid Interface Sci. 7, 343-354 (2002).

69 Dao, Q. D., Sosa-Vargas, L., Higashi, T., Ohmori, M., Itani, H., Fujii, A., Shimizu, Y. \& Ozaki, M. Efficiency enhancement in solution processed small-molecule based organic solar cells utilizing various phthalocyanine-tetrabenzoporphyrin hybrid macrocycles. Org. Electron. 23, 44-52 (2015).

70 Masuda, T., Hori, T., Fukumura, K., Miyake, Y., Duy, D. Q., Hayashi, T., Kamikado, T., Yoshida, H., Fujii, A., Shimizu, Y. \& Ozaki, M. Photovoltaic properties of 1, 4, 8, 11, $15, \quad 18,22,25$-octaalkylphthalocyanine doped polymer bulk heterojunction solar cells. Jpn. J. Appl. Phys. 51, 02BK15 (2012).

71 Jeong, S., Kwon, Y., Choi, B. D., Ade, H. \& Han, Y. S. Improved efficiency of bulk heterojunction poly (3-hexylthiophene):[6, 6]-phenyl-C61-butyric acid methyl ester photovoltaic devices using discotic liquid crystal additives. Appl. Phys. Lett. 96, 183305 (2010).

72 Bajpai, M., Yadav, N., Kumar, S., Srivastava, R. \& Dhar, R. Bulk heterojunction solar cells based on self-assembling disc-shaped liquid crystalline material. Liq. Cryst. 43, 305-313 (2016)

73 Selvaraj, A. R. K., Lakshminarayanan, V., Dhar, R. \& Kumar, S. Dye-sensitised solar cells with iodine-free discotic electrolytes. Liq. Cryst. 42, 1815-1822 (2015).

74 Gregg, B. A., Fox, M. A. \& Bard, A. J. Photovoltaic effect in symmetrical cells of a liquid crystal porphyrin. J. Phys. Chem. 94, 1586-1598 (1990).

75 Petritsch, K., Friend, R. H., Lux, A., Rozenberg, G., Moratti, S. C. \& Holmes, A. B. Liquid crystalline phthalocyanines in organic solar cells. Synth. Met. 102 1776-1777 (1999).

76 Herwig, P., Kayser, C. W., Müllen, K. \& Spiess, H. W. Columnar mesophases of alkylated hexa-peri-hexabenzocoronenes with remarkably large phase widths. Adv. Mater. 8, 510-513 (1996).

77 van de Craats, A. M., Warman, J. M., Müllen, K., Geerts, Y. \& Brand, J. D. Rapid charge transport along self-assembling graphitic nanowires. Adv. Mater. 10, 36-38 (1998)

78 van de Craats, A. M., Warman, J. M., Fechtenkötter, A., Brand, J. D., Harbison, M. A \& Müllen, K. Record charge carrier mobility in a room-temperature discotic liquidcrystalline derivative of hexabenzocoronene. Adv. Mater. 11, 1469-1472 (1999).

79 Hesse, H. C., Weickert, J., Al-Hussein, M., Dössel, L., Feng, X., Müllen, K. \& Schmidt-Mende, L. Discotic materials for organic solar cells: effects of chemical structure on assembly and performance. Sol. Energy Mater. Sol. Cells 94, 560-567 (2010)

80 Schmidt-Mende, L., Fechtenkötter, A., Müllen, K., Friend, R. H. \& MacKenzie, J. D. Efficient organic photovoltaics from soluble discotic liquid crystalline materials. Physica E 14, 263-267 (2002).

81 Schmidt-Mende, L., Watson, M., Müllen, K. \& Friend, R. H. Organic thin film photovoltaic devices from discotic materials. Mol. Cryst. Liq. Cryst. 396 73-90 (2003).

82 Hassheider, T., Benning, S. A., Lauhof, M. W., Kitzerow, H. S., Bock, H., Watson, M D. \& Müllen, K. Organic heterojunction photovoltaic cells made of discotic, mesogenic materials. Mol. Cryst. Liq. Cryst. 413, 461-472 (2004).

83 Jung, J., Rybak, A., Slazak, A., Bialecki, S., Miskiewicz, P., Glowacki, I., Ulanski, J., Rosselli, S., Yasuda, A., Nelles, G. \& Tomović, Ž. Photogeneration and photovoltaic effect in blends of derivatives of hexabenzocoronene and perylene. Synth. Met. 155, 150-156 (2005)

84 Li, J. L., Kastler, M., Pisula, W., Robertson, J. W. F., Wasserfallen, D., Grimsdale, A. C., Wu, J. S. \& Müllen, K. Organic bulk-heterojunction photovoltaics based on alkyl substituted discotics. Adv. Funct. Mater. 17, 2528-2533 (2007).

85 Schmidtke, J. P., Friend, R. H., Kastler, M. \& Müllen, K. Control of morphology in efficient photovoltaic diodes from discotic liquid crystals. J. Chem. Phys. 124, 174704 (2006).

86 Al-Hussein, M., Hesse, H. C., Weickert, J., Dössel, L., Feng, X., Müllen, K. \& Schmidt-Mende, L. Structural properties of the active layer of discotic hexabenzocoronene/perylene diimide bulk hetero junction photovoltaic devices: The role of alkyl side chain length. Thin Solid Films 520, 307-313 (2011).

87 Wong, W. W. Singh, T. B., Vak, D., Pisula, W., Yan, C., Feng, X., Williams, E. L., Chan, K. L., Mao, Q., Jones, D. J. \& Ma, C. Q. Solution processable fluorenyl hexa-peri-hexabenzocoronenes in organic field-effect transistors and solar cells. Adv. Funct. Mater. 20, 927-938 (2010).

88 Wong, W. W., Ma, C. Q., Pisula, W., Yan, C., Feng, X., Jones, D. J., Müllen, K., Janssen, R. A., Bäuerle, P. \& Holmes, A. B. Self-assembling thiophene dendrimers with a hexa-peri-hexabenzocoronene core- synthesis, characterization and performance in bulk heterojunction solar cells. Chem. Mater. 22, 457-466 (2009).

89 Dam, H. H., Sun, K., Hanssen, E., White, J. M., Marszalek, T., Pisula, W., Czolk, J., Ludwig, J., Colsmann, A., Pfaff, M. \& Gerthsen, D. Morphology change and improved efficiency in organic photovoltaics via hexa-peri-hexabenzocoronene templates. Appl. Mater. Interfaces 6, 8824-8835 (2014).

90 Kang, S. J., Ahn, S., Kim, J. B., Schenck, C., Hiszpanski, A. M., Oh, S., Schiros, T., Loo, Y. L. \& Nuckolls, C. Using self-organization to control morphology in molecular photovoltaics. J. Am. Chem. Soc. 135, 2207-2212 (2013).

91 Battersby, A. R., Fookes, C. J., Matcham, G. W. \& McDonald, E. Biosynthesis of the pigments of life: formation of the macrocycle. Nature 285, 17-21 (1980).

92 Wasielewski, M. R. Self-assembly strategies for integrating light harvesting and charge separation in artificial photosynthetic systems. Acc. Chem. Res. 42, 1910-1921 (2009).

93 Guldi, D. M. Fullerene-porphyrin architectures; photosynthetic antenna and reaction center models. Chem. Soc. Rev. 31, 22-36 (2002).

94 Wong, W. W., Khoury, T., Vak, D., Yan, C., Jones, D. J., Crossley, M. J. \& Holmes, A. B. A porphyrin-hexa-peri-hexabenzocoronene-porphyrin triad: synthesis, photophysical properties and performance in a photovoltaic device. J. Mater. Chem. 20, 7005-7014 (2010). 
95 Campbell, W. M., Jolley, K. W., Wagner, P., Wagner, K., Walsh, P. J., Gordon, K. C., Schmidt-Mende, L., Nazeeruddin, M. K., Wang, Q., Grätzel, M. \& Officer, D. L. Highly efficient porphyrin sensitizers for dye-sensitized solar cells. J. Phys. Chem. C 111, 11760-11762 (2007).

96 Li, L. L. \& Diau, E. W. G. Porphyrin-sensitized solar cells. Chem. Soc. Rev. 42 , 291-304 (2013).

97 Walter, M. G., Rudine, A. B. \& Wamser, C. C. Porphyrins and phthalocyanines in solar photovoltaic cells. J. Porphyrins Phthalocyanines 14, 759-792 (2010).

98 Gregg, B. A., Fox, M. A. \& Bard, A. J. Photovoltaic effect in symmetrical cells of a liquid crystal porphyrin. J. Phys. Chem. 94, 1586 (1990).

99 Sun, Q., Dai, L., Zhou, X., Li, L. \& Li, Q. Bilayer-and bulk-heterojunction solar cells using liquid crystalline porphyrins as donors by solution processing. Appl. Phy. Lett. 91, 253505 (2007)

100 Li, L., Kang, S. W., Harden, J., Sun, Q., Zhou, X., Dai, L., Jakli, A., Kumar, S. \& Li, Q. Nature-inspired light-harvesting liquid crystalline porphyrins for organic photovoltaics. Liq. Cryst. 35, 233-239 (2008).

101 Thomas, A. L. Phthalocyanine Research and Applications (CRC Press, 1990).

102 Claessens, C. G., Hahn, U. \& Torres, T. Phthalocyanines: from outstanding electronic properties to emerging applications. Chem. Rec. 8, 75-97 (2008).

103 Piechocki, C., Simon, J., Skoulios, A., Guillon, D. \& Weber, P. Annelides. 7. Discotic mesophases obtained from substituted metallophthalocyanines. Toward liquid crystalline one-dimensional conductors. J. Am. Chem. Soc. 104, 5245-5247 (1982).

104 Petritsch, K., Friend, R. H., Lux, A., Rozenberg, G., Moratti, S. C. \& Holmes, A. B. Liquid crystalline phthalocyanines in organic solar cells. Synth. Met. 102, 1776-1777 (1999).

105 Petritsch, K., Dittmer, J. J., Marseglia, E. A., Friend, R. H., Lux, A., Rozenberg, G. G., Moratti, S. C. \& Holmes, A. B. Dye-based donor/acceptor solar cells. Sol. Energy Mater. Sol. Cells 61, 63-72 (2000).

106 Levitsky, I. A., Euler, W. B., Tokranova, N., Xu, B. \& Castracane, J. Hybrid solar cells based on porous Si and copper phthalocyanine derivatives. Appl. Phys. Lett. 85, 6245-6247 (2004).

107 Hori, T., Miyake, Y., Yamasaki, N., Yoshida, H., Fujii, A., Shimizu, Y. \& Ozaki, M. Solution processable organic solar cell based on bulk heterojunction utilizing phthalocyanine derivative. Appl. Phys. Exp. 3, 101602 (2010).

108 Hori, T., Fukuoka, N., Masuda, T., Miyake, Y., Yoshida, H., Fujii, A., Shimizu, Y. \& Ozaki, M. Bulk heterojunction organic solar cells utilizing $1,4,8,11,15,18$, 22, 25-octahexylphthalocyanine. Sol. Energy Mater. Sol. Cells 95, 3087-3092 (2011).

109 Dao, Q. D., Hori, T., Fukumura, K., Masuda, T., Kamikado, T., Fujii, A., Shimizu, Y. \& Ozaki, M. Efficiency enhancement in mesogenic-phthalocyanine-based solar cells with processing additives. Appl. Phys. Lett. 101, 263301 (2012).

110 Dao, Q. D., Hori, T., Fukumura, K., Masuda, T., Kamikado, T., Fujii, A., Shimizu, Y. \& Ozaki, M. Effects of processing additives on nanoscale phase separation, crystallization and photovoltaic performance of solar cells based on mesogenic phthalocyanine. Org. Electron. 14, 2628-2634 (2013).

111 Dao, Q. D., Hori, T., Masuda, T., Fukumura, K., Kamikado, T., Nekelson, F., Fujii, A., Shimizu, Y. \& Ozaki, M. Mechanism of degradation and improvement of stability on mesogenic-phthalocyanine-based bulk heterojunction solar cell. Jpn. J. Appl. Phys. 52, 012301 (2012)

112 Dao, Q. D., Saito, T., Nakano, S., Fukui, H., Kamikado, T., Fujii, A., Shimizu, Y. \& Ozaki, M. Alkyl substituent length dependence of octaalkylphthalocyanine bulk heterojunction solar cells. Appl. Phys. Exp. 6, 122301 (2013).

113 Hori, T., Masuda, T., Fukuoka, N., Hayashi, T., Miyake, Y., Kamikado, T., Yoshida, H., Fujii, A., Shimizu, Y. \& Ozaki, M. Non-peripheral octahexylphthalocyanine doping effects in bulk heterojunction polymer solar cells. Org. Electron. 13, 335-340 (2012).

114 Sun, Y., Welch, G. C., Leong, W. L., Takacs, C. J., Bazan, G. C. \& Heeger, A. J. Solution-processed small-molecule solar cells with $6.7 \%$ efficiency. Nat. Mater. 11 , 44-48 (2012).

115 Miyake, Y., Shiraiwa, Y., Okada, K., Monobe, H., Hori, T., Yamasaki, N., Yoshida, H., Cook, M. J., Fujii, A., Ozaki, M. \& Shimizu, Y. High carrier mobility up to $1.4 \mathrm{~cm}^{2} \mathrm{~V}^{-1}$ $\mathrm{s}^{-1}$ in non-peripheral octahexyl phthalocyanine. Appl. Phys. Exp. 4, 021604 (2011).

116 Jurow, M. J., Hageman, B. A., DiMasi, E., Nam, C. Y., Pabon, C., Black, C. T. \& Drain, C. M. Controlling morphology and molecular packing of alkane substituted phthalocyanine blend bulk heterojunction solar cells. J. Mater. Chem. A 1, 1557-1565 (2013).

117 Kumar, S. Recent developments in the chemistry of triphenylene-based discotic liquid crystals. Liq. Cryst. 31, 1037-1059 (2004).

118 Kumar, S. Triphenylene-based discotic dimers, oligomers and polymers. Liq. Cryst. 32, 1089-1113 (2005).

119 Pal, S. K., Setia, S., Avinash, B. S. \& Kumar, S. Triphenylene-based discotic liquid crystals: recent advances. Liq. Cryst. 40, 1769-1816 (2013).

120 Oukachmih, M., Destruel, P., Seguy, I., Ablart, G., Jolinat, P., Archambeau, S., Mabiala, M., Fouet, S. \& Bock, H. New organic discotic materials for photovoltaic conversion. Sol. Energy Mater. Sol. Cells 85, 535-543 (2005).

121 Destruel, P., Bock, H., Séguy, I., Jolinat, P., Oukachmin, M. \& Bedel-Pereira, E. Influence of indium tin oxide treatment using UV-ozone and argon plasma on the photovoltaic parameters of devices based on organic discotic materials. Polym. Int. 55, 601-607 (2006).

122 Zheng, Q., Fang, G., Bai, W., Sun, N., Qin, P., Fan, X., Cheng, F., Yuan, L. \& Zhao, X. Efficiency improvement in organic solar cells by inserting a discotic liquid crystal. Sol. Energy Mater. Sol. Cells 95, 2200-2205 (2011).
123 Bajpai, M., Yadav, N., Kumar, S., Srivastava, R. \& Dhar, R. Incorporation of liquid crystalline triphenylene derivative in bulk heterojunction solar cell with molybdenum oxide as buffer layer for improved efficiency. Liq. Cryst. 43, 928-936 (2016).

124 Bajpai, M., Yadav, N., Kumar, S., Srivastava, R. \& Dhar, R. Bulk heterojunction solar cells made from carbazole copolymer and fullerene derivative with an inserted layer of discotic material with improved efficiency. Liq. Cryst. doi:10.1080/ 02678292.2016.1209793 (2016).

125 Chen, X., Chen, L., Yao, K. \& Chen, Y. Self-assembly of diblock polythiophenes with discotic liquid crystals on side chains for the formation of a highly ordered nanowire morphology. Appl. Mater. Interfaces 5, 8321-8328 (2013).

126 Yuan, K., Chen, L. \& Chen, Y. Photovoltaic performance enhancement of P3HT/PCBM solar cells driven by incorporation of conjugated liquid crystalline rod-coil block copolymers. J. Mater. Chem. C 2, 3835-3845 (2014).

127 Shi, Y., Tan, L. \& Chen, Y. Dye-sensitized nanoarrays with discotic liquid crystals as interlayer for high-efficiency inverted polymer solar cells. Appl. Mater. Interfaces 6, 17848-17856 (2014).

128 Chen, X., Chen, L. \& Chen, Y. Self-assembly of discotic liquid crystal decorated ZnO nanoparticles for efficient hybrid solar cells. RSC Adv. 4, 3627-3632 (2014).

$129 \mathrm{Kim}$, J. Y. \& Bard, A. J. Organic donor/acceptor heterojunction photovoltaic devices based on zinc phthalocyanine and a liquid crystalline perylene diimide. Chem. Phys. Lett. 383, 11-15 (2004).

130 Archambeau, S., Bock, H., Seguy, I., Jolinat, P. \& Destruel, P. Organic solar cells with an ultra thin organized hole transport layer. J. Mater. Sci. Mater. Electron. 18, 919-923 (2007).

131 Keinan, E., Kumar, S., Moshenberg, R., Ghirlando, R. \& Wachtel, E. J. Trisubstituted decacyclene derivatives: bridging the gap between the carbonaceous mesophase and discotic liquid crystals. Adv. Mater. 3, 251-254 (1991).

132 Hirota, K., Tajima, K. \& Hashimoto, K. Physicochemical study of discotic liquid crystal decacyclene derivative and utilization in polymer photovoltaic devices. Synth. Met. 157, 290-296 (2007).

133 Feng, X., Liu, M., Pisula, W., Takase, M., Li, J. \& Müllen, K. Supramolecular organization and photovoltaics of triangle-shaped discotic graphenes with swallowtailed alkyl substituents. Adv. Mater. 20, 2684-2689 (2008).

134 Lee, C. C. \& Huang, W. Y. Insertion of poly (acrylamide) disc-columnar liquid crystals as a functional template in organic photovoltaics. J. Appl. Polym. Sci. 126, E70-E77 (2012).

135 Kusabayashi, S. \& Labes, M. M. Conductivity in liquid crystals. Mol. Cryst. Liq. Cryst. 7, 395-405 (1969).

136 Kamei, H., Katayama, Y. \& Ozawa, T. Photovoltaic effect in the nematic liquid crystal. Jpn. J. Appl. Phys. 11, 1385 (1972).

137 Carrasco-Orozco, M., Tsoi, W. C., O'Neill, M., Aldred, M. P., Vlachos, P. \& Kelly, S. M. New photovoltaic concept: liquid-crystal solar cells using a nematic gel template. Adv. Mater. 18, 1754-1758 (2006)

138 Lei, C., Al Khalifah, M. S., O'Neill, M., Aldred, M. P., Kitney, S. P., Vlachos, P. \& Kelly, S. M. Calamatic liquid crystal blends for organic photovoltaics. Photonic Devices + Applications 7052, 705214-705214 (2008).

139 Tsoi, W. C., O'Neill, M., Aldred, M. P., Kitney, S. P., Vlachos, P. \& Kelly, S. M. Distributed bilayer photovoltaics based on nematic liquid crystal polymer networks. Chem. Mater. 19, 5475-5484 (2007).

140 AlKhalifah, M. S., Lei, C., Myers, S. A., O’Neill, M., Kitney, S. P. \& Kelly, S. M. Solution-processed bilayer photovoltaic devices with nematic liquid crystals. Liq. Cryst. 41, 402-417 (2014).

141 Dröge, S., Al Khalifah, M. S., O'Neill, M., Thomas, H. E., Simmonds, H. S., Macdonald, J. E., Aldred, M. P., Vlachos, P., Kitney, S. P., Löbbert, A. \& Kelly, S. $M$. Grazing incidence X-ray diffraction of a photoaligned nematic semiconductor. J. Phys. Chem. B 113, 49-53 (2008).

142 Kekuda, D., Huang, J. H., Ho, K. C. \& Chu, C. W. Modulation of donor- acceptor interface through thermal treatment for efficient bilayer organic solar cells. J. Phys. Chem. C. 114, 2764-2768 (2010).

143 Sun, Q., Park, K. \& Dai, L. Liquid crystalline polymers for efficient bilayer-bulkheterojunction solar cells. J. Phys. Chem. C. 113, 7892-7897 (2009).

144 Hindson, J. C., Ulgut, B., Friend, R. H., Greenham, N. C., Norder, B., Kotlewski, A. \& Dingemans, T. J. All-aromatic liquid crystal triphenylamine-based poly (azomethine) $\mathrm{s}$ as hole transport materials for opto-electronic applications. J. Mater. Chem. 20, 937-944 (2010).

145 Chen, W., Chen, Y., Li, F., Chen, L., Yuan, K., Yao, K. \& Wang, P. Ordered microstructure induced by orientation behavior of liquid-crystal polythiophene for performance improvement of hybrid solar cells. Sol. Energy Mater. Sol. Cells 96, 266-275 (2012).

$146 \mathrm{Li}, \mathrm{F} .$, Chen, W. \& Chen, Y. Mesogen induced self-assembly for hybrid bulk heterojunction solar cells based on a liquid crystal D-A copolymer and $\mathrm{ZnO}$ nanocrystals. J. Mater. Chem. 22, 6259 (2012).

147 Yao, K., Chen, L., Hu, T. \& Chen, Y. Photocrosslinkable liquid-crystalline polymers for stable photovoltaics by adjusting side-chains spacing and fullerene size to control intercalation. Org. Electron. 13, 1443-1455 (2012).

148 Li, F., Chen, W., Yuan, K. \& Chen, Y. Photovoltaic performance enhancement in $\mathrm{P} 3 \mathrm{HT} / \mathrm{ZnO}$ hybrid bulk-heterojunction solar cells induced by semiconducting liquid crystal ligands. Org. Electron. 13, 2757-2762 (2012).

149 Yuan, K., Li, F., Chen, L., Li, Y. \& Chen, Y. Liquid crystal helps ZnO nanoparticles selfassemble for performance improvement of hybrid solar cells. J. Phys. Chem. C 116, 6332-6339 (2012) 
150 Yuan, K., Chen, L. \& Chen, Y. Direct anisotropic growth of CdS nanocrystals in thermotropic liquid crystal templates for heterojunction optoelectronics. Chem. Eur. J. 20, 11488-11495 (2014).

151 Chen, L., Xie, C. \& Chen, Y. Self-assembled conjugated polyelectrolyte-ionic liquid crystal complex as an interlayer for polymer solar cells: Achieving performance enhancement via rapid liquid crystal-induced dipole orientation. Macromolecules 47, 1623-1632 (2014).

152 Liu, C., Tan, Y., Li, C., Wu, F., Chen, L. \& Chen, Y. Enhanced power-conversion efficiency in inverted bulk heterojunction solar cells using liquid-crystalconjugated polyelectrolyte interlayer. Appl. Mater. Interfaces 7, 19024-19033 (2015).

153 Shin, W., Yasuda, T., Watanabe, G., Yang, Y. S. \& Adachi, C. Self-organizing mesomorphic diketopyrrolopyrrole derivatives for efficient solution-processed organic solar cells. Chem. Mater. 25, 2549-2556 (2013).

154 Sun, K., Xiao, Z., Lu, S., Zajaczkowski, W., Pisula, W., Hanssen, E., White, J. M., Williamson, R. M., Subbiah, J., Ouyang, J. \& Holmes, A. B. A molecular nematic liquid crystalline material for high-performance organic photovoltaics. Nat. Commun. 6, 6013 (2015).

155 Canli, N. Y., Günes, S., Pivrikas, A., Fuchsbauer, A., Sinwel, D., Sariciftci, N. S., Yasa, Ö. \& Bilgin-Eran, B. Chiral (S)-5-octyloxy-2-[\{4-(2-methylbuthoxy)-phenylimino\}methyl]-phenol liquid crystalline compound as additive into polymer solar cells. Sol. Energy Mater. Sol. Cells 94, 1089-1099 (2010).

156 Canli, N. Y., Safak-Boroglu, M., Bilgin-Eran, B. \& Günes, S. Bilayer polymer/fullerene solar cells with a liquid crystal. Thin Solid Films 560, 71-76 (2014).

157 Jeong, S., Kwon, Y., Choi, B. D., Kwak, G. \& Han, Y. S. Effects of nematic liquid crystal additives on the performance of polymer solar cells. Macromol. Chem. Phys. 211, 2474-2479 (2010).

158 Shi, J., Lv, L., Zhou, W. \& Zhang, L. Improvement of the photovoltaic properties for $\mathrm{P} 3 \mathrm{HT}$ : $\mathrm{PCBM}$ system annealed at the temperature in liquid crystalline regions induced by liquid crystal molecules. Polym. Bull. 71, 2963-2979 (2014).

159 O'Regan, B. \& Grätzel, M. A low-cost, high-efficiency solar cell based on dye-sensitized colloidal $\mathrm{TiO}_{2}$ films. Nature 353, 737-740 (1991).

160 Mathew, S., Yella, A., Gao, P., Humphry-Baker, R., Curchod, B. F., Ashari-Astani, N., Tavernelli, I., Rothlisberger, U., Nazeeruddin, M. K. \& Grätzel, M. Dye-sensitized solar cells with $13 \%$ efficiency achieved through the molecular engineering of porphyrin sensitizers. Nat. Chem. 6, 242-247 (2014).

161 Yamanaka, N., Kawano, R., Kubo, W., Kitamura, T., Wada, Y., Watanabe, M. \& Yanagida, S. Ionic liquid crystal as a hole transport layer of dye-sensitized solar cells. Chem. Commun. 6, 740-742 (2005).

162 Yamanaka, N., Kawano, R., Kubo, W., Masaki, N., Kitamura, T., Wada, Y., Watanabe, M. \& Yanagida, S. Dye-sensitized TiO2 solar cells using imidazolium-type ionic liquid crystal systems as effective electrolytes. J. Phys. Chem. B 111, 4763-4769 (2007).

$163 \mathrm{Kim}$, H. K. Lee, M. J., Jin, S. H. \& Lee, G. D. Optimization of liquid crysta concentration in the dye-sensitized solar cell for high efficiency. Mol. Cryst. Liq. Cryst. $510,323=[1457]-328=[1462](2009)$.

164 Kim, S. C., Song, M., Ryu, T. I., Lee, M. J., Jin, S. H., Gal, Y. S., Kim, H. K., Lee, G. D. \& Kang, Y. S. Liquid crystals embedded in polymeric electrolytes for quasi-solid state dye-sensitized solar cell applications. Macromol. Chem. Phys. 210, 1844-1850 (2009).

165 Karim, M. A., Song, M., Park, J. S., Kim, Y. H., Lee, M. J., Lee, J. W., Lee, C. W. Cho, Y. R., Gal, Y. S., Lee, J. H. \& Jin, S. H. Development of liquid crystal embedded in polymer electrolytes composed of click polymers for dye-sensitized solar cell applications. Dyes Pigments 86, 259-265 (2010).

166 Wang, M., Pan, X., Fang, X., Guo, L., Zhang, C., Huang, Y., Huo, Z. \& Dai, S. Liquid crystal based electrolyte with light trapping scheme for enhancing photovoltaic performance of quasi-solid-state dye-sensitized solar cells. J. Power Sources 196 5784-5791 (2011).

167 Ahn, S. K., Ban, T., Sakthivel, P., Lee, J. W., Gal, Y. S., Lee, J. K., Kim, M. R. \& Jin, S. H. Development of dye-sensitized solar cells composed of liquid crystal embedded, electrospun poly (vinylidene fluoride-co-hexafluoropropylene) nanofibers as polymer gel electrolytes. Appl. Mater. Interfaces 4, 2096-2100 (2012).

168 Costa, R. D., Werner, F., Wang, X., Grönninger, P., Feihl, S., Kohler, F. T., Wasserscheid, P., Hibler, S., Beranek, R., Meyer, K. \& Guldi, D. M. Beneficial effects of liquid crystalline phases in solid-state dye-sensitized solar cells. Adv. Energy Mater. 3, 657-665 (2013).

169 Högberg, D., Soberats, B., Yatagai, R., Uchida, S., Yoshio, M., Kloo, L., Segawa, H. \& Kato, T. Liquid-crystalline dye-sensitized solar cells: design of two-dimensional molecular assemblies for efficient ion transport and thermal stability. Chem. Mater. 28, 6493-6500 (2016)

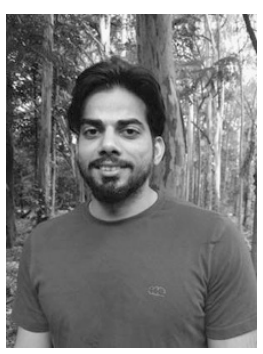

Manish Kumar was born in Jerathi, India in 1989. He is a PhD student at Soft-condensed matter Group (SCM), Raman Research Institute, Bengaluru, India under the supervision of Professor Sandeep Kumar. He received his MTech in Nanotechnology from Amity University, Noida, India in 2014. His major interests are the synthesis and characterization of novel functional liquid crystalline nanocomposites, fabrication of organic solar cell, OLEDs and nanomaterial synthesis. His research currently focuses on the synthesis of functionalized metallic and semiconducting nanostructures materials and their self-assembly in discotic liquid crystals.
Sandeep Kumar obtained his PhD in Chemistry-Medicinal Chemistry from Banaras Hindu University, Varanasi in 1986. He was a Postdoctoral Research Fellow at the Hebrew University of Jerusalem, Jerusalem, Israel; Technion, Israel Institute of Technology, Haifa, Israel; the Scripps Research Institute, La Jolla, CA, USA and the University of Mainz, Mainz, Germany during 1988-1995. He joined the Centre for Liquid Crystal Research, Bengaluru, India to start a new Chemistry laboratory in 1995. In 2002, he moved to the Raman Research Institute, Bengaluru, India. He was a visiting Research Professor at the Naval Research Laboratory, Washington DC, USA during 1999-2000 and the National Dong Hwa University, Hualien, Taiwan during 2008 and E.T.S. Walton Visiting Professor at the Trinity College, Dublin during 2012-2013. He has published 220 research papers in peer reviewed international journals. He also authored a book entitled 'Chemistry of Discotic Liquid Crystals: from monomers to polymers and several book chapters. He is also having many patents in his credit. He was awarded the inaugural LG Philips Display Mid-Career Award by the International Liquid Crystal Society in 2008. His current research interests include design, synthesis and applications of liquid crystals, green chemistry and nanotechnology. 